Portland State University

PDXScholar

$11-18-2020$

\title{
The Impact of Paternal Caregivers for Youth Who Commit Sexual Offenses
}

\author{
Miranda Hope Sitney \\ Portland State University
}

Follow this and additional works at: https://pdxscholar.library.pdx.edu/open_access_etds

Part of the Social Psychology Commons

Let us know how access to this document benefits you.

\section{Recommended Citation}

Sitney, Miranda Hope, "The Impact of Paternal Caregivers for Youth Who Commit Sexual Offenses" (2020). Dissertations and Theses. Paper 5615.

https://doi.org/10.15760/etd.7487

This Dissertation is brought to you for free and open access. It has been accepted for inclusion in Dissertations and Theses by an authorized administrator of PDXScholar. Please contact us if we can make this document more accessible: pdxscholar@pdx.edu. 
The Impact of Paternal Caregivers for Youth Who Commit Sexual Offenses

by

Miranda Hope Sitney

A dissertation submitted in partial fulfillment of the requirements for the degree of

Doctor of Philosophy

in

Applied Psychology

\author{
Dissertation Committee: \\ Keith Kaufman, Chair \\ Greg Townley \\ Joel Steele \\ Kathryn Wuschke
}

Portland State University

2020 


\begin{abstract}
This dissertation presents three manuscripts exploring the impact of caregivers, particularly male caregivers, on the development of juvenile sexual offending behavior. The first manuscript investigated the role of disrupted caregiving for juvenile sexual offenders compared to nonoffending juveniles and youth who committed non-sexual crimes. The results indicated that juvenile sexual offenders have particularly poor relationships with their primary caregivers, especially if their primary caregiver was male. The second manuscript is a systematic literature review that explored the pathways through which male caregivers may influence the sexually aggressive behavior of their sons. A total of thirty-four articles describing three pathways (i.e., direct transmission of offending, father-son relationships, and paternal socio-emotional characteristics) revealed having a sexually aggressive father dramatically increases the risk that the son will also engage in sexual offending. Poor father-son relationship quality also significantly increased the chance of the son becoming sexually aggressive. Finally, the third study tested an integrated model of paternal caregiving risk factors that may predict juvenile engagement in sexually aggressive behaviors. Results again indicated that abusive paternal parenting is more predictive of juvenile sexual offending than is witnessing a father act violently or nonbiological paternal caregiving. Overall, the three manuscripts aim to enhance our understanding of the impacts of early caregiving experiences for young sexual offenders and highlights prevention and treatment implications by engaging male caregivers.
\end{abstract}




\section{Dedication}

This dissertation is dedicated to my father, P.Adams Sitney, for his tremendous paternal caregiving, which most recently manifested in workshopping hundreds of the sentences written here. 


\section{Table of Contents}

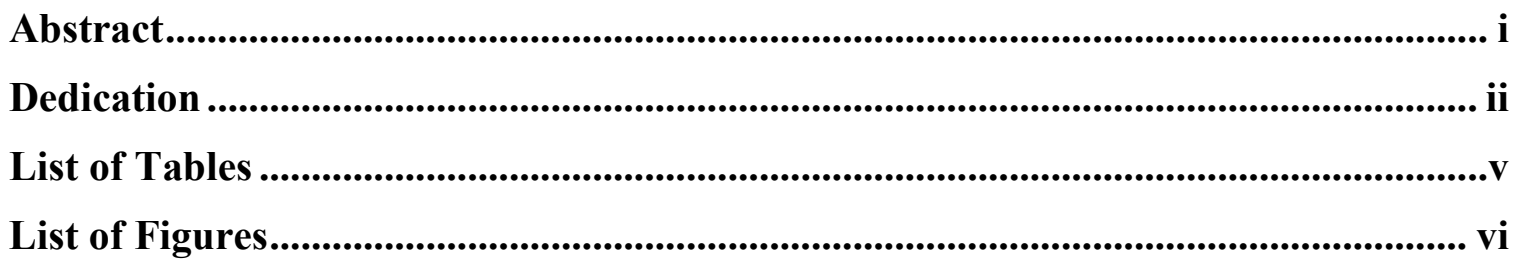

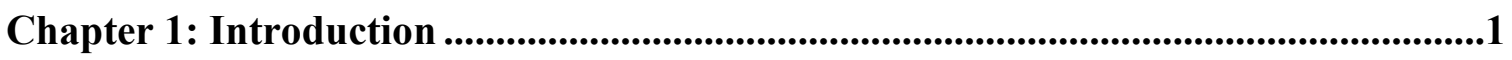

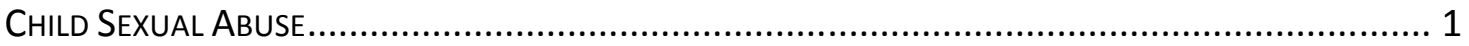

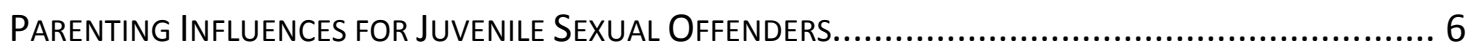

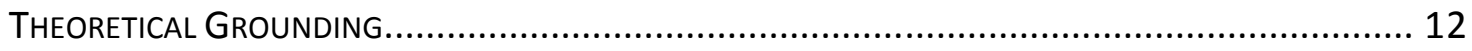

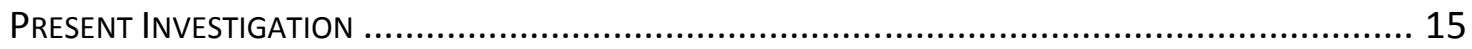

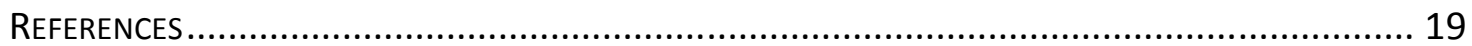

Chapter 2: Manuscript One - The impact of disrupted caregiving for juvenile

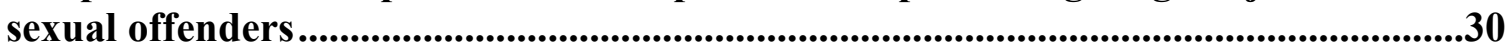

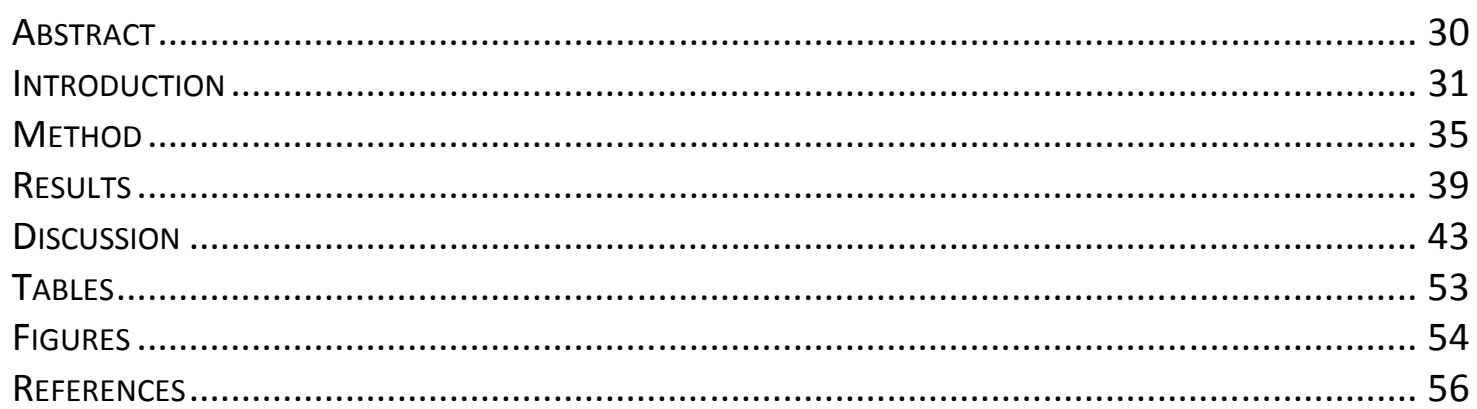

Chapter 3: Manuscript Two - A chip off the old block: The impact of fathers on sexual offending behavior.....................................................................................63

ABSTRACT 
Chapter 4: Manuscript Three - Paternal impacts specific to sexual offending: A confluence model ........................................................................................................................106

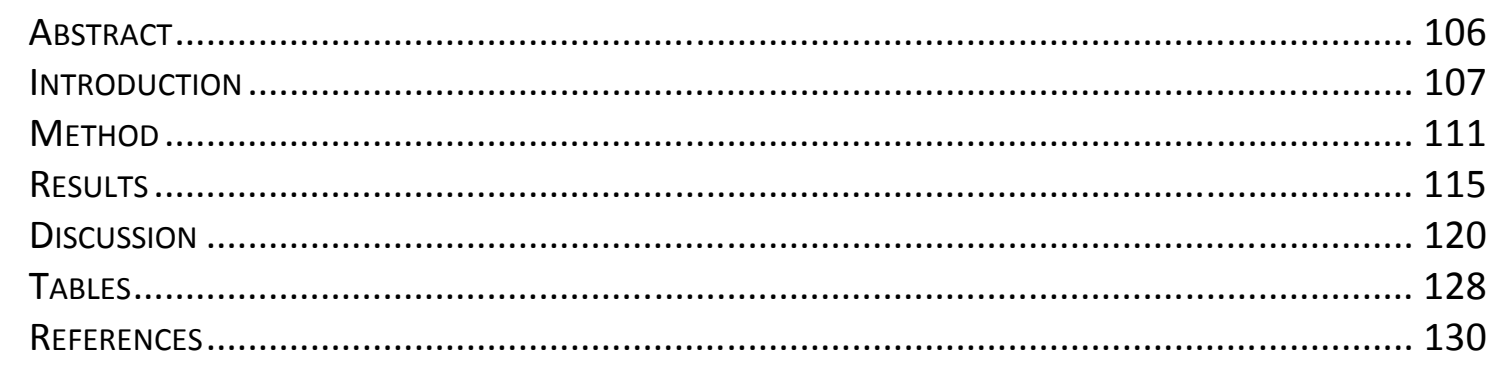

Chapter 5: Conclusion ............................................................................................................138

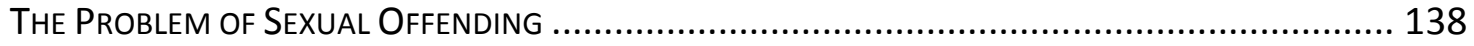

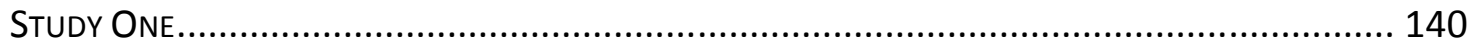

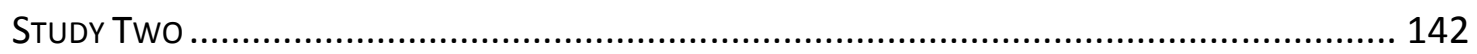

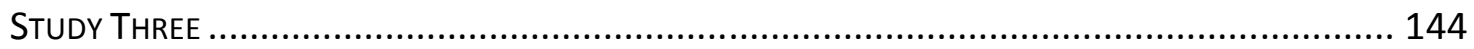

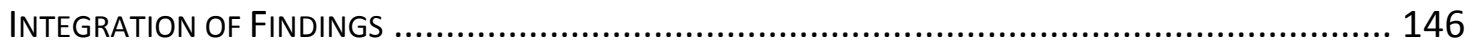

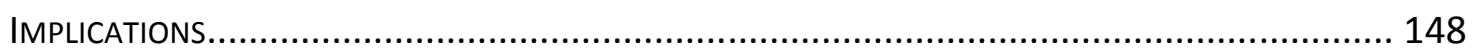

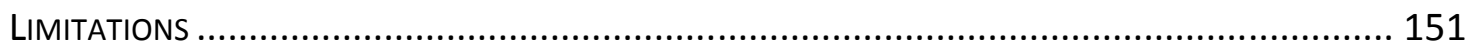

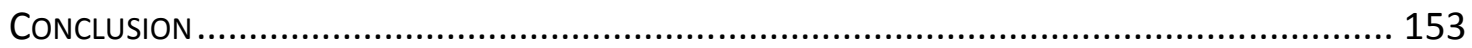

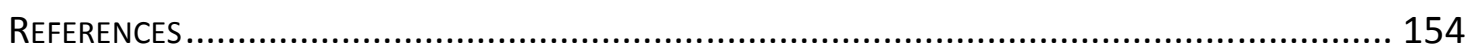




\section{List of Tables}

Table 1.1 Raw count and percentages of disrupted caregiving by offense type...............53

Table 2.1 Studies related to the transmission of sexual offending from father to son.......89

Table 2.2 Studies related to paternal attachment or relationship quality ........................90

Table 2.3 Studies related to paternal social and emotional characteristics......................92

Table 3.2 Adjusted odds ratios (AOR) from multinominal regression analysis.............129 


\section{List of Figures}

Figure 1.1 Mean Values of the PRSS by Offense Type. ................................................54

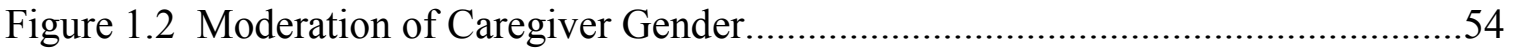

Figure 1.3 Moderation of Biological-Parent Status ................................................55

Figure 2.1 Model Of Electronic Search Strategy.......................................................93 


\section{Chapter 1: Introduction}

"We are the sons of our fathers" reflects a young man when asked to evaluate the events leading up to his sexual offense (Mathe, 2007). This dissertation seeks to highlight the truth of that statement. Through three manuscripts, the impacts that parental caregivers have on their sons' decisions to sexually offend will be explored. The role of male caregivers will be given particular attention, as these older men may inform a young boy's conceptualization of masculinity, the importance of power in relationships, and the acceptability of violence in community. By the conclusion of this work, the specific pathways and mechanisms that connect fathers to their sons' sexual aggression will be clarified. After doing so, new avenues for the prevention of sexual violence which involve early identification of family risk factors and home-based interventions will be presented.

\section{Child Sexual Abuse}

To create a framework for the remainder of this dissertation, this section outlines the prevalence and consequences of child sexual abuse (CSA) in the United States. Further, it provides a broad overview of the literature related to perpetrators of sexual assault, especially when those perpetrators are minors. Finally, this section highlights the laws related to the perpetration of child sexual abuse.

Child sexual abuse is so pervasive in the United States that it affects most, if not all, members of our society. Estimates available from the US Department of Justice suggest that approximately twenty-five percent of young woman suffer from sexual abuse 
as children (Finkelhor, Shattuck, Turner, \& Hamby, 2014). This is a shocking statistic. So is the revelation that five percent of young men were also sexual abuse victims (Finkelhor et al., 2014). However, these numbers are crude estimates. The true scope of CSA may never be known due to the vast numbers of children and young adults who do not report their assaults due to psychological barriers (e.g. internalized blame), coercion from others (e.g. threats of further harm), and society pressures (e.g. the taboos of sexuality; Collin-Vézina, De La Sablonniere-Griffin, Palmer, \& Milne, 2015). Thus, while 60,000 children are the victims of "substantiated or indicted sexual abuse" each year, this number represents a small subpopulation of CSA survivors (US Department of Health and Human Services, 2009; 2014).

Consequences of CSA. Whether reported or not, these crimes reverberate throughout the lives of everyone connected to the assault. CSA has lasting effects on the survivors as well as their family members, peers, and the social institutions charged with protecting children. Meta-analyses have found that individuals who experienced child sexual abuse often developed long-term health consequences (Irish, Kobayashi, \& Delahanty, 2009), were at high risk for several psychological disorders (Chen et al., 2010), and were likely to continue to accumulate adverse life experiences, such as low academic achievement and experiencing intimate partner violence (Norman et al., 2012).

Parallel signs of PSTD and distress can be found in high rates among the parents of CSA survivors (Manion et al., 1996; Newberger, Gremy, Waternaux, \& Newberger, 1993) and among female peers who have heard a sexual abuse disclosure by a friend (Banyard, Moynihan, Walsh, Cohn, \& Ward, 2010). As a result, policy experts estimate that the United States loses $\$ 122,461$ per sexual assault victim in medical costs, missed 
labor opportunities, and criminal justice proceedings. Across the population, this creates an annual economic burden of $\$ 3.1$ trillion (Peterson, DeGue, Florence, \& Lokey, 2017).

Perpetrators of CSA. While the consequences of CSA are well documented, less consensus has been drawn concerning the patterns and typology of sexually aggressive offenders (CSOM, 2008). Statistics show that the individuals who commit sex crimes are highly diverse (Planty, Langton, Krebs, Berzofsky, \& Smiley-McDonald, 2013). For example, between 1994 and 2010, individuals arrested for sexual assault were 57\% white, $27 \%$ black, and 16\% "other." About one third (37\%) of them had been previously convicted of felonies. Although more than half of assaults (55\%) happened in or near the survivor's home, many (33\%) occurred in public spaces (Planty et al., 2013). These figures alone suggest the difficulty of isolating coherent patterns related to perpetration.

At the same time, there are some high-frequency risk factors for offending. Men commit $94 \%$ of sex crimes, with $90 \%$ of perpetrators acting alone (Planty et al., 2013). Overwhelmingly, sexual assault survivors know their attacker, with $93 \%$ of sexually abused children suffering at the hands of a family member or friend, and $71 \%$ of adult victims known to their offender (Planty et al., 2013). Further, studies have found that some men who are arrested for sexual crimes exhibited similar patterns of psychological dysfunction, including difficulties with emotional regulation and interpersonal interactions, poor empathy development, and deviant sexual arousal (Fapul, 2014; Simons, 2015).

Juvenile Sexual Offenders (JSO). One final area of note regarding the demographic typologies describing sexual offenders is that of age. Many more young people are convicted of sexual assaults than the public generally perceives. In fact, $18 \%$ 
of the people arrested for sexual crimes in 2010 were minors, including 20,000 young people who committed forcible rape (Snyder, 2010). The state of Oregon reflects these percentages. In 2014, three thousand juveniles (12\%) were listed among the twenty-five thousand individuals arrested for sexual offenses (Lahna \& Long, 2014). In fact, juvenile sexual offenders make up the largest percentage of youth held in the state's locked detention facilities (29\%; OYA, 2017). Commensurate with the greater Oregon population, youth convicted for sexual offenses in Oregon are predominantly white (64\%), though the disproportionate confinement of people of color can still be seen through the $17 \%$ of Hispanic youth referred to detention for sex crimes in 2018 (OYA, 2018). In contrast, only 13\% of Oregon's general population is Hispanic (U.S. Census Bureau, 2019). Youth who commit sex crimes tend to be arrested at a rather young age, with $48 \%$ of youth arrested in Oregon falling between the ages of $13-15$, and $13 \%$ receiving a referral before the age of 12 (OYA, 2018). Finally, just as is seen nationally, youth convicted of sex crimes in Oregon are overwhelmingly male (93\%; OYA, 2018).

Sex Crime Law. For what exactly are these youth being arrested? That question entails a consideration of Oregon law and the national sex crime registry. In America, each state differs in their specific definitions of sexual offenses. In the state of Oregon, for example, there are 29 separate charges classified as sex crimes (ORS 181.805). The most violent of these is the charge of "rape" which occurs whenever a victim is compelled to perform a sex act, when a victim is younger than twelve, when a victim is mentally incapable of consenting, or in special cases where a family member has sex with 
a victim under sixteen years old (ORS 163.375). Rape is classified separately from the charge of "sexual abuse," which is defined by as sexual molestation without penetration (ORS 163.427).

Although these statutes apply to both adults and children, some Oregon laws focus on sexual crimes specifically directed at minors (ORS 163.432-163.689). These laws criminalize possession of images depicting sex acts with or between underage children, paying for sex with children, seducing children via computers, or the blanket category of "contributing to the sexual delinquency of a minor." Of note, anytime a child under twelve takes part in a sexual act in Oregon, a crime has been committed. This includes cases when two children under twelve participate together (Lahna \& Long, 2014). Furthermore, when the minors are over twelve but have an age difference of three or more years, the elder becomes legally the abuser of the younger (Lahna \& Long, 2014). These laws extend even to non-contact sexual activity. For instance, two youth who exchange nude pictures with one another may both be found guilty of possessing child pornography, a felony offense (Lahna \& Long, 2014).

Nationally, statistics indicate that nearly $50 \%$ of youth arrested for sex crimes were charged with engaging in non-penetrative coercive sex. An additional $36.5 \%$ of youth were arrested for coercive penetrative sex, and 10\% were arrested for non-forcible sexual offenses (Finkelhor, Ormrod, \& Chaffin, 2009). Most juveniles act against an acquaintance $(63.2 \%)$, although $25 \%$ were arrested for offending against a family member. In line with those percentages, almost $70 \%$ of juveniles who commit sex crimes 
did so in their home or in the home of an acquaintance, with an additional $11 \%$ of youth committing their assaults at school (Finkelhor et al., 2009).

\section{Parenting Influences for Juvenile Sexual Offenders}

What evidence-based strategies are being used to reduce these sexual offenses? The sexual abuse prevention literature has been criticized for largely focusing on victim self-defense strategies (e.g. martial arts classes for young women) or for intervening only with youth who are already engaged in coercive sexual activity (Ryan, 2016).

Nevertheless, some early prevention strategies have found success by mobilizing parents or guardians of young people who have not yet offended. This section details what is known regarding parental influences for juvenile sexual offending, including two prevention strategies focused on parents or guardians.

Disrupted Caregiving. Since the early $19^{\text {th }}$ century, social scientists have been writing about the link between "broken homes" and delinquency. Originally, authors opined that children with non-nuclear families turn to crime due to a failure of parents instilling proper moral values in their children and their lack of sufficient disciplining practices (Frazier, 1950). Since then, systemic poverty, insufficient access to resources, and low levels of parental monitoring have replaced the focus on morality and discipline as the causes linking broken homes to delinquent behavior. Still, three-quarters of a century later, we continue to chart a relationship between non-nuclear family systems and juvenile offending (Gormon-Smith, Tolan, Loeber, \& Henry, 1998; Sillekens \& Notten, 2018). More specifically, the research in this area has focused on two types of atypical caregivers as primary guardians: (1) fathers; and (2) substitute caregivers (e.g. custodial grandparents; step-parents, foster families). When fathers or substitute caregivers become 
the primary caregivers for boys, both types of guardians have been shown to increase the risk that a child will become delinquent.

Fathers as primary guardians. Youth in the United States are unlikely to live with a male as their sole primary guardian. In 2016, only five percent (5\%) of all U.S. homes with children had a single male as the head of household (U.S. Census Bureau, 2016). However, a number of studies have demonstrated that youths' relationships with their fathers are particularly significant for the potential development of delinquency and externalizing disorders. In his comprehensive review of the literature on parenting outcomes among fathers, Coles (2015) reported that nearly all of the studies of conduct disorders and delinquency as functions of family systems show that youth raised by men were the most likely to engage in delinquent behavior or be diagnosed with an externalizing disorder. In a second study, Shears, Robinson, and Emde (2002) asked adult men to report retrospectively on their relationships with their fathers when they were teens. They found that the negative quality of the father-son relationship was directly correlated with delinquent acts. Additionally, Breivik and Olweus (2006) found that youth who ended up in single-father households following their parents' divorce had significantly higher levels of externalizing problems than did children with married parents, children whose divorced parents were sharing custody, or post-divorce children living with single-mothers or mothers and stepfathers.

The most commonly proposed mechanisms for the relationship between primarymale parenting and delinquency are the reduction of emotional closeness and a lack of monitoring or supervision. A consistent body of literature has shown that single fathers are less emotionally close to their children, know less about their children's friends and 
school behaviors, and are less likely to supervise their children than are single-mothers or married parents (Breivik \& Owleus, 2006; Bronte-Tinkew, Scott, \& Lilja, 2010; Coles, 2015). Lack of adult involvement in a child's life may leave the child free to begin experimenting with illegal substances, forming negative peer relationships, and engaging in delinquent behavior (Demuth \& Brown, 2004).

Substitute caregivers. Compared to single-father households, many more children live with at least one substitute caregiver. For instance, U.S. Census data between the years of 1991 and 2011 documented a 64\% increase in children living with at least one grandparent. In total, over 2.5 million grandparents in the US were responsible for the primary care of their grandchildren in 2011 (Ellis \& Simmons, 2014). An additional two million children live with adopted parents, and over four million children live in a home with a step-parent (Kreider \& Lofquist, 2014). Finally, approximately 500,000 youth are in the foster care system in the United States (CWIG, 2016). Thus, roughly 7\% of children in the United States live with some form of substitute caregiver.

In all of these family configurations, some degree of relationship has been found to juvenile delinquency. For example, Poehlmann (2005) reported that children who lived with their grandparents had overwhelmingly negative relationships with both their biological mother and their custodial grandparent. Poor behavioral and emotional outcomes for children with custodial grandparents persisted even when the researchers controlled for depression in grandparents or economic burdens (Poehlmann et al., 2008). Further, Juffer and van Ijzendoorn's (2005) meta-analysis revealed that adopted children were more likely to receive mental health services and to exhibit externalizing conduct problems than were non-adopted controls. Finally, Apel and Kaukinen (2008) compared 
youth living with two, biological, married parents to a wide array of disrupted caregiving situations. They found that youth who lived with a biological father and their father's new cohabitating partner exhibited unusually high rates of antisocial behavior. Youth living in foster care, with adoptive families, or with other variations of primary-father custody (father-stepmother, single-father) were also at high risk for delinquency.

Various mechanisms have been proposed to explain the link between substitute caregivers and delinquency. These include the trauma of losing a primary caregiver through death, divorce, absenteeism, or court mandate. Acquiring a substitute caregiver (e.g. a stepparent) may also be traumatic, as it necessarily entails a reworking of the abiding mode of family functioning (Rebellon, 2002). However, one consistent mediator found to explain the relationship between substitute caregiving and delinquency was child maltreatment (Felizzi, 2015b). Child abuse and neglect may have been the reason that a youth was placed with a substitute caregiver, as is often the case in foster care situations. Additionally, one study on custodial grandparents found that $71 \%$ of the interviewed grandmothers reported that their grandchildren had suffered abuse or neglect in their previous home before being placed with them (Williamson, Softas-Nall, \& Miller, 2003). Unfortunately, children with substitute caregivers are often at increased risk for child abuse with their new caregiver as well. Research has demonstrated that stepfathers are more abusive toward their step-children than their biological children, even when all of the children live together (Hilton, Harris, \& Rice, 2015). Studies examining police reports have indicated that fathers were more than twice as likely to assault their genetically-unrelated children as their biological children, even when the number of children in the household and level of paternal antisocial behavior were 
controlled for in the analyses (Hilton et al., 2015). Following abuse, children are then at great risk for developing externalizing disorders and delinquent behavior (Rebellon \& Van Gundy, 2005)

Disrupted Caregiving and Sexual Offending. Even though the literature connecting disrupted caregiving to juvenile sexual offending is much smaller than the broader juvenile delinquency literature, its underlying patterns also suggest that youth who commit sexual offenses come from non-nuclear families or have atypical caregiving experiences. That small literature is summarized in this section.

Caregiver instability has been linked to sexual offending in a number of studies (Felizzi, 2015a; Smith, Wampler, Jones, and Reifman, 2005; Van Wijk et al., 2005). The parents who raise sexual offenders are often abusive or neglectful (Whitaker et al., 2008). In fact, rates of abuse or neglect have been found to occur at even higher rates for juvenile sexual offenders than for juveniles who commit other serious offenses (Barra, Bessler, Landolt \& Aebi, 2017). In addition, as many as $80 \%$ of JSOs have been often found to experience changing caregivers or an out-of-home placement (Duane, Carr, Cherry, McGrath, \& O'Shea, 2003; Felizzi, 2015a). It is theorized that the changing "safety nets" (i.e., primary caregivers) make it more difficult for the child to feel actually safe, exacerbates behavioral problems, and reduces the influence of the current caregiver (Felizzi, 2015b). All of these factors increase the risk that the child will offend.

Additional research on parenting correlates for juvenile sexual offending has revealed that JSOs are more likely to be parented by poorly educated and young mothers than are violent non-sexual offenders (Van Wijk et al., 2006). Family members of juvenile sexual offenders are also frequently engaging in criminal behavior, though their 
families tend to be equally or less criminal than juveniles who commit non-sexual crimes (Seto \& Lalumière, 2010). However, more information is needed to differentiate these correlates. Currently, there is no comprehensive comparison of caregiver types for youth who engage in coercive sex.

Parenting Prevention Interventions for Sexual Offenses. With the literature consistently confirming the finding that youth who commit sex crimes are likely to have experienced insufficient or disruptive parenting, two avenues of primary prevention have been pursued. First, given that these young people often have suffered child maltreatment themselves, a number of applied researchers have created parent-training programs that aim to decrease or prevent juvenile offending through strengthening parental empathy and warmth (Lundahl, Nimer, \& Parsons, 2006; Prinz, Sanders, Shapiro, Whitaker, \& Lutzker, 2009). Parent-training programs of this nature hope to foster environments which are incompatible with the development of sexually aggressive behavior in youth, rather than focusing on how potential victims can protect themselves or on preventing recidivism amongst previously convicted offenders.

The second prevention strategy that has garnered some success comes from the criminal justice literature. It focuses on parental guardianship and monitoring which has been shown to significantly reduce the numbers of youth who commit crimes (Racz \& McMahon, 2011). As it is used here, "monitoring" is an umbrella term that encompasses traditional supervisory behavior (e.g. "keeping an eye on" one's children), but also includes parental solicitation (e.g. asking your child questions about their whereabouts and with whom they are spending time (i.e., their friends), parental knowledge (e.g. having accurate information about the child's whereabouts), and parental control (e.g. 
creating and enforcing curfews). Of these four subcomponents, lack of parental knowledge has been shown to be the strongest predictor of juvenile conduct problems (Kerr \& Stattin; 2000; Stattin \& Kerr, 2000). Furthermore, recent work comparing youth who commit sexual offenses to both juvenile non-sexual offenders and juvenile nonoffenders has shown that both offender groups report lower levels of parental monitoring, knowledge, solicitation, and control than non-offenders. Additionally, juvenile sexual offenders, in particular, indicated that their caregivers demonstrated significantly lower levels of traditional monitoring behavior than did juvenile non-sexual offenders (Stewart, Sitney, Kaufman, DeStefano, \& Bui, 2019). These works suggest that increasing parental monitoring, especially among traditionally low-monitoring caregivers (e.g. single fathers), may be effective at preventing juvenile sexual offending.

\section{Theoretical Grounding}

A few core theories underlie much of this empirical literature and applied prevention efforts. This section will outline three of the most widely used theoretical frameworks in the field of juvenile delinquency research and describe their relationship to the etiology and prevention of sexual offending.

The Public Health Model of Prevention. The Centers for Disease Control's public health model of prevention strives to improve wellbeing for entire populations through the prevention of violence. It focuses on systemic stages that can be broadly applied to many different areas of concern. This model finds its strength in its simplicity. It argues that there are four major steps for the prevention of violence and the promotion of health. It recommends: A) an identification of the problem, B) noting risk and protective factors, C) developing and testing prevention strategies, and D) assuring 
widespread adoption of those strategies through trainings and technical assistance (Mercy, Rosenberg, Powell, Broome, \& Roper, 1993). Further, the public health model advocates for interventions spanning three time points. Primary prevention interventions aim to universally eliminate a problematic behavior before it occurs. Secondary prevention interventions focus their efforts on groups at high-risk for engagement in the behavior. Lastly, tertiary prevention interventions aim to reduce recidivism by involving only those individuals who have already initiated the problematic behavior.

This model has been widely adopted by researchers striving to end the perpetration of sexual violence (McMahon, 2000). Treatment professionals have employed the public health model of prevention for primary interventions to educate community members on the risk factors associated with child sexual abuse (Basile, 2003). Secondary prevention interventions have attempted to prevent sexual violence in high school relationships (Foshee et al., 2005). Finally, the public health model has been used in a number of tertiary interventions to reduce recidivism among convicted sexual offenders (Brown, 2005). Its flexibility indicates its usefulness in dealing both with youth at risk of offending and those who have already committed a sexual offense.

Social Learning Theory. Prevention efforts would be ineffective without a comprehensive understanding of the etiology of violent and criminal behavior. The acquisition of behaviors is often explained through Bandura's (1978) social learning theory. This paradigm contends that all people, especially children, mimic the behaviors that they see enacted by those around them. If behaviors are rewarded or are inherently pleasurable, the behavior will likely persist. Conversely, behaviors that are punished or otherwise painful will often desist. 
From its earliest conceptualization, social learning theory has been used to explain the development of aggressive behavior in children. For example, the classic Bobo doll experiment may be considered an early demonstration of how social learning shapes children's aggressive behaviors (Bandura, Ross, \& Ross, 1961). In this experiment, children were found to be more likely to hit a doll after watching an adult act violently. Subsequently, social learning theory has been a cornerstone of the literature on delinquency and conduct disorders in youth. It has been used to predict a range of problematic adolescent behavior including nonmedical prescription drug use (Ford, 2008), deliberate self-harm (Jarvi, Jackson, Swenson, \& Crawford, 2013), and dating violence (Tontodonato \& Crew, 1992). Social learning theories have also found support in the sexual offense literature, where many studies have found that either witnessing or experiencing sexual violence increases one's risk of perpetrating sexual assault (Burton, Miller, \& Shill, 2002; Seto \& Lalumière, 2010).

Attachment Theory. A foundational method of understanding the impacts of parent-child relationships has been John Bowlby and Mary Ainsworth's attachment theory. Bowlby and Ainsworth maintained that a child's history with a primary guardian provides a "working model" for all subsequent interpersonal relationships (Bowlby, 1944; Bowlby 1969; Bowlby, 1982). In this model, securely attached children view their caregivers as safe and comforting. They enjoy being around them and are affectionate toward them. Insecurely attached children, on the other hand, display hostile/combative (insecure-anxious attachment) or affectless/indifferent (insecure-avoidant attachment) relationships with their caregivers. 
Overwhelmingly, examinations of the home lives of juvenile offenders suggest these youth are insecurely attached to their parents or guardians. These attachment deficits are thought to significantly increase their risk of engaging in delinquency (Hoeve et al., 2012). The most prominent writings linking poor parental attachment to sexual offending argue that a child's insecure attachment to may result in unstable emotional bonds with peers. Children may then express their subsequent loneliness and frustration as callousness and sexual violence, especially if they are also the victims of sexual abuse (Marshall, 1989; Marshall, 1993; Marshall \& Marshall, 2010). Young people who engage in coercive sex have been shown to be lonelier, have greater intimacy problems, and weaker peer social skills than other offenders or non-criminal youth (Pallini, Baiocco, Schneider, Madigan, \& Atkinson, 2014; Schneider, Atkinson, \& Tardif, 2001; Seidman, Marshall, Hudson, \& Robinson, 1994; Van Wijk et al., 2006). Such evidence provides added support for this potential pathway to offending, as well as for the proposition that sexual offenders may have more disturbed parental attachments than do other incarcerated men to their primary caregivers (Smallbone \& Dadds, 1998).

\section{Present Investigation}

Although the juvenile delinquency literature is comprehensive in its empirical knowledge regarding caregiver impacts, researchers are still attempting to connect those findings directly to the subset of adolescents whose crimes are sexual in nature. It is possible that juveniles who commit sexual crimes are simply a subpopulation of general juvenile delinquents, and thus are affected by their caregivers through the known juvenile delinquency mechanisms. Alternatively, some investigators have argued that juveniles who commit sex crimes may be a totally unique population, and thus their developmental 
antecedents cannot be assumed to coincide with either their peers who commit nonsexual crimes or with adults who commit sexual offenses (Lussier, Blokland, Mathesius, Pardini, \& Loeber, 2015; Seto \& Lalumière, 2010).

One of the reasons for this failure to explore the caregiver impacts for juveniles who commit sexual offenses derives from the historical conceptualization of aggressive sexual behavior as a strictly individual-level dysfunction. The early "monster model" of sexual offending positioned men who committed acts of sexual aggression as callous or evil beings whose reform would take tremendous effort (Marshall, 1996). Sexual offender treatment, therefore, has worked tirelessly to suppress or modify deviant cognitions, improve social skills, and even retrain responses to sexual stimuli. During treatment, sexual offenders were incarcerated or institutionalized in an effort to keep the community safe from their brutality. In recent years, however, the field has expanded its view of the potential impacts and intervention opportunities for sexual offenders to include community and society-level factors (Casey \& Lindhorst, 2009). While the monster model houses the entirety of the sexual offense behavior within the offender themselves, current research has found that some external factors (e.g., environments that support toxic masculinity, ease of access to pornography via the internet) are also predictive of sexual aggression. Attention to the impact of caregivers on the development of aggressive sexual behavior in youth is representative of this broader conceptualization and provides opportunities for prevention or intervention outside of the prison cell.

How might we then extend the literature to fill in these gaps? The following chapters will explore three empirical manuscripts which sought to clarify the impacts of caregivers on young people's sexually aggressive behavior. Further, they explore whether 
these impacts are unique to sexual offending or apply more broadly to juvenile criminality. Moreover, the role that paternal caregivers play in their sons' sexual development appears to be a particularly underexplored area of concern. Thus, these three manuscripts together make an attempt to narrow-in on the unique impacts of paternal caregivers for who have begun engaging in coercive sex.

To begin this investigation, it is critical to understand what aspects of parental caregiving may impact sexual offending. Thus, Manuscript One is a published study in the Journal of Sexual Aggression that examined the potentially moderating role of disrupted caregiving in the relationship between juvenile sexual offending and caregiverchild relationship quality (Sitney \& Kaufman, 2020). Two distinct moderators were tested: (1) the gender of the caregiver and (2) the biological relationship between caregiver and child. Results indicated that youth who commit sex crimes have particularly poor relationships with their primary caregivers compared to youth incarcerated for other crimes and community controls. Furthermore, sexual offenders with male primary caregivers were found to have lower relationship quality scores than sexual offenders with female primary caregivers.

Given the impact of male caregivers for juvenile sexual offenders found in Manuscript One, Manuscript Two offers a systematic literature review of what is known regarding the fathers of sexual offenders. This review has been published in the Journal of Trauma, Violence, and Abuse. Thirty-four studies were categorized according to four distinct research questions, each addressing theoretical mechanisms by which fathers might influence the violent sexual behavior of their sons. The results suggest that the strongest impacts occur when sons have witnessed their fathers engaging in acts of sexual 
abuse or domestic violence, in accordance with social learning theory. Father-son attachment or relationship quality also appears to have a measurable impact on the son's engaging in sexual violence. However, paternal demographics and characteristics were generally ineffective at predicting sons' sexual offenses.

As Manuscript Two identified multiple pathways through which fathers may impact the sexual offending behaviors of their sons, Manuscript Three tested an integrated model of paternal caregiving risk factors that may predict juvenile engagement in sexually aggressive behaviors. This study has been submitted to the Journal of Child Sexual Abuse. The intention of this final work was to examine (1) the impacts of exposure to the violent behavior of a parent, (2) youth's attachment to paternal caregivers, and (3) youth's experiences when cared for by nonbiological fathers on sexual offending behavior. Findings from this research clarified that an abusive paternal parenting style is the most predictive of the son's sexual offending. Recommendations include focusing family therapy on the father-son relationship and providing additional supports for substitute male caregivers of young boys. 


\section{References}

Apel, R., \& Kaukinen, C. (2008). On the relationship between family structure and antisocial behavior: Parental cohabitation and blended households. Criminology; An Interdisciplinary Journal, 46, 35-70. doi:10.1111/j.1745-9125.2008.00107.x

Bandura, A. (1978). Social learning theory of aggression. Journal of Communication, 28, $12-29$.

Bandura, A., Ross, D. \& Ross, S.A. (1961). Transmission of aggression through imitation of aggressive models. Journal of Abnormal and Social Psychology, 63, 575-82.

Banyard, V. L., Moynihan, M. M., Walsh, W. A., Cohn, E. S., \& Ward, S. (2010). Friends of survivors: The community impact of unwanted sexual experiences. Journal of Interpersonal Violence, 25, 242-256. doi:10.1177/0886260509334407

Barra, S., Bessler, C., Landolt, M. A., \& Aebi, M. (2018). Patterns of adverse childhood experiences in juveniles who sexually offended. Sexual Abuse, 30(7), 803-827.

Basile, K. C. (2003). Implications of public health for policy on sexual violence. Annals of the New York Academy of Sciences, 989, 446-463.

Bowlby, J. (1944). Forty-four juvenile thieves: Their characters and home lives. International Journal of Psycho-Analysis, 25, 19-52.

Bowlby, J. (1969). Attachment and loss, Vol. I: Attachment. New York: Basic Books. Bowlby, J. (1982). Attachment and loss: Retrospect and prospect. American Journal of Orthopsychiatry, 52(4), 664-678.

Breivik, K., \& Olweus, D. (2006). Adolescent's adjustment in four post-divorce family structures: Single mother, stepfather, joint physical custody and single father 
families. Journal of Divorce \& Remarriage, 44, 99-124.

doi:10.1300/J087v44n03_07

Bronte-Tinkew, J., Scott, M. E., \& Lilja, E. (2010). Single custodial fathers' involvement and parenting: Implications for outcomes in emerging adulthood. Journal of Marriage and Family, 72(5), 1107-1127. doi:10.1300/J087v44n03_07

Brown, S. (2005). Treating sex offenders: An introduction to sex offender treatment programmes. London: Willan Publishing.

Burton, D. L., Miller, D. L., \& Shill, C. T. (2002). A social learning theory comparison of the sexual victimization of adolescent sexual offenders and nonsexual offending male delinquents. Child Abuse \& Neglect, 26, 893-907.

Casey, E. A., \& Lindhorst, T. P. (2009). Toward a multi-level, ecological approach to the primary prevention of sexual assault: Prevention in peer and community contexts. Trauma, Violence, \& Abuse, 10(2), 91-114. doi:

$10.1177 / 1524838009334129$

Center for Sex Offender Management (CSOM). (2014). Fact sheet: What you need to know about sex offenders. Retrieved from: http://www.csom.org/pubs/needtoknow_fs.pdf

Chen, L. P., Murad, M. H., Paras, M. L., Colbenson, K. M., Sattler, A. L., Goranson, E. N., Elamin, M. B., Seime, R. J., Shinozaki, G., Prokop, L. J., \& Zirakzadeh, A. (2010). Sexual abuse and lifetime diagnosis of psychiatric disorders: systematic review and meta-analysis. Mayo Clinic Proceedings, 85, 618-629. doi: 10.4065/mcp.2009.0583 
Child Welfare Information Gateway (CWIG). (2016). Foster care statistics: 2015. Washington, DC: U.S. Department of Health and Human Services, Children's Bureau.

Coles, R. L. (2015). Single-father families: A review of the literature. Journal of Family Theory \& Review, 7, 144-166. doi:10. 1111/jftr.12069

Collin-Vézina, D., De La Sablonniere-Griffin, M., Palmer, A., \& Milne, L. (2015). A preliminary mapping of individual, relational and social factors that impede disclosure of childhood sexual abuse. Child Abuse \& Neglect, 43, 123-134. doi:10.1016/j.chiabu.2015.03.010

Demuth, S., \& Brown, S. L. (2004). Family structure, family processes, and adolescent delinquency: The significance of parental absence versus parental gender. Journal of Research in Crime and Delinquency, 41(1), 58-81.

Duane, Y., Carr, A., Cherry, J., McGrath, K., \& O’Shea, D. (2003). Profiles of the parents of adolescent CSA perpetrators attending a voluntary outpatient treatment programme in Ireland. Child Abuse Review, 12(1), 5-24. doi:10.1002/car.776

Ellis, R. R., \& Simmons, T. (2014). Coresident grandparents and their grandchildren: 2012. U.S. Census Bureau. Retrieved from: https://www.census.gov/content/dam/Census/library/publications/2014/demo/p20576.pdf

Fapul, S. (2014). Etiology of adult sexual offending. In C. Lobanov-Rotovsky \& R. Przybylski (Eds.) Sex offender management and planning initiative (pp. 33-53). Washington DC: Department of Justice. 
Felizzi, M. V. (2015a). Family or caregiver instability, parental attachment, and the relationship to juvenile sex offending. Journal of Child Sexual Abuse, 24(6), 641658. doi:10.1080/10538712.2015.1057668

Felizzi, M. V. (2015b). Emotional abuse, parent and caregiver instability, and disrupted attachment: The relationship to juvenile sexual offending. In K. Rice, \& M.V. Felizzi, (Eds.), Global youth: Understanding challenges, identifying solutions, offering hope, (pp. 5-16). Newcastle upon Tyne: Cambridge Scholars Publishing.

Finkelhor, D., Ormrod, R., \& Chaffin, M. (2009). Juveniles who commit sex offenses against minors (NCJ Publication No. 227763). Washington, DC: U.S. Department of Justice.

Finkelhor, D., Shattuck, A., Turner, H. A., \& Hamby, S. L. (2014). The lifetime prevalence of child sexual abuse and sexual assault assessed in late adolescence. Journal of Adolescent Health, 55, 329-333. doi:10.1016/j.jadohealth.2013.12.026

Ford, J. (2008). Social learning theory and nonmedical prescription drug use amongst adolescents. Sociological Spectrum, 28, 299-316.

Foshee, V. A., Bauman, K. E., Ennett, S. T., Suchindran, C., Benefield, T., \& Linder, G. F. (2005). Assessing the effects of the dating violence prevention program "Safe Dates" using random coefficient regression modeling. Prevention Science, 6, 245258.

Frazier, E. F. (1950). Problems and needs of Negro children and youth resulting from family disorganization. The Journal of Negro Education, 19(3), 269-277. 
Gorman-Smith, D., Tolan, P. H., Loeber, R., \& Henry, D. B. (1998). Relation of family problems to patterns of delinquent involvement among urban youth. Journal of Abnormal Child Psychology, 26(5), 319-333.

Hilton, N. Z., Harris, G. T., \& Rice, M. E. (2015). The step-father effect in child abuse: Comparing discriminative parental solicitude and antisociality. Psychology of Violence, 5, 8-15. doi:10.1037/a0035189

Hoeve, M., Dubas, J. S., Eichelsheim, V. I., Van Der Laan, P. H., Smeenk, W., \& Gerris, J. R. (2009). The relationship between parenting and delinquency: A metaanalysis. Journal of Abnormal Child Psychology, 37(6), 749-775.

Irish, L., Kobayashi, I., \& Delahanty, D. L. (2009). Long-term physical health consequences of childhood sexual abuse: A meta-analytic review. Journal of Pediatric Psychology, 35, 450-461. doi: 10.1093/jpepsy/jsp118

Jarvi, S., Jackson, B., Swenson, L., \& Crawford, H. (2013). The impact of social contagion on non-suicidal self-injury: A review of the literature. Archives of Suicide Research, 17, 1-19.

Juffer, F., \& van IJzendoorn, M. H. (2005). Behavior problems and mental health referrals of international adoptees: A meta-analysis. JAMA, 293(20), 2501-2515.

Kerr, M., \& Stattin, H. (2000). What parents know, how they know it, and several forms of adolescent adjustment: further support for a reinterpretation of monitoring. Developmental Psychology, 36(3), 366-380.

Kreider, R., \& Lofquist, D. (2015). Matching survey data with administrative records to evaluate reports of same-sex married couple households (SEHSD Working Paper 2014-36). Washington, DC: U.S. Census Bureau. 
Lahna, D., \& Long, C. (2014). Oregon's sex offender registry: How to handle juvenile offenders. City Club of Portland Bulletin, 97, 1-52.

Lundahl, B. W., Nimer, J., \& Parsons, B. (2006). Preventing child abuse: A meta-analysis of parent training programs. Research on Social Work Practice, 16(3), 251-262.

Lussier, P., Blokland, A., Mathesius, J., Pardini, D., \& Loeber, R. (2015). The childhood risk factors of adolescent $\square$ onset and adult $\square$ onset of sex offending: Evidence from a prospective longitudinal study. In A. Blokland \& P. Lussier (Eds.), Sex offenders: A criminal career approach (1st ed., pp. 93-128). Oxford: Wiley Blackwell.

Manion, I. G., McIntyre, J., Firestone, P., Ligezinska, M., Ensom, R., \& Wells, G. (1996). Secondary traumatization in parents following the disclosure of extrafamilial child sexual abuse: Initial effects. Child Abuse \& Neglect, 20, 10951109. doi:10.1016/0145-2134(96)00098-1

Marshall, W. L. (1989). Intimacy, loneliness and sexual offenders. Behaviour Research and Therapy, 27, 491-503.

Marshall, W. L. (1993). The role of attachments, intimacy and loneliness in the etiology and maintenance of sexual offending. Sexual and Marital Therapy, 8, 109-121.

Marshall, W. L. (1996). The sexual offender: Monster, victim, or everyman? Sexual Abuse, 8(4), 317-335.

Marshall, W. L., \& Marshall, L. E. (2010). Attachment and intimacy in sexual offenders: An update. Sexual and Relationship Therapy, 25, 86-90.

Mathe, S. (2007). Juvenile sexual offenders: We are the sons of our fathers. Agenda, 21(74), 133-140. 
McMahon, P. M. (2000). The public health approach to the prevention of sexual violence. Sexual Abuse: A Journal of Research and Treatment, 12, 27-36.

Mercy, J. A., Rosenberg, M. L., Powell, K. E., Broome, C. V., \& Roper, W. L. (1993). Public health policy for preventing violence. Health Affairs, 12, 7-29.

Newberger, C. M., Gremy, I. M., Waternaux, C. M., \& Newberger, E. H. (1993). Mothers of sexually abused children: Trauma and repair in longitudinal perspective. American Journal of Orthopsychiatry, 63, 92-102. doi:10.1037/h0079398

Norman, R. E., Byambaa, M., De, R., Butchart, A., Scott, J., \& Vos, T. (2012). The longterm health consequences of child physical abuse, emotional abuse, and neglect: a systematic review and meta-analysis. PLoS medicine, 9(11), e1001349.

Oregon Youth Authority (OYA). (2017). OYA Quick Facts. Retrieved from http://www.oregon.gov/oya/docs/QuickFacts/QuickFacts-Jan2017.pdf

Oregon Youth Authority (OYA). (2018). JJIS Annual Data and Evaluation Reports. Retrieved from https://www.oregon.gov/oya/Pages/jjis_data_eval_rpts.aspx\#Detention

Pallini, S., Baiocco, R., Schneider, B. H., Madigan, S., \& Atkinson, L. (2014). Early child-parent attachment and peer relations: A meta-analysis of recent research. Journal of Family Psychology, 28, 118-123.

Peterson, C., DeGue, S., Florence, C., \& Lokey, C. N. (2017). Lifetime economic burden of rape among US adults. American Journal of Preventive Medicine, 52(6), 691701. doi:10.1016/j.amepre.2016.11.014 
Planty, M., Langton, L., Krebs, C., Berzofsky, M., \& Smiley-McDonald, H. (2013). Female victims of sexual violence, 1994-2010. Washington DC: Department of Justice.

Poehlmann, J. (2005). Representations of attachment relationships in children of incarcerated mothers. Child Development, 76(3), 679-696.

Poehlmann, J., Park, J., Bouffiou, L., Abrahams, J., Shlafer, R., \&amp; Hahn, E. (2008). Representations of family relationships in children living with custodial grandparents. Attachment \& Human Development, 10(2), 165-188.

Prinz, R. J., Sanders, M. R., Shapiro, C. J., Whitaker, D. J., \& Lutzker, J. R. (2009). Population-based prevention of child maltreatment: The US Triple P system population trial. Prevention Science, 10(1), 1-12.

Racz, S. J., \& McMahon, R. J. (2011). The relationship between parental knowledge and monitoring and child and adolescent conduct problems: A 10-year update. Clinical Child and Family Psychology Review, 14(4), 377-398.

Rebellon, C. J. (2002). Reconsidering the broken homes/delinquency relationship and exploring its mediating mechanism(s). Criminology, 40(1), 103-136.

Rebellon, C. J., \& Van Gundy, K. (2005). Can control theory explain the link between parental physical abuse and delinquency? A longitudinal analysis. Journal of Research in Crime and Delinquency, 42(3), 247-274.

Ryan, E. P. (2016). Juvenile sex offenders. Current Psychiatry Reports, 18(7), 81-97.

Schneider, B. H., Atkinson, L., \& Tardif, C. (2001). Child-parent attachment and children's peer relations: A quantitative review. Developmental Psychology, 37, 86-100. 
Seidman, B., Marshall, W. L., Hudson, S. M., \& Robertson, P. J. (1994). An examination of intimacy and loneliness in sex offenders. Journal of Interpersonal Violence, 9, 518-534.

Seto, M. C., \& Lalumière, M. (2010). What is so special about male adolescent sexual offending? A review and test of explanations through meta-analysis.

Psychological Bulletin, 136, 526-575. doi:10.1037/a0019700

Shears, J., Robinson, J., \& Emde, R. N. (2002). Fathering relationships and their associations with juvenile delinquency. Infant Mental Health Journal, 23(1 $\square$ 2), 79-87.

Sillekens, S., \& Notten, N. (2018). Parental divorce and externalizing problem behavior in adulthood: A study on lasting individual, family and peer risk factors for externalizing problem behavior when experiencing a parental divorce. Deviant Behavior, 1-16.

Simons, D. (2015). Sex offender typologies. In C. Lobanov-Rotovsky \& R. Przybylski (Eds.) Sex offender management and planning initiative (pp. 55-75). Washington DC: U.S. Department of Justice.

Sitney, M. H., \& Kaufman, K. L. (2020). The impact of disrupted caregiving for juvenile sexual offenders. Journal of Sexual Aggression, 26, 274-287.

Smallbone, S. W., \& Dadds, M. R. (1998). Childhood attachment and adult attachment in incarcerated adult male sex offenders. Journal of Interpersonal Violence, 13(5), $555-573$. 
Smith, S., Wampler, R., Jones, J., \& Reifman, A. (2005). Differences in self-report measures by adolescent sex offender risk group. International Journal of Offender Therapy and Comparative Criminology, 49(1), 82-106.

Snyder, H. N. (2000). Sexual assault of young children as reported to law enforcement: Victim, incident, and offender characteristics. Washington, DC: U.S. Department of Justice.

Stattin, H., \& Kerr, M. (2000). Parental monitoring: A reinterpretation. Child Development, 71(4), 1072-1085.

Stewart, K. E., Sitney, M. H., Kaufman, K. L., DeStefano, J., \& Bui, T. (2019). Preventing juvenile sexual offending through parental monitoring: a comparison study of youth's experiences of supervision. Journal of Sexual Aggression, 25(1), 16-30.

Tontodonato, P., \& Crew, B. K. (1992). Dating violence, social learning theory, and gender: A multivariate analysis. Violence and Victims, 7, 3-14.

U.S. Census Bureau. (2016). Household relationship and living arrangements of children under 18 years, by age and sex: 2016. Retrieved from: https://www.census.gov/data/tables/2016/demo/families/cps-2016.html

U.S. Census Bureau. (2019). Quick facts: Oregon. Retrieved from: https://www.census.gov/quickfacts/OR

U.S. Department of Health and Human Services. (2014). Child maltreatment: 2012. Retrieved from: http://www.acf.hhs.gov/programs/cb/resource/childmaltreatment2012 
U.S. Department of Health and Human Services. (2009). Child maltreatment: 2007.

Retrieved from: http://www.acf.hhs.gov/programs/cb/resource/childmaltreatment2007

Van Wijk, A., Vermeiren, R., Loeber, R., Hart-Kerkhoffs, L. T., Doreleijers, T., \& Bullens, R. (2006). Juvenile sex offenders compared to non-sex offenders: A review of the literature 1995-2005. Trauma, Violence, \& Abuse, 7, 227-243.

Whitaker, D. J., Le, B., Hanson, R. K., Baker, C. K., McMahon, P. M., Ryan, G., \& Rice, D. D. (2008). Risk factors for the perpetration of child sexual abuse: A review and meta-analysis. Child Abuse \& Neglect, 32, 529-548.

Williamson, J., Softas-Nall, B., \& Miller, J. (2003). Grandmothers raising grandchildren: An exploration of their experiences and emotions. The Family Journal, 11(1), 2332. 


\title{
Chapter 2: Manuscript One -
}

\section{The impact of disrupted caregiving for juvenile sexual offenders}

Note: As this study has been published in a British journal, British spelling is used throughout the manuscript. The citation for that article is as follows:

Sitney, M. H., \& Kaufman, K. L. (2020). The impact of disrupted caregiving for juvenile sexual offenders. Journal of Sexual Aggression, 26, 274-287.

\begin{abstract}
Research that attempts to understand why young people commit sex crimes points to an array of family factors that may uniquely contribute to sexual offending over general juvenile delinquency. This study examines the potentially moderating role of disrupted caregiving in the relationship between offending and caregiver-child relationship quality. Two distinct moderators were tested: gender of caregiver and biological relationship between caregiver and child. Results indicate that juvenile sexual offenders have particularly poor relationships with their primary caregivers compared to incarcerated non-sexual offenders and community controls. Furthermore, sexual offenders with male caregivers were found to have lower relationship quality scores than sexual offenders with female caregivers. In contrast, sexual offenders raised by nonbiological caregivers reported better relationship quality than did offenders raised by their biological parents. These findings suggest opportunities for early intervention, before caregiving is disrupted.




\section{Introduction}

Whether juvenile sexual offenders (JSOs) should be thought of as a distinct population from general juvenile delinquents continues to be a subject of much debate (Seto \& Lalumière, 2010; Smallbone, 2006; Starzyk \& Marshall, 2003). Though the population of youth who are arrested for sexual offences are overwhelmingly male, they are also so vastly heterogeneous that research has struggled to identify a consistent profile for JSOs (Righthand \& Welch, 2004). However, recent reviews have identified some areas of commonality among youth who commit sex crimes. Family factors have emerged as an important area in which JSOs may be set apart from youth who do not engage in sexually aggressive acts (Felizzi, 2015a). This line of research may be especially worthwhile as family contexts are proving to be essential when researchers and treatment professionals focus on issues of primary prevention (Ryan, Leversee, \& Lane, 2011), recidivism (Zankman \& Bonomo, 2004), and treatment trajectories for sexually aggressive youth (Borduin, Schaeffer, \& Heiblum, 2009; Henggeler et al., 2009; Yoder, 2014). Thus, the continued development of this line of inquiry is paramount.

For at least a half-century, parental influence has been at the forefront of the discussion of criminal behaviour in juveniles. Much of this work has utilised attachment theory to explain how parents may influence the delinquent behaviour of their children (Bowlby, 1944, 1969, 1982). Proponents of attachment theory argue that a child's relationship to their early primary caregivers shapes their subsequent interpersonal interactions throughout their lifetimes. The largely successful application of attachment theory to the etiology of sexual offending has been explored with both adult and juvenile 
populations (Keogh, 2012; Rich, 2006). These studies suggest that insecurely attached children tend to experience isolation, loneliness, and frustration that may express itself as sexual aggression in their teen and adult years (Marshall, 1989; Seidman, Marshall, Hudson, \& Robertson, 1994; Ward, Hudson, \& Marshall, 1996). Among adults, sexual offenders have been shown to be less securely attached than their incarcerated and nonincarcerated peers (Sigre-Leirós, Carvalho, \& Nobre, 2016; Smallbone \& Dadds, 1998; Smallbone \& Dadds, 2001). In fact, as many as $93 \%$ of adult sexual offenders have shown insecure attachment patterns (Lyn \& Burton, 2005; Marsa et al., 2004). Insecure attachments are common in juvenile samples, as well. Smallbone (2006) and Whitaker et al. (2008) discovered that young sexual offenders were less attached to parents than were other incarcerated youth, while Funari (2005) found that JSOs had higher levels of disorganised attachment than other violent or non-violent juvenile offenders.

These findings may be explained by the body of literature which explores the likelihood that JSOs have experienced caregiver disruption (Seto \& Lalumière, 2010; Tidefors \& Strand, 2012; Worley, Church, \& Clemmons, 2012). The term "caregiver disruption" is used here to describe any instance in which a child receives insufficient or substitute care as a result of their biological parents' inability to meet their physical and emotional needs. Meta-analytic results indicate that between $27-87 \%$ of JSOs have experienced disrupted caregiving, depending on the operationalisation of "disruption" in the particular study (Seto \& Lalumière, 2010). Recent works touching upon caregiver disruption report that, compared to other incarcerated and non-incarcerated youth, JSOs are more likely to have: lived in an out-of-home placement (Duane, Carr, Cherry, McGrath, \& O'Shea, 2003; Funari, 2005); lived in a single-parent family (Margari et al., 
2015), and witnessed or experienced high levels of domestic violence, physical punishment, and parental substance abuse (Ryan et al., 2011). Furthermore, instances of disrupted caregiving often negatively impact the relationships between youths and their guardians. JSOs frequently report poor or problematic relationships with their caregivers (Yoder, Dillard, \& Stehlik, 2018) and have significantly greater deficits in relationship quality when compared to non-sexual offenders (Yoder, Leibowitz, \& Peterson, 2016). Thus, caregiver disruption must be considered a potentially precipitating factor for sexual offending, insofar as it may exacerbate the poor attachment relationships between a youth and their parents (Felizzi, 2015b).

Yet, despite the relative importance of caregiver disruption, some areas of disruption remain unexplored. For instance, the impact of the gender of the youths' primary caregivers, especially with regard to male caregivers, is deserving of increased attention. To date, no study has explicitly examined the father-son relationships of JSOs (e.g. single father, step-father, absent father, in a nuclear family). Studies which have examined both mother and father dynamics have found that juvenile sexual offenders often have male caregivers who are dominant and controlling (Mathe, 2007). Further, young sexual offenders feel more alienated and less trusting of their fathers than do youth who commit other types of crimes (Yoder et al., 2018).

More is known about the role of male caregivers in the development of juvenile delinquency generally. Coles (2015) demonstrated that youth living with only male caregivers were more likely to engage in delinquent behaviour or be diagnosed with an externalising disorder than those living in households with women. Similarly, Breivik and Olweus (2006) found that youth living solely with single-fathers had significantly 
higher levels of externalising problems than did children living with single mothers. Given the overlap between JSOs and their non-sexually offending peers, it seems possible, but yet to be examined, that father-son relationships may impact sexual offending as well as general delinquent behaviour.

Non-biological guardians represent another under-investigated form of caregiver disruption for JSOs. Some research has shown that JSOs are more likely than average to live with a non-biological caregiver (Duane et al., 2003; Felizzi, 2015a; Funari, 2005). Yet little is known about how that relationship impacts their sexual offending behaviour. Even though the literature on non-biological caregivers and delinquency does not distinguish sexual crimes from other offences, its findings offer some guidelines for future JSO investigations. Generally, this research concludes that living with nonbiological guardians is associated with delinquent and externalising behaviours in young people. Children who live in foster care (Apel \& Kaukinen, 2008), with adoptive families (Juffer \& van Ijzendoorn, 2005; Miller, Fan, Christensen, Grotevant, \& Van Dulmen, 2000), or in step-families (Bronte-Tinkew, Scott, \& Lilja, 2010; Evenhouse \& Reilly, 2004) have all been shown to be at unusually high risk for delinquency. The contributions of non-biological parenting to general juvenile offending justifies more specific research into juvenile sexual offenders' relationships with their non-biological guardians.

In addition to examining the potentially moderating role of disrupted caregiving in the relationship between offending and caregiver-child relationship quality, this study also strives to address a number of significant gaps in the literature. Specifically, it aims to: (1) determine whether youth who commit sex crimes perceive their relationships with their primary caregivers differently than do general juvenile delinquents or non-offending 
youth; and (2) specify the impact of caregiver gender and non-biological status on caregiver-child relationship's quality. In order to do so, the following hypotheses are proposed: Hypothesis 1 - Offence status is expected to predict relationship quality scores such that JSOs will have the lowest mean relationship score of any offence type, closely followed by violent juvenile delinquents. Non-violent incarcerated youth and community controls are expected to have higher relationship scores, with community controls reflecting the best overall relationship quality; Hypothesis 2 - Gender of the primary caregiver is expected to moderate the youth's perceived relationship quality with their caregiver such that youths who identify males as their primary caregivers are expected to report poorer quality relationships than youths who identify females as their primary caregiver; Hypothesis 3 - Biological status is expected to moderate the youth's perceived relationship quality with their caregiver such that youth raised by their biological parents are expected to have higher relationship quality scores than those raised by a substitute guardian.

\section{Method}

\section{Participants}

The data utilised in this study comes from a larger investigation exploring the modus operandi of young male sexual offenders (CDC Grant R49/CCR016517-01). Female offenders were excluded from this study. Participants included convicted juvenile offenders who were incarcerated in correctional facilities in Florida, New York, Oregon, South Carolina, and Texas. A second sample of juvenile control participants were recruited from community centres in those same states. 
Thus, participants in this study $(\mathrm{n}=826)$ comprised four distinct groups. Juvenile sexual offenders (JSOs, $\mathrm{n}=310$ ) were found guilty of committing a sexual offence before their 18th birthday and were incarcerated for that sex crime. Violent juvenile delinquents $(\mathrm{JD}-\mathrm{Vs}, \mathrm{n}=119)$ were incarcerated for a crime they committed as a youth that was intended to cause harm against persons (e.g. murder, assault, robbery). Nonviolent juvenile delinquents (JD-NVs, $n=139)$ had identical screening criteria to JD-Vs, except with regard to the crime for which they were incarcerated. These youths committed crimes that did not include an intent to harm others (e.g. car theft, drug possession, destruction of property). Finally, juvenile control participants $(J C s, n=258)$ were nonincarcerated youth who had never been convicted of a crime. Screening criteria ensured that the youth were literate by means of the Wide Range Achievement Test - Third Edition (WRAT-3; Wilkinson, 1993), and that they did not have an interfering mental illness (e.g. psychotic disorder, depressive disorder) based on staff report.

All youth identified as male. The average age in this sample was 15.90 years old ( $\mathrm{SD}=1.77$ years). Overall, $41 \%$ of youth identified as White/Caucasian, $21.6 \%$ identified as Black/African American, $17.1 \%$ identified as Hispanic/Latino and $23.1 \%$ identified as Other or Mixed Race. In the overall sample, $52.4 \%$ of the participants reported that they were raised in nuclear families (See Table 1.1).

\section{Demographics}

This measure asked participants questions regarding their demographic characteristics. The questions used in the current study solicited the participants' (1) age, (2) biological sex, (3) race or ethnicity, and (4) current education level. The youth were also asked to identify their primary caregiver(s) for each year of their life (1-17). 
Additionally, participants were asked to indicate at which ages they switched or added a primary caregiver.

\section{Measures}

Perceived Relationship with Supervisor Scale. A six-item questionnaire was used to examine how the youth perceived their relationship with their primary caregivers (PRSS; Kaufman, 2001). This scale was developed specifically for a larger study to examine the relationship between juvenile offenders and their parents or guardians (i.e. their "supervisors"). For incarcerated juveniles, the instructions asked that they report on the last year in which they lived in the community. For juvenile control participants living in the community, they were simply asked to report on the previous year. The six items included in this measure were developed based on the existing research literature, as well as input from an advisory group of "experts" from the areas of adolescent development, parenting, and juvenile delinquency and sexual offending.

The instructions for completing this measure included a definition of the term "supervisor" as "an adult who was in charge of you (like a parent, guardian or babysitter)." Youth were asked to indicate who their primary supervisors were and to list what days of the week and times of day those adults were responsible for their care. Project staff were available to answer questions, while participants completed this and other study measures. Participants were asked to indicate their answers on a five-point Likert scale where $0=$ never and $4=$ always. Items assessed perceptions of trust ("my supervisor trusted me"), acceptance ("my supervisor accepted me for who I am"), morality ("my supervisor expected me to do the "right thing"”), understanding ("my supervisor understood where I was coming from"), respect ("my supervisor asked for my 
opinion on things"), and attention ("my supervisor asked about personal things"). Thus, the dependent variable used for these analyses is the composite mean score of these six items.

Offense History. Incarcerated youth were asked to indicate the criminal charge that resulted in their incarceration. They additionally reported the total number of times they had been arrested, their age at their first arrest, the age that they began engaging in criminal behaviour, and the date that they began serving their sentences. These questions also established that the juvenile controls did not have a criminal record.

\section{Procedures}

University institutional review board (IRB) approval was obtained before the beginning of data collection. Since the current project relied solely on a secondary analysis of de-identified data, the IRB board determined that this study did not require additional review and approval.

The original data collection procedure was as follows: as incarcerated youth are unable to independently consent to research participation in accordance with APA ethical standards, youth were presented with an assent form that was then read aloud to them. This assent form described the purpose, risks, and benefits of the study. Youth were assured that their participation was voluntary and would be kept anonymous. Those who chose to participate in this study signed the assent form. Their signature indicated that they understood their role in this research and that they would like to participate. Participating facilities determined that obtaining parental consent was not possible and that the institution's consent was sufficient, to which the IRB concurred. Therefore, consent was provided by administrative staff at the juvenile correctional facilities, who 
have legal custody of the youth during their incarceration. Juvenile control participants were recruited from community centres located in the same states as the detention facilities. Parental consent was obtained for all youth recruited from the community.

On average, participants took 1.5 hours to complete all the questionnaires included in the larger study. More than $98 \%$ of youth returned completed packets. Packets were then returned to the university where they are maintained in a locked filing cabinet and password protected files.

\section{Results}

\section{Preliminary Analyses}

Exploratory Factor Analysis. The factor structure of the items on the Perceived Relationship with Supervisor Scale (Kaufman, 2001) was explored before proceeding with the analyses. An eigen-analysis was conducted using SPSS 24 to determine if a single-factor structure best explained the pattern of data from this measure. Results from this analysis determined that a single-factor model was indeed best, as indicated by Kaiser's criteria for Eigenvalues as well as by examining a Scree Plot and the item's correlation matrix to determine the amount of variance explained by this assessment device. All items loaded adequately and cleanly onto one factor, with the smallest loading being .35 and the highest being .83 . Cronbach's alpha was also calculated and reflected good internal consistency $(\alpha=.86)$. Thus, all six items in this measure are used in the subsequent analyses to represent youths' perceived relationship with their primary caregivers. 
Sample Differences. Offence groups were examined for systematic differences on variables that may impact study findings but were not investigation outcomes. Juvenile control participants were significantly younger $(M=14.7, S D=1.73)$ than were any of the incarcerated groups (JSO: $M=16.7, S D=2.16$; JD-NV: $M=16.4, S D=1.27$; JD-V: $M=17.1, S D=1.72), F(3,839)=74.6, p<.001$. Despite the significance of this difference, these age ranges all fall within the traditional high-school years of middle adolescence (Patterson, 2008; Santrock, 2013), suggesting that all four groups of youth are developmentally comparable. A chi-square analysis revealed that White participants were more likely to fall in the JSO offence-type than any other group, $\chi^{2}(9, N=888)=$ $111.68, p<.01$. This finding mirrors United States national statistics, which suggests that White youth are more likely to be incarcerated for a sexual offence than are any other ethnic or racial group (Greenfeld, 1997). Offence groups were also examined for differences in the types of disrupted caregiving they experienced (See Table 1.1).

Overwhelmingly, JSOs experienced higher rates of caregiver disruption than all other groups, $\chi^{2}(3, N=840)=133.047, p<.001$. Only $32.3 \%$ of JSOs reported that they had lived in a nuclear family for their entire lives prior to incarceration. In contrast, $74.4 \%$ of juvenile controls reported living in nuclear families, as did $55 \%$ of both the violent and nonviolent incarcerated youth.

\section{Inferential Analyses}

Overall Relationship Quality. Hypothesis One, stating that JSOs were expected to report the lowest relationship quality scores of all offence types, was partially confirmed. A univariate analysis of variance found that offence group differed significantly from one another in terms of perceived relationship quality with their 
caregivers, $F(3,834)=8.34, p<.001$. Levene's test for equality of error variances was significant, $F(3,834)=14.82, p<.001$, therefore, the Games-Howell post-hoc test was used to assess group differences (See Figure 1.1). Juvenile sexual offenders $(M=2.68$, $S D=.84)$ and juvenile delinquents - violent $(M=2.69, S D=1.10)$ had significantly lower relationship quality scores than did juvenile control youth $(M=3.08, S D=.70)$. JSO and JD-V youth did not differ from one another in terms of relationship quality. Non-violent incarcerated youth $(M=2.84, S D=.84)$ formed a middle group that did not significantly differ from either the high-scoring juvenile control group, or the low-scoring JSO/JD-V group.

Caregiver Disruption Moderators. Since significant differences in overall relationship quality was found between groups, a moderated regression analysis was conducted to test the remaining hypotheses. The primary predictor in the regression was offence type (JC, JD-NV, JD-V, JSO). The dependent variable was the composite mean value of the Perceived Relationship with Supervisor Scale. The overall model was significant $\left(R_{\text {adj }}^{2}=.126, F(11,862)=6.066, p<.001\right)$.

Male Caregivers. Hypothesis Two, which predicted that gender of the primary caregiver would moderate the youth's perceived relationship quality with their guardian, was partially confirmed. Youth who indicated that their primary caregiver was male (biological father, step-father, adoptive father, grandfather) were grouped together for these analyses. Using juvenile control youth with female primary caregivers as the constant, the interaction terms for JSOs $(\beta=-.324, t(866)=-2.513, p<.05)$ and JD-Vs $(\beta=-.489, t(866)=-1.956, p<.05)$ were significant. Thus, there is a greater drop in relationship quality between JSOs/JD-Vs with male caregivers compared to female 
caregivers than the corresponding drop for control youth. The simple effect for juvenile controls was non-significant $(\beta=.056, t(866)=.673, p=n s)$, indicating that there is no discernible change to relationship quality between juvenile controls with female or male caregivers. Similarly, no significant interaction was observed for nonviolent juvenile delinquents with regard to caregiver gender $(\beta=.236, t(866)=1.046, p=n s)$. Thus, this result suggests that the adverse impact of caregiver gender on relationship quality only occurs when juvenile sexual offenders or violent juvenile delinquents are being primarily cared for by men (See Figure 1.2).

Substitute Caregivers. Hypothesis Three, which predicted that biological status would moderate the youth's perceived relationship quality with their caregiver, was partially confirmed. Youth who indicated that their primary caregiver was not closely biologically related to them (i.e. step-parent, adoptive parent, foster parent, distant relative) were grouped together. Consistent with expectations, JCs who were raised by their biological parents had significantly higher relationship quality scores than did JCs who were raised in substitute care situations $(\beta=-.298, t(866)=-1.758, p<.05)$. Further, no significant interactions were found for JD-NVs $(\beta=1.45, t(866)=.558, p=$ $n s)$ or JD-Vs $(\beta=.223, t(866)=.842, p=n s)$ with regard to the type of relationship with their caregiver.

However, a significant interaction effect was found for juvenile controls and the juvenile sexual offenders $(\beta=.547, t(866)=2.709, p<.01)$. This interaction revealed that, while relationship quality was lower for JCs with non-biological caregivers compared to JCs with biological caregivers, the opposite pattern was true for JSOs. Contrary to the hypothesis, juvenile sexual offenders had higher relationship quality 
scores when their caregivers were non-biological. Furthermore, when using JSOs as the reference group, a significant simple effect was obtained, confirming that JSOs with biological guardians had significantly lower relationship quality scores than did JSOs with substitute guardians $(\beta=.274, t(866)=2.532, p<.05)$.

As this interaction was in the opposite direction of the hypothesised effect, further investigation was necessary. Therefore, a separate moderated regression was conducted in which biological status was the only moderator entered into the model. The results were consistent with those of the full model, $\left(F(7,827)=6.65, p<.001, R^{2}{ }_{\text {adj }}=.04\right)$. Again, a significant interaction was found for JSO youth with biological and nonbiological caregivers, such that youth with non-biological caregivers had higher relationship quality scores $(\beta=.743, t(827)=3.21, p<.01)$. Thus, having a nonbiological caregiver may provide a buffering effect for relationship quality between juvenile sexual offender and their guardian (See Figure 1.3).

\section{Discussion}

This study was designed to investigate the unique effects of caregiver disruption on the development of juvenile sexual offending. It does so by analysing the relationship between offence type and the youths' perceived relationship quality with their caregivers, while including the potentially moderating factors of caregiver gender and biological relationship between caregiver and child. In general, the data supports the hypotheses that offence status and caregiver disruption history are important factors to consider in evaluating the quality of the relationship between a youth and their primary guardian.

The relationship of sexually aggressive youth to their caregivers may prove to be 
a key to understanding their aberrant behaviour. The comparison of juvenile sexual offenders, violent and nonviolent juvenile delinquents, and young people who have never been convicted of criminal activity may offer insights into the impact that criminal offending has on the relationship quality between a youth and their primary caregiver. It is widely accepted that poor-quality parenting and strained parent-child relationships are associated with juvenile delinquency (Hoeve et al., 2009). The data from this study support the hypothesis that more serious offence statuses are related to low relationship quality scores. Both juvenile sexual offenders and violent juvenile delinquents reported poor quality relationships, with JSOs reporting slightly worse relationships than JD-Vs. However, this study did not address the directionality of the relationship between offence status and caregiver quality scores. It has been suggested that youth with weak attachments are more likely to engage in violent or sexually delinquent acts (Felizzi, 2015b). Inadequate caregiving may also mean that these youths are poorly supervised and monitored, and thus are at increased risk for delinquency and sexual offending (Zankman $\&$ Bonomo, 2004). On the other hand, another feasible argument holds that committing a juvenile offence may, in and of itself, adversely impact the quality of the primary caregiver relationship. Research examining shame and stigma associated with parenting sexual offenders clearly documents that parents of juvenile sexual offenders struggle with accepting their child's crime and have difficulties expressing love for their child after the offence (Jones, 2015). Thus, there is evidence that the low quality caregiver-child relationships seen in the two high-delinquency groups both influence and are influenced by offence status. 
The initial finding described above is an important contribution to understanding the family dynamics of young offenders. However, it also elicits questions regarding the impact of distinct family systems. Examining nuance in the types of family disruptions that characterise juvenile sexual offenders' households would make those discriminations even more useful. Therefore, two central moderators related to caregiver disruption have been selected for examination, caregiver gender and substitute caregivers.

\section{Caregiver Gender}

The first of these moderators distinguishes the perceptions of relationship quality from youth with male or female caregivers. Overwhelmingly, the literature examining parental gender effects on children's behaviour has found that children who are parented by males are at increased risk for a broad range of negative social and emotional outcomes (Coles, 2015). It was anticipated that youth with male primary caregivers would report lower quality relationships than would youth who were cared for by women.

Consistent with this hypothesis, the data shows that for certain youth, the presence of a male primary caregiver is associated with a decrease in relationship quality scores. For youth with low levels of delinquency (JC \& JD-NV), no differences in relationship quality were found between those who had female or male caregivers. However, for the high-delinquency group (JD-V \& JSO), significant interactions were found, such that high-delinquent youth with male primary caregivers had lower relationship quality scores than did high-delinquent youth with female primary caregivers.

One possible interpretation of this finding is that the men who parent the JC/JDNV youth are involved, supportive, and reasonable caregivers. On the other hand, highdelinquency youth may be more likely to be parented by absent or hostile male 
caregivers. Attentive and sympathetic parenting might potentially affect both the relationship quality score and the youth's type of offending. This conclusion is consistent with the body of literature which suggests that attentive and supportive caregiving is a protective factor against juvenile delinquency (Hoeve et al., 2009). Future research should more closely examine the parenting styles of these male primary caregivers. Analyses of this nature would add to the interpretability of this study's finding.

\section{Substitute Caregivers}

Just as youth have distinct reactions to male and female caregivers, they may react in measurably different ways to their biological parents or the substitute caregivers that raise them. Youths in biologically-intact families are thought to be at lower risk for child abuse and neglect, insecure attachment styles, and engagement in delinquency compared to their peers with substitute guardians (Hilton, Harris, \& Rice, 2015; Miller et al., 2000).

In this study it was hypothesised that biological status would act as a moderator between offence type and relationship quality, with the presence of a substitute guardian negatively affecting the caregiver-child relationship. The results of this moderation analysis partially supported this hypothesis. As expected, having a non-biological caregiver resulted in lower relationship quality scores for JC, JD-NV, and JD-V youth. Thus, for the majority of youth in this sample, being raised by a biological parent can be considered a protective factor for maintaining a strong and high-quality bond, even while the child is incarcerated.

However, these data yielded surprising results for JSO youth whose reports were inconsistent with the proposed hypothesis. For youth who have committed sexual 
offences, relationship quality scores were lower if their primary caregiver was a biological parent. Since this difference was not seen in either of the other two incarcerated groups, it is reasonable to conclude that neither criminal offending in general, nor separation from one's biological parents via the justice system, are the cause of this unusual finding. Instead, these results indicate something unique about young sexual offenders and their parents. One possible explanation is that society views sexual offenders, and by extension the parents of sexual offenders, with more stigma and disgust than they do other delinquent teens and families (Smith \& Trepper, 1992). Parents of sexual offenders simultaneously deal with the internal self-blame for their child's offence, the public shame and stigma of having a child convicted of a sex crime, and the exhaustion that comes with navigating the court and juvenile justice system. This may be overwhelming for JSO's parents, causing their relationship with their child to suffer. It is also probable that the social stigma attached to sexual crimes may cause parents to demonstrate a loss of respect for the offending child. That loss, in turn, may further undermine the caregiver-child relationship.

While sexual crimes are more stigmatised than almost any other criminal offences (Tewksbury, 2012), stigmatisation is not the only unique aspect of this type of offending. Sexual offences also constitute a rare type of criminal offence that is almost as likely to occur within the household as outside of it, and as likely to include a family member as an extra-familial victim (Magalhães et al., 2009). Intrafamily sexual abuse puts parents in an impossible position, given their emotional attachment to both the perpetrator and the victim. In some cases, parents themselves must even report one child's sexual offence to the authorities in order to protect another family member. Within this sample of 
offenders, $48 \%$ of JSO youth reported that they lived in the same household as their victim. In the future, researchers should investigate the relationship quality between intraand extra-familial offences to see if these results can be explained by victim type (i.e. intra- vs. extra-familial).

\section{Study Strengths}

This study contributes to the existing literature in three important ways. First, it succeeds in clarifying crucial distinctions between juvenile sexual offenders and general juvenile delinquents, while also elucidating group commonalities. These results support the classification of juvenile sexual offenders as a population similar to those juvenile delinquents who commit violent crimes. Yet, it is essential to note that the sexual offenders in this study differed on almost all measures from the nonviolent incarcerated youth. It is evident then, that while juvenile sexual offenders and violent juvenile delinquents may emanate from a single population, these youth should not be considered the same as youth who commit minor offences, even if these youths are incarcerated together.

Even though this study suggests that youth who commit sexual offences are in many ways similar to youth who commit other crimes against persons, juvenile sexual offenders and violent juvenile delinquents were not identical on all measures. Two differences stand out: (1) A higher percentage of JSOs were found to have experienced disrupted caregiving than JD-Vs; and (2) the positive impact of non-biological caregivers was significant for JSOs but not JD-Vs. These findings indicate that the uniqueness of the juvenile sexual offender population needs to be investigated more fully and future findings need to be incorporated into the literature to enhance existing theories. 
A second strength of this study is its inclusion of the juvenile control group. Among the few studies that have examined JSOs as a unique population, almost none of them have included a non-incarcerated control group. The results of this study indicate that this comparison may be particularly valuable, especially in light of the additional contrasts made with the other groups of incarcerated youth. Findings from this investigation demonstrate that JSOs have dramatically different home lives than do the average, non-criminal teens. Compared to control youth, JSOs were at greater risk for every type of caregiver disruption. This finding points to potential areas for the prevention of juvenile sexual offending by intervening with families on the brink of disrupting a child's primary caregiving relationships. By maintaining children's connection to a biological parent, they can extend the protective advantages of this type of parenting.

Finally, the measurement of variables related to caregiver disruption, in and of itself, represents one of this study's strengths. To date, the literature examining family factors in the etiology of juvenile sexual offending has been sporadic and disjointed. This study offers a touchstone for important further research which may consider the construct of caregiver disruption as a whole. There is much more work to be done in this area, but the results of this study suggest that continuing research on this line of inquiry will be both informative and valuable.

\section{Study Limitations}

Despite the strengths of this study, it is also not without its limitations. First, all of the data comes from self-report surveys. Those surveys touch upon a number of sensitive topics. The primary limitation is that some of the participants may not have answered the 
questions truthfully. Though the participants were assured of the anonymity of this data, incarcerated youth might well have felt that reporting on their poor relationships with their primary caregivers could have negative consequences for their therapy or release plans. While fewer than two percent of youth dropped out of the study, no follow-up information was collected from those youth who chose to end their participation. This means that an evaluation of their concerns regarding the study and a comparison of their demographic profile to youth who completed study measures is not possible. Thus, these findings must be evaluated with this caution in mind.

Second, as the data was collected while many of the youth were incarcerated, they were asked to report on their relationships with their primary caregivers during the last year that they were living in the community. This is particularly problematic insofar as youth who had been incarcerated for long sentences may well have more distorted memories about the quality of their relationships at that time. Furthermore, this assessment method creates a disparity between incarcerated youth and controls, since control youth were reporting on their current relationship with their caregivers, while those incarcerated responded retrospectively.

Third, the very idea of organising youth by the type of their latest offence is a dubious and an unstable system for categorisation. Many of these youth may have committed crimes previously that would have placed them in different categories. Some may go on to recidivate with a different type of criminal offence. Though this study did confirm that no youth in the control groups had previously been convicted of a sexual offence, it fails to take into account the potential fluidity of criminal activity by these young men over time. 
Finally, the relationship quality scale used in this study presents a fourth limitation. The original researchers asked youth to identify a single primary caregiver. As such, it is possible that youth living in two-parent families may have had difficulty in choosing only one parent to rate. Further, we lack comparative data on the relative quality of the youth's relationship between parents, as well as data which would allow for a comparison of two-parent households to single-parent households.

\section{Treatment Implications}

Understanding risk and protective factors in family relationships has broad implications for encouraging and shaping family therapy for young sexual offenders. Since family dynamics are critical to the development and maintenance of appropriate sexual behaviour among at-risk youth (Yoder, 2014), services that are attuned to the particular risk factors present in a JSO's family structure may be more effective at facilitating a positive home environment for the youth. This study suggests that service providers should be vigilant for youth who have experienced caregiver disruptions. In particular, youth who are being primarily cared for by men and those youth who have experienced substitute care seem to be at increased risk for relationship quality problems. Providers may consider encouraging households with these risk factors to engage in more extensive family therapy than they would otherwise.

On the other hand, previous research has also demonstrated that family dynamics may be a protective factor against sexual recidivism in youth (Spice, Viljoen, Latzman, Scalora, \& Ullman, 2013). Though contrary to our hypothesis, this study finds that nonbiological caregivers may be more accepting, understanding, and compassionate toward sexually delinquent youth. One may tentatively conclude from these results that living in 
a non-biological home may, in fact, be particularly beneficial for young sexual offenders, since it gives them a chance to develop relations with adults who have not been personally impacted by their assaultive behaviour. This result should certainly not be used to recommend that youth be removed from their biological homes in favour of foster or adoptive homes. However, it does suggest a potential for strengths-based approaches that may be used by therapists and other treatment practitioners to capitalise on the emotional distance that is present in non-biological living environments in a proactive therapeutic manner.

\section{Future Directions}

This study's findings lend themselves to a number of future directions for research on sexual offending and caregiver disruption. First, a more in-depth examination of the interconnectedness of caregiver disruption risk-factors is warranted. Though outside the scope of this study, information should be gathered regarding the impact on relationship quality of caregivers who represent two or more areas of disrupted caregiving (e.g. a step-father, who is both male and non-biological). Second, due to small cell sizes, some nuance was lost in the moderators in this study. For example, too few youth lived with a non-parental family member (e.g. custodial grandparents) for that type of family structure to be examined independently. It would be valuable for future researchers to seek samples of youth who have lived with a broader variety of caregivers (e.g. grandmothers, foster care) in order to gain a clearer picture of the ways in which a disruption can affect youth. 


\section{Tables}

Table 1.1 Raw count and percentages of disrupted caregiving by offense type.

\begin{tabular}{r|cccc}
\multicolumn{1}{c}{ JC } & JD-NV & JD-V & JSO \\
Nuclear Family & 192 & 75 & 66 & 100 \\
Male Caregiver & $(74.4 \%)$ & $(55.0 \%)$ & $(55.5 \%)$ & $(32.3 \%)$ \\
Biological Father & 14 & 25 & 20 & 91 \\
(5.4\%) & $(10$ & 13 & 14 & 48 \\
Step/Adoptive/Foster Father & 3 & 10 & 6 & 40 \\
Grandfather/Uncle & 1 & 2 & 0 & 3 \\
Non-Biological Caregiver & 20 & 31 & 28 & 125 \\
Adoptive/Step Parent & $(7.8 \%)$ & $(27.0 \%)$ & $(20.0 \%)$ & $(40.3 \%)$ \\
Foster Parent & 5 & 16 & 13 & 61 \\
Distant Relative & 12 & 11 & 8 & 32 \\
\hline
\end{tabular}

Note. For brevity, this table represents only the relevant types of disrupted caregiving for the corresponding analyses. Some youth in the sample are not represented here (e.g., youth raised by a single biological mother). 


\section{Figures}

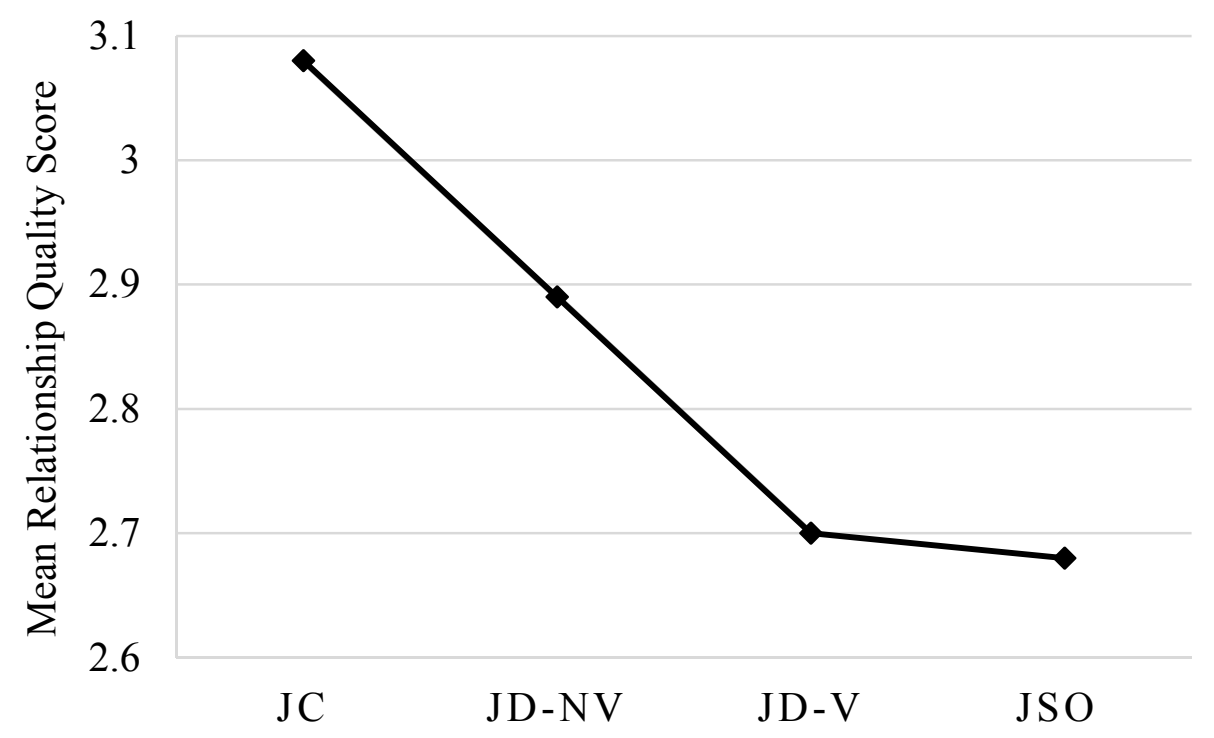

Figure 1.1 Mean values of the PRSS by offense type.

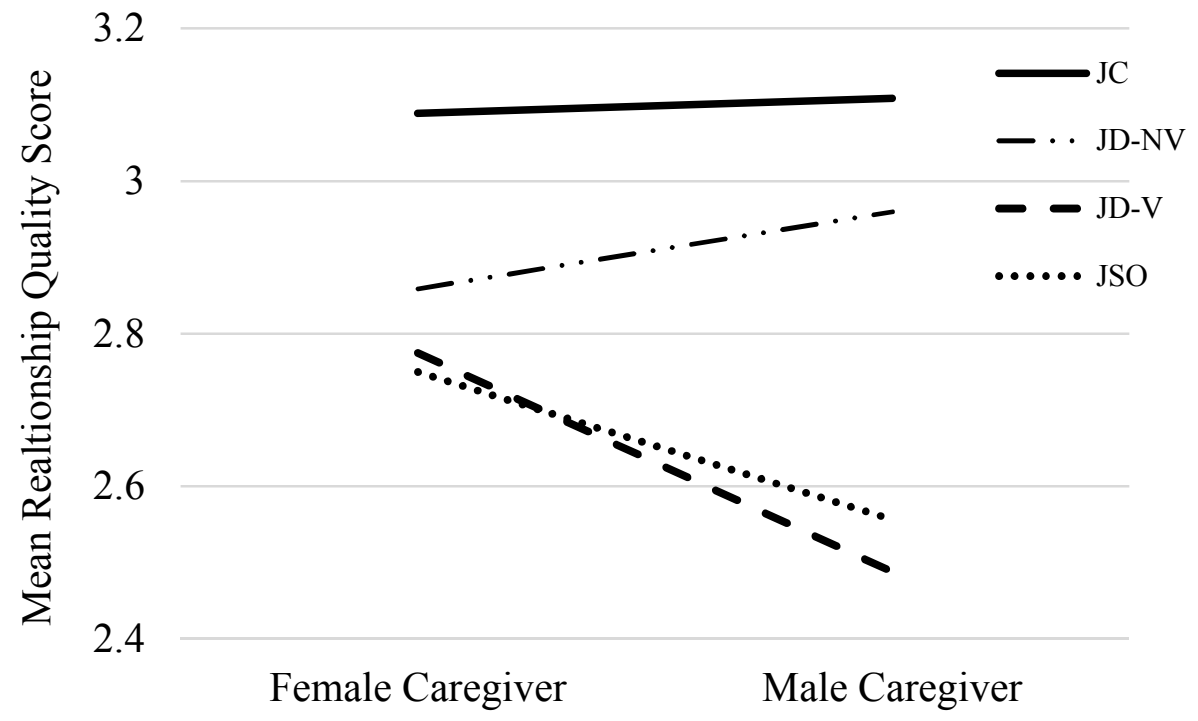

Figure 1.2 Moderation of caregiver gender between offense type and relationship quality. 


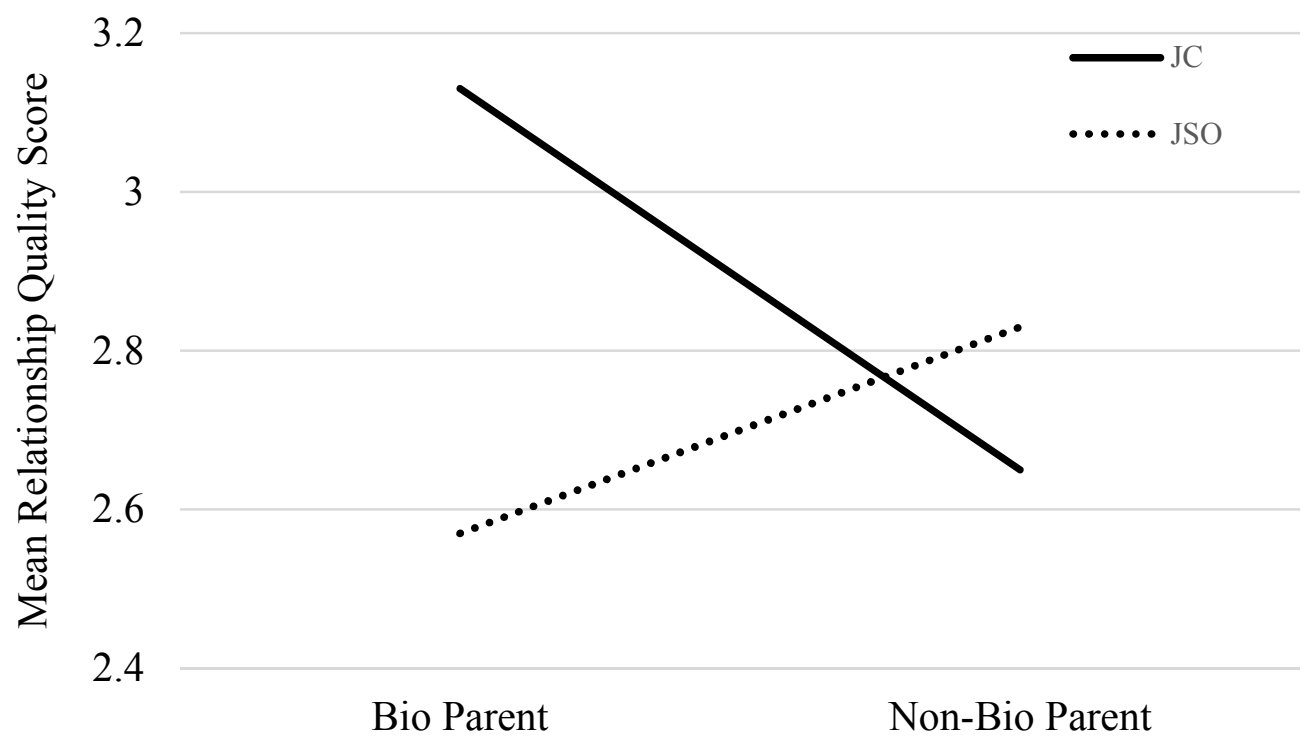

Figure 1.3 Moderation of biological parent on the relationship quality of JCs and JSOs. 


\section{References}

Apel, R., \& Kaukinen, C. (2008). On the relationship between family structure and antisocial behavior: Parental cohabitation and blended households. Criminology; An Interdisciplinary Journal, 46, 35-70. doi:10.1111/j.1745-9125.2008.00107.x

Borduin, C. M., Schaeffer, C. M., \& Heiblum, N. (2009). A randomized clinical trial of multisystemic therapy with juvenile sexual offenders: Effects on youth social ecology and criminal activity. Journal of Consulting and Clinical Psychology, 77 (1), 26-37. doi:10.1037/a0013035

Bowlby, J. (1944). Forty-four juvenile thieves: Their characters and home lives. International Journal of Psycho-Analysis, 25, 19-52.

Bowlby, J. (1969). Attachment and loss, Vol. I: Attachment. New York, NY: Basic Books.

Bowlby, J. (1982). Attachment and loss: Retrospect and prospect. American Journal of Orthopsychiatry, 52(4), 664-678. doi:10.1111/j.19390025.1982.tb01456.x

Breivik, K., \& Olweus, D. (2006). Adolescent's adjustment in four post-divorce family structures: Single mother, stepfather, joint physical custody and single father families. Journal of Divorce \& Remarriage, 44, 99-124. doi:10.1300/J087v44n03_ 07

Bronte-Tinkew, J., Scott, M. E., \& Lilja, E. (2010). Single custodial fathers' involvement and parenting: Implications for outcomes in emerging adulthood. Journal of Marriage and Family, 72(5), 1107-1127. doi:10.1300/J087v44n03_07

Coles, R. L. (2015). Single-father families: A review of the literature. Journal of Family Theory \& Review, 7, 144-166. doi:10. 1111/jftr.12069 
Duane, Y., Carr, A., Cherry, J., McGrath, K., \& O’Shea, D. (2003). Profiles of the parents of adolescent CSA perpetrators attending a voluntary outpatient treatment programme in Ireland. Child Abuse Review, 12(1), 5-24. doi:10.1002/car.776

Evenhouse, E., \& Reilly, S. (2004). A sibling study of stepchild well-being. Journal of Human Resources, 39(1), 248-276. doi:10.2307/3559012

Felizzi, M. V. (2015a). Family or caregiver instability, parental attachment, and the relationship to juvenile sex offending. Journal of Child Sexual Abuse, 24(6), 641658. doi:10.1080/10538712.2015.1057668

Felizzi, M. V. (2015b). Emotional abuse, parent and caregiver instability, and disrupted attachment: The relationship to juvenile sexual offending. In K. Rice \& M. V. Felizzi (Eds.), Global youth: Understanding challenges, identifying solutions, offering hope (pp. 5-16). Newcastle upon Tyne: Cambridge Scholars Publishing.

Funari, S. K. (2005). An exploration of impediments to attachment in a juvenile offender population: Comparisons between juvenile sex offenders, juvenile violent offenders and juvenile non-sex, non-violent offenders (Doctoral dissertation). Virginia Commonwealth University Richmond, Virginia.

Greenfeld, L. A. (1997). Sex offences and offenders: An analysis of data on rape and sexual assault. Washington, DC: U.S. Department of Justice.

Henggeler, S. W., Letourneau, E. J., Chapman, J. E., Borduin, C. M., Schewe, P. A., \& McCart, M. R. (2009). Mediators of change for multisystemic therapy with juvenile sexual offenders. Journal of Consulting and Clinical Psychology, 77(3), 451-462. doi:10.1037/a0013971 
Hilton, N. Z., Harris, G. T., \& Rice, M. E. (2015). The step-father effect in child abuse: Comparing discriminative parental solicitude and antisociality. Psychology of Violence, 5, 8-15. doi:10.1037/a0035189

Hoeve, M., Dubas, J. S., Eichelsheim, V. I., Van Der Laan, P. H., Smeenk, W., \& Gerris, J. R. (2009). The relationship between parenting and delinquency: A metaanalysis. Journal of Abnormal Child Psychology, 37, 749-775. doi:10.1007/s10802-009-9310-8

Jones, S. (2015). Parents of adolescents who have sexually offended: Providing support and coping with the experience. Journal of Interpersonal Violence, 30, 12991321. doi:10.1177/0886260514540325

Juffer, F., \& van Ijzendoorn, M. H. (2005). Behavior problems and mental health referrals of international adoptees: A metaanalysis. Jama, 293(20), 2501-2515. doi:10.1001/jama.293.20.2501

Kaufman, K. (2001). Perceived Relationship with Supervisor Scale. Portland, OR: Portland State University.

Keogh, T. (2012). The internal world of the juvenile sex offender: Through a glass darkly then face to face. London: Karnac Books.

Lyn, T. S., \& Burton, D. L. (2005). Attachment, anger and anxiety of male sexual offenders. Journal of Sexual Aggression, 11, 127-137. doi:10.1080/13552600500063682

Magalhães, T., Taveira, F., Jardim, P., Santos, L., Matos, E., \& Santos, A. (2009). Sexual abuse of children. A comparative study of intra and extra-familial cases. Journal of Forensic and Legal Medicine, 16, 455-459. doi:10.1016/j.jflm.2009. 05.007 
Margari, F., Lecce, P. A., Craig, F., Lafortezza, E., Lisi, A., Pinto, F., ... Grattagliano, I. (2015). Juvenile sex offenders: Personality profile, coping styles and parental care. Psychiatry Research, 229(1), 82-88. doi:10.1016/j.psychres.2015. 07.066

Marsa, F., O’Reilly, G., Carr, A., Murphy, P., O’Sullivan, M., Cotter, A., \& Hevey, D. (2004). Attachment styles and psychological profiles of child sex offenders in Ireland. Journal of Interpersonal Violence, 19, 228-251. doi:10.1177/ 0886260503260328

Marshall, W. L. (1989). Intimacy, loneliness, and sexual offenders. Behaviour Research and Therapy, 27, 491-504. doi:10. 1177/088626097012003001

Mathe, S. (2007). Juvenile sexual offenders: We are the sons of our fathers. Agenda (Durban, South Africa), 21(74), 133-140. doi:10.1080/10130950.2007.9674887

Miller, B. C., Fan, X., Christensen, M., Grotevant, H. D., \& Van Dulmen, M. (2000). Comparisons of adopted and nonadopted adolescents in a large, nationally representative sample. Child Development, 71(5), 1458-1473. doi:10.1111/14678624. 00239

Patterson, C. (2008). Child development. New York, NY: McGraw-Hill.

Rich, P. (2006). Attachment and sexual offending: Understanding and applying attachment theory to the treatment of juvenile sexual offenders. Hoboken, NJ: John Wiley \& Sons.

Righthand, S., \& Welch, C. (2004). Characteristics of youth who sexually offend. Journal of Child Sexual Abuse, 13, 15-32. doi:10.1300/J070v13n03_02 
Ryan, G., Leversee, T. F., \& Lane, S. (2011). Juvenile sexual offending: Causes, consequences, and correction. Hoboken, NJ: John Wiley \& Sons. Santrock, J. W. (2013). Children. New York, NY: McGraw-Hill.

Seidman, B., Marshall, W. L., Hudson, S. M., \& Robertson, P. J. (1994). An examination of intimacy and loneliness in sex offenders. Journal of Interpersonal Violence, 9, 518-534. doi:10.1177/088626094009004006

Seto, M. C., \& Lalumière, M. (2010). What is so special about male adolescent sexual offending? A review and test of explanations through meta-analysis.

Psychological Bulletin, 136, 526-575. doi:10.1037/a0019700

Sigre-Leirós, V., Carvalho, J., \& Nobre, P. J. (2016). Early parenting styles and sexual offending behavior: A comparative study. International Journal of Law and Psychiatry, 46, 103-109. doi:10.1016/j.ijlp.2016.02.042

Smallbone, S. (2006). Social and psychological factors in the development of delinquency and sexual deviance. In H. E. Barbaree \& W. L. Marshall (Eds.), The juvenile sex offender (2nd ed., pp. 105-127). New York, NY: Guildford Press.

Smallbone, S. W., \& Dadds, M. R. (1998). Childhood attachment and adult attachment in incarcerated adult male sex offenders. Journal of Interpersonal Violence, 13, 555573. doi:10.1177/088626098013005001

Smallbone, S. W., \& Dadds, M. R. (2001). Further evidence for a relationship between attachment insecurity and coercive sexual behavior in nonoffenders. Journal of Interpersonal Violence, 16, 22-35. doi:10.1177/088626001016001002 
Smith, B. J., \& Trepper, T. S. (1992). Parents' experience when their sons sexually offend: A qualitative analysis. Journal of Sex Education and Therapy, 18, 93103. doi:10.1080/01614576.1992.11074043

Spice, A., Viljoen, J. L., Latzman, N. E., Scalora, M. J., \& Ullman, D. (2013). Risk and protective factors for recidivism among juveniles who have offended sexually. Sexual Abuse: A Journal of Research and Treatment, 25, 347-369. doi:10.1177/ 1079063212459086

Starzyk, K. B., \& Marshall, W. L. (2003). Childhood family and personological risk factors for sexual offending. Aggression and Violent Behavior, 8(1), 93-105. doi:10.1016/S1359-1789(01)00053-2

Tewksbury, R. (2012). Stigmatization of sex offenders. Deviant Behavior, 33(8), 606623. doi:10.1080/01639625.2011. 636690

Tidefors, I., \& Strand, J. (2012). Life history interviews with 11 boys diagnosed with attention-deficit/hyperactivity disorder who had sexually offended: A sad storyline. Journal of Trauma \& Dissociation, 13(4), 421-434. doi:10.1080/15299732. 2011.652344

Ward, T., Hudson, S. M., \& Marshall, W. L. (1996). Attachment style in sex offenders: A preliminary study. Journal of Sex Research, 33, 17-26. doi:10.1080/00224499609551811

Whitaker, D. J., Le, B., Hanson, R. K., Baker, C. K., McMahon, P. M., Ryan, G., ... Rice, D. D. (2008). Risk factors for the perpetration of child sexual abuse: A review and meta-analysis. Child Abuse \& Neglect, 32, 529-548. doi:10.1016/j.chiabu. 2007.08.005 
Wilkinson, G. S. (1993). The Wide Range Achievement Test administration manual. Wilmington, DE: Wide Range.

Worley, K., Church, J., \& Clemmons, J. (2012). Parents of adolescents who have committed sexual offences: Characteristics, challenges, and interventions. Clinical Child Psychology and Psychiatry, 17(3), 433-448. doi: $10.1177 / 1359104511417787$

Yoder, J. R. (2014). Service approaches for youths who commit sexual crimes: A call for family-oriented models. Journal of Evidence-Based Social Work, 11(4), 360-372. doi:10.1080/10911359.2014.897108

Yoder, J. R., Dillard, R., \& Stehlik, L. (2018). Disparate reports of stress and family relations between youth who commit sexual crimes and their caregivers. Journal of Sexual Aggression, 24(1), 114-124. doi:10.1080/13552600.2017.1372938

Yoder, J. R., Leibowitz, G. S., \& Peterson, L. (2016). Parental and peer attachment characteristics: Differentiating between youth sexual and non-sexual offenders and associations with sexual offence profiles. Journal of Interpersonal Violence, 33, 2643-2663. doi:10.1177/0886260516628805

Zankman, S., \& Bonomo, J. (2004). Working with parents to reduce juvenile sex offender recidivism. Journal of Child Sexual Abuse, 13, 139-156.

doi:10.1300/J070v13n03_08 


\title{
Chapter 3: Manuscript Two -
}

\section{A chip off the old block: The impact of fathers on sexual offending behavior}

Note: This manuscript has been published. The citation for this article is:

Sitney, M. H., \& Kaufman, K. L. (2020). A chip off the old block: the impact of fathers on sexual offending behavior. Trauma, Violence, \& Abuse. Advance online publication.

\begin{abstract}
While parenting factors are commonly included as early risk markers for sexual aggression, data specific to paternal impacts on sexual offending is scattered. This review provides a thorough and systematic account of what is known regarding the fathers of sexual offenders. Thirty-four studies were categorized according to four distinct research questions, each addressing theoretical mechanisms by which fathers may influence the violent sexual behavior of their sons. The results suggest that the strongest impacts occur when sons are witness to their fathers engaging in acts of sexual abuse or domestic violence, in accordance with social learning theory. Father-son attachment or relationship quality also appears to have a measurable impact on the son's engagement in sexual violence. However, paternal demographics and characteristics were generally ineffective at predicting sons' sexual offenses. Finally, the differences between fathers of adult and juvenile sexual offenders are explored. Implications of those findings for research and applied interventions are included as they may be informative for prevention programming.
\end{abstract}




\section{Introduction}

The 21st century has seen a dramatic shift in the composition of family systems (U.S. Census Bureau, 2018). One manifestation of this change is that the fathering role has become more varied, with increasing numbers of step-fathers, adoptive fathers, foster fathers, and custodial grandfathers entering family systems (U.S. Census Bureau, 2018). Additionally, men increasingly take on a primary parenting role. In fact, in the last twenty-five years, the number of families with stay-at-home male caregivers and working female caregivers have doubled (Livingston, 2014). Current estimates suggest that as many as one-in-five fathers now manage the daily activities of their children (Livingston, 2014). Despite men's increasing roles as primary caregivers, they are generally excluded from conversations regarding the impact of parenting practices on child development (Boller et al., 2006; Furstenberg \& Harris, 1993; Yeung, Duncan, \& Hill, 2000). Yet, the few studies that have examined the unique roles of fathers found positive outcomes for children with active and involved male caregivers (Lundahl, Tollefson, Risser, \& Lovejoy, 2008; Zanoini, Warburton, Bussey, \& McMaugh, 2013). That is to say, fathers matter too.

The influence of parents and caregivers on the criminal behavior of their children is hardly a new topic. Meta-analyses on the causes and correlates of juvenile delinquency have found that parenting factors may predict youth engagement in criminality (Hoeve et al., 2009; Hoeve et al., 2012; Loeber \& Stouthamer-Loeber, 1986). Importantly, this body of research has found that fathers may have an even greater impact on their children's delinquency than do mothers (Hoeve et al., 2009), with a few potential explanations underlying this finding. First, numerous studies have examined the intergenerational 
transmission of criminal offending, which has predominantly been conceptualized as passed on from father to son (Besemer \& Farrington, 2012). Fathers may model antisocial behavior for their sons, who then proceed to enact such behaviors themselves (Dishion, Owen, \& Bullock, 2004). Secondly, delinquency may also be the result of strained father-son attachments, as youth with hostile relationships to their fathers are likely to become oppositional (Hayslett-McCall \& Bernard, 2002). Finally, certain paternal characteristics (i.e. absent fathers, fathers who abuse drugs) heighten the risk of insufficient parental monitoring of their children's behavior, leaving the youth free to associate with delinquent peers (Basile, Rostad, Leemis, Espelage, \& Davis, 2018; Demuth \& Brown, 2004).

Though these pathways have been explored for youth delinquency in general, the role of the father remains a critically understudied factor in the development of juvenile sexual offenders. However, it is becoming increasingly important to distinguish between youth who commit sexual and non-sexual crimes, as research has revealed there may be heightened family risk for young sexual offenders. A limited body of literature suggests that sexually offending youth are supervised less well by their caregivers than are nonoffending youth (Stewart, Sitney, Kaufman, DeStephano, \& Bui, 2019). Additionally, family functioning for sexual offenders has been found to lack cohesion and to have elevated rates of both domestic violence and child maltreatment (Seto \& Lalumière, 2010; Worley, Church, \& Clemmons, 2011). Furthermore, disrupted caregiving factors, such as experiencing an out-of-home placement or domestic trauma, have been shown to be independently predictive of sexual offending status over general delinquency (Felizzi, 2015; Grady, Yoder, \& Brown, 2018). However, the bulk of this literature is not focused 
on fathers. Rather, these works emphasize mother-specific factors or include the experiences of both mothers and fathers combined. Given the importance of fathers noted in juvenile delinquency studies, this paper seeks to review the current literature on the impact of paternal factors in the development of sexually problematic behaviors among males.

An additional consideration in this literature is the potential distinction between types of sexual offending. Though juvenile sexual offenders make up as many as $20 \%$ of all arrests for sex crimes committed in the United States (CSOM, 2008; Department of Justice, 2014), adult and juvenile sexual offenders are often considered as separate populations (Lussier, Blokland, Mathesius, Pardini, \& Loeber, 2015). Those who argue that juvenile and adult sexual offenders are fundamentally different populations note the profound developmental differences between the two groups in terms of emotion regulation, behavioral control, and ability to anticipate future consequences of their actions (Department of Justice, 2014). There are others, however, who argue that there is some overlap between adults and juveniles who commit acts of sexual aggression. For instance, while most juvenile sexual offenders do not become adult sexual offenders, many adult sexual offenders began their sexually coercive behavior in their youth (Lussier et al., 2015; Prentky \& Knight, 1993). Furthermore, overlapping risk factors have been identified in both populations, including sexual victimization history and chaotic family-of-origin environments (Jespersen, Lalumière, \& Seto, 2009; Seto \& Lalumière, 2010). However, a thorough account of the potential ways in which fathers may have influenced adult and juvenile offenders has yet to be explored.

\section{Theoretical Grounding}


Much of the work regarding family factors of juvenile sexual offenders has roots in two core theories. First, Bandura's (1978) social learning theory contends that children repeat the behavioral patterns that they observe in the people closest to them. Research has found that either witnessing or experiencing sexual violence increases the risk of perpetrating a sexual assault (Burton, Miller, \& Shill, 2002; Seto \& Lalumière, 2010). Social learning perspectives have also been consistently integrated into theories of how young boys learn masculinity norms (O’Neil, 1982; 2015; Pleck, 1981; 1995). Sexual assault can be considered consistent with the male gender role norms that entail devaluing women and femininity, along with over-estimating dominance and aggression (Reidy, Shirk, Sloan, \& Zeichner, 2009). This theory may be particularly applicable to the father-son relationship insofar as, for many young men, their fathers are a primary source of male gender norms (Marsiglio \& Cohan, 2000). Therefore, one of the primary purposes of this review is to explore the role of social learning theory, as transmitted from father to son, in the development of sexual offending.

Second, the foundational method of understanding the impact of parent-child relationships on juvenile delinquency has been attachment theory (Bowlby, 1944; Bowlby 1969). It maintains that a child's history with their primary guardian provides a "working model" for all subsequent interpersonal relationships. Overwhelmingly, examinations of the home lives of juvenile offenders suggest these youth have weak attachments to their guardians, which is thought to significantly increase their risk of delinquency (Hoeve et al., 2012). The most prominent writings linking poor parental attachment to sexual aggression argue that youth with poor attachments experience loneliness and frustration which may be expressed as sexual violence, especially if the 
youth has also been the victim of sexual abuse (Yoder, Grady, \& Dillard, 2018; Marshall, 1989; Marshall, 1993; Marshall \& Marshall, 2010). Young sexual offenders have been shown to be lonelier, have greater intimacy problems, fewer peer social skills, and more disturbed parental attachment than other offenders or non-criminal youth (Pallini et al., 2014; Seidman, Marshall, Hudson, \& Robinson, 1994; Smallbone \& Dadds, 1998).

However, the specific impact of father-son attachments for sexual offenders is still poorly understood. Clarity on this issue is a second goal of the current study.

\section{Current Study}

Given the potential impact on sexual aggression made by fathers, it is important to review the available evidence to better understand the role that fathers play in their sons' sexual offenses. The present study aims to conduct a systematic literature review of all available studies regarding adults and juveniles who have committed sexual crimes that have incorporated aspects of paternal caregiving. This review is guided by four research questions:

(RQ1) What impact does a father's own history of perpetrating sexual violence have on his son's sexual offending behavior?

(RQ2) What impact does the quality of the relationship between father and son have on the son's sexual offending behavior?

(RQ3) What impact does a father's situational and socio-emotional characteristics have on their son's sexual offending behavior?

These questions have been derived based on prior theory and directly relate to social learning theory (RQ1), attachment theory (RQ2), and the caregiver disruption literature (RQ3). Additionally, as there is considerable controversy in the literature regarding the 
potential distinctiveness of youth who commit sexual crimes (Lussier et al., 2015; Seto \& Lalumière, 2010), this review will investigate areas of commonality or difference between the fathers of adult and juvenile sexual offenders. Therefore, a fourth research question is posited:

(RQ4) In what ways are paternal impacts distinct for juvenile and adult sexual offenders?

\section{Method}

\section{Inclusion and Exclusion Criteria}

To answer these research questions, we conducted an exhaustive literature search of all available research on juveniles and adults who commit sexual crimes and their male caregivers. The following criteria were utilized to ensure that the papers included in this review fell within the scope of the research questions and goals.

Fathers. As this review focuses on the unique contribution of fathers to sexual offending behaviors, articles were only included if they involved analyses or conclusions that were specific to male caregivers. In addition to biological fathers, results that included step-fathers or other live-in male caregivers for children (e.g. mother's boyfriend, adoptive fathers) were included. Papers that concerned general parenting practices or that did not separately analyze mothers and fathers were excluded.

Offenders. Due to the cultural and legal ambiguities surrounding what constitutes a sexual offense, a broad definition of sexual offenders was employed. While most studies used populations of men who had been convicted of a sexual offense, articles were also included if the participants admitted to engaging in abusive sexual acts but had never been arrested or convicted. However, literature regarding the impact of fathers on 
non-coercive sexual behavior (e.g. early sexual debut, teen pregnancy, masturbation) were excluded.

Time Period. Literature published before the year 2000 was not considered. This cutoff was determined in conjunction with U.S. Census data demonstrating the changing parenting practices in America (U.S. Census Bureau, 2018). Those who study familysystem trends have concluded that the new millennium brought with it a shift in viewing fathers as legitimate caregivers for children (Milkie \& Denny, 2014). It is assumed that papers published after 2000 would reflect this public perception of male caregiving.

Study Methodological Criteria. Articles were included in this review if they met the standards of empirical research. Peer-reviewed journal articles were included as were some forms of "grey literature." Specifically, official reports commissioned by government agencies were included, as were peer-reviewed, international articles that were reprinted in English. No articles were ultimately excluded on the basis of poor methodology.

\section{Search Strategy}

Articles were collected primarily through the psychology research database PsychInfo. Secondary searches were performed using Google Scholar and by reviewing the reference lists of each relevant article. Refer to Figure 2.1 for a diagram of the electronic search strategy. In order to identify articles, "sexual offen*" was used as the primary search term. In addition, the following supplementary keywords were used in combination with the "sexual offen*" keyword to narrow down the literature: "father", "paternal", "parent", and "family". Thus, in total, four searches were conducted in both PsychInfo and Google Scholar. 
In order to capture the full extent of the literature, the "sexual offen*," "parent," and "family" keywords were searched for using the "all but full text" command. This required some variant of the keyword to be present in either the title, the abstract, or the listed search terms of the article. However, for the more specific supplemental keywords ("father" and "paternal"), the criteria were widened to the "anywhere" condition. Thus, studies that mention fathers of sexual offenders only in the body of the paper would still be captured in this review.

\section{Coding Strategy}

All papers generated through the search procedures were scanned to determine their relevance to the aims of this review. Papers that appeared to include some measure of paternal impacts for sexually aggressive behavior were then read thoroughly by the first author. All findings that related to the male caregivers of sexually aggressive men were extracted. Similar findings were then grouped together by their ability to address any of the four research questions. Findings that pertained to multiple research questions were included in all relevant areas.

\section{Systematic Literature Review}

\section{Search Results}

Included in this literature review are 34 studies that report on fathers of sexual offenders. For the remainder of this review, articles are organized based on their relevance to the research questions that guided the search. A brief summary of the articles and their positions within these groups can be found in Tables $2.1-2.3$. As fathers of sexual offenders were not the sole focus for many of the evaluations, the reported 
findings for each article have been truncated to include only material directly pertaining to this review's research questions.

\section{Intergenerational Transmission of Offending}

The first research question asked how a father's history of perpetrating sexual violence may impact his son's sexual offending behavior (See Table 2.1). Eight articles included hypotheses related to the intergenerational transmission of offending, which suggested that aggressive sexual behavior may be learned through witnessing fathers commit sexual violence, by internalizing the masculinity norms displayed by fathers, and though genetic heritability.

Sexually Violent Fathers. Overall, these articles provide a strong argument for the contribution of social learning to the consideration of how fathers influence the development of sexual offenders. Multiple studies found that sexual offenders are likely to cluster within families (Bijleveld, Hill, \& Hendricks, 2016; Långström, Babchishin, Fazel, Lichtenstein, \& Frisell, 2015; Van de Weijer, Besemer, Bijleveld, \& Blokland, 2015). Two such examinations found that children whose fathers had committed a sexual offense were between 3.7 - 6.95 times more likely to offend themselves (Långström et al., 2015; Van de Weijer et al.; 2015). Many offenders, both youth and adult, had directly observed their fathers enacting some form of violence against women (Stirpe and Stermac, 2003; Hunter, Figueredo, Becker, \& Malamuth, 2007). In one study, 54\% of young sexual offenders reported witnessing an older male relative beat a woman, while 19\% reported witnessing a father figure rape a woman (Hunter et al., 2007).

In qualitative interviews, offenders describe this experience as formative (Davids, Londt, \& Wilson, 2015; Mathe, 2007). They learned from observation that their paternal 
role-models were comfortable mistreating women, and that these displays of violence empowered their fathers. When reflecting on these learned norms, sexual offenders directly pinpoint witnessing their fathers commit gendered violence as the experience that distorted their perceptions of masculinity (Davids et al., 2015; Mathe, 2007). Entering their late teen or early adult years with a construct of masculinity that supports the degradation of women gave these men the freedom to commit their sexual offenses.

Abused-Abuser Pathway. This literature also does a laudable job of testing and rejecting various competing hypotheses that attempt to otherwise explain the clustering of sexual offenses in families. Most common is the proposed abuser-abused pathway, whereby experiencing sexual violence as a child makes one more likely to perpetrate sexual violence against others. None of the included studies found support for the abuserabused pathway in the context of father-son incest (Hunter, Figueredo, Malamuth, \& Becker, 2003; Van de Weijer et al., 2015). While both youth and adult offenders in the samples were more likely than controls to have experienced some form of sexual abuse, they overwhelmingly denied that the perpetrators were their fathers (Hunter et al., 2003; Van de Weijer et al., 2015). The abuser-abused pathway, therefore, fails to explain why having a sexually violent father dramatically increases the risk of committing a sexual offense oneself.

Genetics. Three studies investigated whether the clustering of sexual offending in families might be due to genetic heritability (Bijleveld et al., 2016; Hunter et al., 2003; Långström et al., 2015). Two articles found that father-son genetics accounted for a significant portion the variability in the prediction of the son's sexual offending over-andabove the presence of sexually violent step-fathers (Bijleveld et al., 2016; Långström et 
al., 2015). However, these same authors reported that they were better able to predict sexual offenses when the father and son lived in the same household, and, furthermore, when the father offended against children when his son was over the age of five. These qualifications ultimately provide yet another strong argument for the social learning hypothesis, since the son's age and location at the time of his father's offending should have no relevance on genetically transmitted behavior.

Finally, a study comparing characteristics of adolescents who sexually offended against pre-pubescent or pubescent girls, failed to differentiate the influence of genetic and social fathers (Hunter et al., 2003). Experiencing sexual abuse by either a genetic or social father did not predict the type of victim (i.e., pre-pubescent vs. pubescent) chosen by the juvenile offender. Therefore, the results regarding genetics are mixed. More research is needed in order to confidently side with either or both the hereditary or social learning positions on the transmission of sexual offending.

\section{Father and Son Attachment}

While social learning considers behavioral transmission to occur via internalizing the actions of others, attachment theory argues that the relationships built with primary caregivers serve as a model for all future interpersonal interactions (Bowlby, 1969; Bowlby, 1982). This review's second research question asks if the quality of the relationship between father and son impacts sexual offending behavior (See Table 2.2). Nineteen articles employing an attachment theory framework were compiled to address this question.

Paternal Attachments of Sexual Offenders. The bulk of this literature found that sexual offenders often have insecure attachments to their fathers and that poor 
paternal attachments have some predictive validity for the development of sexual aggression (Kingston et al., 2017; Smallbone \& Dadds, 2000). Consistently, sexual offenders reported that they viewed their fathers as harsh, emotionally distant, and unduly strict (Bogaerts, Vervaeke, \& Goethals, 2000; Marsa et al., 2004; McKillop, Smallbone, Wortley, \& Andjic, 2012; Sitney \& Kaufman, 2020; Smallbone \& Wortley, 2000; Steptoe, Lindsay, Forrest, \& Power, 2006; Yoder, Dillard, \& Leibowitz, 2018; Yoder, Leibowitz, \& Peterson, 2016). This affectless and controlling parenting style often fostered poor father-son relationships, with estimates suggesting that between $63-78 \%$ of sexual offenders have an insecure attachment to their fathers (Kingston et al., 2017; McKillop et al., 2012). Furthermore, studies that sought to explore early attachment correlates for abusive sexual behavior found that paternal relationships may be especially important (Smallbone \& Dadds, 2000; Kingston et al., 2017). In fact, these studies demonstrated that experiencing emotional abuse and neglect by one's father were the primary predictors for engagement in coercive sexual behaviors or hypersexuality, providing more explanatory power than maternal attachment variables.

However, there is also some research that brings into question the importance of paternal attachment on sexual offending behavior. While Smallbone and Dadds (2000) found a decided impact of paternal attachment on engagement in coercive sex, their follow-up study produced insignificant effects using the same variables with a second sample (Smallbone \& Dadds, 2001). Explaining this shift in findings, the authors noted that the strength of the effect of paternal attachment remained consistent with the initial study. In contrast, maternal attachment was a much stronger predictor within the replication sample. Nevertheless, both studies (Smallbone \& Dadds, 2000; 2001) found 
that having a loving or caring father negatively correlated with coercive sexual behavior ( $r$ 's $=-.23$ to -.32$)$ while having an abusive or violent father positively correlated with son's sexual aggression ( $r$ 's $=.19$ to .25$)$.

\section{Paternal Attachments of Sexual Offenders vs. Community Controls. One}

avenue that explores the potential unique impact of paternal relationships for sexual offenders is through comparisons of this population and other groups. Four of the five studies that compared sexual offenders to community controls found that sexual offenders tend to consider their fathers to be less warm and more overbearing (Boegarts et al., 2000; Marsa et al., 2004; Sitney \& Kaufman, 2020; Steptoe et al., 2006). Perhaps more interestingly, there is initial evidence that sexual offenders seem to prefer this strained relationship. When asked to imagine their ideal relationships with their fathers, sexual offenders in Steptoe et al.'s (2006) study reported that they were uninterested in their fathers becoming more involved or attentive to their lives. However, this pattern of findings was not universal. The final study found no differences in paternal (or maternal) attachment between a group of juvenile sexual offenders and community control youth (Margari et al., 2015).

\section{Paternal Attachments of Sexual Offenders vs. Incarcerated Controls.}

Additional literature sought to distinguish men who commit sex crimes from other types of offenders. Three studies that examined attachments between sexual and non-sexual offenders concluded that sexual offenders experience particularly harsh relationships with their fathers compared to other incarcerated youth (Sitney \& Kaufman, 2020; Yoder, Dillard, \& Libowitz, 2018; Yoder Libowitz, \& Peterson, 2016). While the trend from this literature suggests that sexual offenders have more disturbed paternal relationships than 
do men incarcerated for non-sexual offenses, some alternative patterns of paternal attachments have also been reported. For instance, Sitney and Kaufman (2020) found no differences when paternal relationships of sexual offenders and youth incarcerated for violent crimes were compared. Second, Felizzi (2015) found that paternal attachments failed to distinguish sexually offending youth from non-sexually offending youth. Further, attachments to fathers did not predict any specific sexual deviant behaviors. A final study reported that sexual offenders in their sample had significantly more secure attachment relationships to their fathers than did non-sexual offenders (Margari et al., 2015). It is therefore unclear whether attachment quality is an accurate predictor of sexual offending over and above general offending.

Paternal Attachments of Peer Rapists vs. Pedophiles. Finally, seven studies investigated the ability of paternal attachment to predict types of sexual offenders (Bogaerts et al., 2000; Craissati, McClurg, and Browne, 2002; Giotakos et al., 2004; McCormack et al., 2002; Sigre-Leirós et al., 2016; Simons et al., 2008; Smallbone \& McCabe, 2003). Of those seven, five found that rapists reported poorer relationships with their fathers than did men who molested children (Giotakos et al., 2004; McCormack et al., 2002; Sigre-Leirós et al., 2016; Simons et al., 2008; Smallbone \& McCabe, 2003). The remaining two studies again produced results that conflict with the general trends (Craissati et al., 2002; Bogaerts et al., 2000). In contrast to the previous studies, these works report that child molesters rated their fathers as significantly less warm and significantly more controlling than did peer rapists or non-offending controls. Thus, the literature regarding attachment comparisons between types of sexual offenders offers mixed findings. 


\section{Paternal Characteristics}

A third segment of the literature argues that a typology of fathers of sexual offenders may be based on a simple examination of paternal characteristics and demographics (See Table 2.3). Eight of the identified articles primarily focused on the impact of various paternal characteristics on the development of sexual offending. These characteristics include paternal absence, paternal age, and paternal histories of victimization, mental illness, substance abuse, or arrests.

Paternal Absence. Three studies investigated the potential for paternal absence to distinguish sexual offenders from non-offenders. This literature suggests that growing up without a father may have a special impact on sexual aggressiveness. For instance, Carpentier and Proulx (2011) found that spending one or more years of childhood without a father tripled the risk that sexual offenders in one study would be arrested for a second sex crime. Furthermore, through qualitative research, participants reported the absence of a father figure as a crucial event in creating the circumstances that allowed the offenses to occur (Davids et al., 2015; Gerhard-Burnham et al., 2016). Youth reported that the abandonment or death of their fathers caused them to enter a state of emotional dysregulation. When that dysregulation was not properly managed, it contributed significantly to their sexual offense.

Paternal Age. Three studies investigated whether the father's age at the son's birth was associated with the son's future sexual offending behavior as an adult. These studies found that fathers of sexual offenders were more likely to be unusually young or unusually old compared to the rest of the population (Babchishin et al., 2017; Babchishin et al., 2018; Langevin et al., 2007). However, the risk of having a sexually aggressive son 
was only slightly increased for young and old fathers. Across two studies, Babchishin et al. $(2017 ; 2018)$ reported young paternal age was a significant predictor of the son's sexual offending behavior. Furthermore, subgroup analyses determined that young paternal age predicted both child molestation and peer rape. However, young paternal age was also equally predictive of violent, non-sexual offending. Finally, Langevin, Langevin, and Curnoe (2007) found that the fathers of sexual offenders tended to be slightly older than average at the time of their first child's birth. However, paternal age did not significantly differentiate sexual offenders from controls in their full model.

Paternal Victimization History. Mixed support was found for paternal victimization history. Of the two studies that examined the proportion of fathers who had experienced child maltreatment themselves, one found that fathers of sexual offenders were more likely to have been victimized than fathers of controls (Duane et al., 2003), while the other did not (Stirpe \& Stermac, 2003). Duane et al. (2003) found that $41 \%$ of fathers of juvenile sexual offenders had experienced some form of maltreatment in their own childhoods. These rates were significantly higher than those of the fathers in the control groups. In contrast, Stirpe and Stermac (2003) found no differences in paternal victimization history within their sample of adult sexual offenders $(6.5 \%)$ violent offenders (4.5\%) and nonviolent offenders (12\%).

Paternal Mental Health, Substance Abuse, \& Criminal History. Across three studies, fathers of sexual offenders were found to be no more likely than fathers of other incarcerated youth to have histories of mental illness, substance abuse, or arrests (Duane et al., 2003; Netland \& Miner, 2012; Stirpe \& Stermac, 2003). Notably, even though the groups did not differ, these factors operated at very high rates across both sexually 
offending and non-sexually offending participants. For instance, Netland and Miner (2012) found that $57 \%$ of the total sample had fathers with substance abuse problems, $42 \%$ had fathers with arrest histories, and $17 \%$ had fathers with mental health concerns.

\section{Relevance for Juvenile Sexual Offenders}

The literature covered in this review is too limited to have fully analyzed adult and juvenile offenders separately. However, a comparison of the impact of fathers on adult and juvenile offenders remains appropriate.

Intergenerational Transmission of Offending. Of the eight articles that contained intergenerational transmission hypotheses, four included juvenile participants in their samples (Bijleveld et al., 2016; Hunter et al., 2007; Hunter et al., 2003; Mathe, 2007). Notably few differences emerged between the findings of adult versus juvenile offenders with regards to the clustering of sexual offenders within families. Studies with both populations found that having a sexually violent father significantly impacted offending behaviors, although the odds ratio was stronger for adults $(\mathrm{OR}=6.95$; Van de Weijer et al., 2015) than for youth (OR = 3.7; Långström et al., 2015; Bijleveld et al., 2016). Furthermore, both adult and juvenile offenders reported, through qualitative interviews, that the act of witnessing their father engage in gendered sexual violence informed their own decision to commit a sexual crime (Davids et al., 2015; Mathe, 2015). The similarities between adult and juvenile offenders in this area may be unsurprising, for the core of social learning theory argues that what one internalizes in early childhood, before self-identity is fully formed, provides the blueprint for how to engage socially throughout the rest of their life (Bandura et al., 1961).

Father and Son Attachment. The literature regarding the attachment 
relationships between sexual offenders and their fathers is dominated by samples of adult offenders. Merely five of the nineteen studies in this area included juvenile participants. Within this literature, sexual offenders consistently report that they are less securely attached to their fathers than do non-offending populations (Boegarts et al., 2000; Marsa et al., 2004; Steptoe et al., 2006). In contrast, there is considerable ambiguity surrounding the ability of paternal attachments to distinguish between juvenile sexual offenders and youth who commit other types of crimes. Two studies (from the same research team) did find that young sexual offenders had significantly poorer attachments to their fathers than did non-sexual offenders, and that poor paternal attachments were predictive of sexual recidivism among previously offending youth (Yoder et al., 2016; Yoder et al., 2018). However, these findings are disputed by an equal weight of evidence that paternal attachments are weak for all incarcerated youth, regardless of their index offense (Felizzi, 2015; Margari et al., 2015). Finally, Sitney and Kaufman (2020) found that juvenile sexual offenders had significantly more strained parental relationships than did nonviolent offenders, but did not differ from violent juvenile offenders on this dimension. A lack of differences in attachment between incarcerated groups is not novel. This is perhaps best discussed in Seto and Lalumière's (2010) seminal meta-analysis on explanations for juvenile sexual offending, which finds that attachment to parents generally did not distinguish male juvenile sexual offenders from non-sexual offenders. Overall, these conflicting studies raise doubts that the quality of paternal attachment has been sufficiently studied in regard to its impact on juvenile sexual offenders.

Paternal Characteristics. The literature surrounding paternal characteristics is predominated by studies utilizing juvenile participants. Of the eight articles that make up 
this section, four exclusively examined juveniles. An additional two studies combined both juvenile and adult offenders. Therefore, the conclusions presented within the integrative review almost uniformly reflect the characteristics of fathers whose sons offended at a young age. The two studies that exclusively examined adult offenders did not find any strongly divergent results that would suggest that these two populations should be considered separately with regard to paternal characteristics (Langevin et al., 2007; Stirpe \& Stermac, 2003).

\section{Discussion}

\section{Synthesis}

This systematic literature review has sought to examine the impact of fathers on the development of their sons' sexual offending behavior. Considering these findings in a more holistic manner allows for a broader understanding of significant pathways. The evidence in this review provides the strongest support for the argument that sexually aggressive fathers have a significant risk of contributing to their child's sexually aggressive behaviors. This is not because fathers are offending directly upon their children, but because witnessing the power and control that is achieved by men through sexual dominance over women creates a lasting impression upon these youth and a roadmap for future emotional and sexual interactions. Strict adherence to the norms of masculinity prescribe that men value social dominance and therefore assert their superiority over women (O’Neil, 2015). Here, one may interpret the experiences of boys interacting with their sexually-violent fathers as an indoctrination as to what it means to be masculine, to hold power, and to gain the respect of other men. 
Furthermore, the findings from the attachment literature suggest that fathers of sexual offenders tend to be emotionally abusive and overly punitive. This parenting style of affectionless control strains the father-son relationship, leaving sexual offenders with insecure attachment bonds. This may be especially true for men who go on to commit peer rape, as opposed to child molesters. The experiences of rejection by their fathers resulted in developing dysfunctional modes of engaging in sexual contact to achieve intimacy. Sex, for these men, is experienced without regard for the emotional wellbeing of their partners (Smallbone \& Dadds, 2000). However, while it appears that sexual offenders often have more insecure attachments to their fathers than do other comparable groups, much of this evidence was mixed. For every pattern of results found in this section, a counterexample was provided by at least one study. Additional evidence, particularly with young sexual offenders, is needed to clarify these trends.

In contrast to the findings from the previous two research questions, the findings from the paternal characteristics literature suggest that fathers of sexual offenders are not demographically different from fathers of other men incarcerated for non-sexual crimes. Examinations of paternal mental health, criminal, and substance use histories fail to discriminate between these groups, suggesting that sexual and non-sexual offenders have fathers with similar socioemotional characteristics. Additional evidence on paternal victimization history, paternal absence, and paternal age at son's birth is so mixed that it further complicates the ability of policymakers and practitioners create an accurate typology of sexual offenders' fathers.

The significance of social learning and attachment theories for explaining sexual offending garner additional support from the extant literature regarding the transmission 
of sexuality norms from father to son. Fathers' norms surrounding masculinity and sexism have been shown to have significant impacts on their sons' own sexist attitudes (Klann, Wong, \& Rydell, 2018). Further, fathers' verbal and non-verbal communications surrounding sex have been shown to predict their son's age of sexual debut, contraceptive use, and their number of sexual partners (Guilamo-Ramos et al., 2012). These findings are also consistent with the juvenile delinquency literature which indicates that witnessing a father commit a violent or illegal act significantly increases the risk that their son will also engage in criminal behavior (Besemer \& Farrington, 2012). Taken together, these three separate but overlapping literatures provide strong support for the importance of including fathers in any future research examining how and why young men develop dysfunctional beliefs and behaviors regarding their sexuality.

Two sexual violence prevention strategies may be suggested by the findings of this review. First, the previously presented results advocate for the inclusion of fathers in family-focused prevention efforts with youth at risk for sexually offending (Zanoini et al., 2013). The results of this review suggest that programs designed to encourage fathers to model appropriate relationships with women and to build strong relationships with their sons early on in their lives may significantly deter sexual offending. Second, studies included in this review found that youth whose fathers were present in their lives were less likely to commit a second sexual crime than were young sexual offenders with absent fathers (Carpentier \& Prolux, 2011). Therefore, special efforts to engage fathers in active parenting and relationship-building activities with their sons are to be encouraged. On the other hand, this review does not support the use of paternal characteristics to guide intervention efforts for sexual offending. Although fathers of sexual offenders were often 
engaged in drug and alcohol use, criminal pursuits, and had mental health concerns, these factors did not differentiate sexual offenders from other young men. This review would discourage interventionists from attempting to use the existing literature to create a typology of juvenile sex offenders' fathers as a mechanism for evaluating risk.

\section{Strengths}

As a whole, the literature reviewed here reflects a number of methodological and conceptual strengths. First and foremost, almost all of the studies constructed their hypotheses based on rigorous theoretical grounds. This is due, in part, to the extensive research efforts that have been undertaken on juvenile delinquency and child development. Measures of social learning, attachment, and masculinity have been tested and validated countless times using samples of incarcerated and community adolescents. As a result, this review was uniformly able to draw clear connections between theory and application, as findings were extended from other literatures to enhance the understanding of sexual offenders.

Second, the variety of methodologies used in the articles reviewed allows for a well-rounded assessment of fathers. While social psychology's general reliance on quantitative methodologies is reflected in this literature. Seven of the thirty-four included articles employed a qualitative or mixed methodology. Utilizing both quantitative and qualitative methodologies promotes triangulation, or the process of using multiple forms of measurement to "view" and confirm the same concept from different angles (Braverman, 2013). The qualitative interviews, coded autobiographies, and phenomenological case studies employed by the authors included in the review adds considerable value to the overall findings. These studies promote the voices of those who 
truly know the context and nuances of father impacts on sexual aggression. Some unusual quantitative methodologies must also be highlighted for their unique contributions to this review. For instance, two studies were able to access records for hundreds of thousands of sexual offenders and controls in order to determine the differential impacts of genetic and environmental risk factors (Babchishin et al., 2017; Långström et al., 2015). Rarely is social science able to use population statistics, and the efforts required to do so are certainly notable.

\section{Limitations}

The underrepresentation of fathers in parenting research is one of several limitations of this review. The fathers of sexual offenders were the sole focus in only one of the included studies (Mathe, 2007). As such, the results highlighted here reflect only a portion of the findings reported in each article. By extracting only the information relevant to fathers, these findings have been stripped of their larger contexts. Moreover, only one study directly questioned the fathers themselves to gather information on their interactions with their sons (Duane et al., 2003). Consequently, fathers' perceptions of how their own behaviors influenced their son's sexual deviancy are almost entirely missing from this analysis.

The second area of limitations concerns the sons, rather than the fathers. With the exception of two studies by the same authors (Smallbone \& Dadds, 2000; Smallbone \& Dadds, 2001), all of the articles recruited samples of sexual offenders from correctional institutions. This presents two limitations. First, incarcerated sexual offenders, by default, have been separated for long periods of time from their parents or caregivers. This may unduly influence their recollections and their perceptions of their relationships with their 
parents. Alternatively, some juvenile sexual offenders may not have been incarcerated at all due to a strong relationship with their primary caregivers. The more affluent fathers with strong emotional ties to their sons may hire better defense lawyers, while sympathetic judges may have diverted young offenders to outpatient services if they felt that their families were supportive and engaged in treatment. These possibilities prevent extending the findings of this review to apply generally.

\section{Future Research Directions}

This review has not exhausted the potential research questions which may be asked surrounding the impacts of fathers on their sons' for sexual offending behaviors. Indeed, since most of the findings of this review are drawn from partially mixed evidence, additional studies that explicitly examine the impacts of social learning theory, attachment theory, or paternal characteristics for sexual offenders are warranted. Further, this review has uncovered specific gaps in the literature which need to be addressed. First, only one study directly interviewed fathers as part of their participant pool. In consequence, findings from these studies represent only the offending sons' perceptions of their fathers. Both qualitative and quantitative research that directly assesses fathers would strengthen our understanding of this phenomenon.

Second, both the literature on paternal attachments and the literature on genetic heritability of offenses produced decidedly mixed results. This may have been due to inconsistent definitions of what it means to be a "father." Research that separates genetic from social fathers is extremely limited and is in dire need of additional examination. Further, cultural considerations of fatherhood may provide greater insights into the mechanisms which underlie the impact of father-son attachments and modeling on sexual 
behaviors.

Finally, as this review suggests that both paternal modeling and paternal relationships may have some unique impacts on sexually aggressive behaviors, models that integrate both social learning and attachment hypotheses are needed. This review has presented the research findings on the roles of social learning, attachment, and paternal characteristics on juvenile sexual offending independently. In reality, these paternal dynamics do not exist in their own silos independent of one another. Integrated models may be able to provide better explanations of how juveniles' experiences of witnessing their fathers committing gendered violence affects the quality of the father-son relationship. This may also shed light on how the quality of the paternal relationship may determine the ways in which sons choose to emulate the actions of their fathers. Without such models, our understanding of paternal impacts will remain incomplete.

\section{Conclusion}

This review has sought to highlight the impact that fathers may have on their sons' sexually coercive behaviors. Through an examination of thirty-four articles, it has become apparent that the systematic exclusion of fathers in the sexual perpetration literature must be rectified. Fathers influence their sons' decisions to commit sexual offenses through modeling sexually aggressive behaviors themselves. Additionally, the father-son relationship is either a risk or a protective factor for offending. Therefore, the inclusion of fathers in primary, secondary, and tertiary prevention efforts for sexually offending is particularly needed. 
Tables

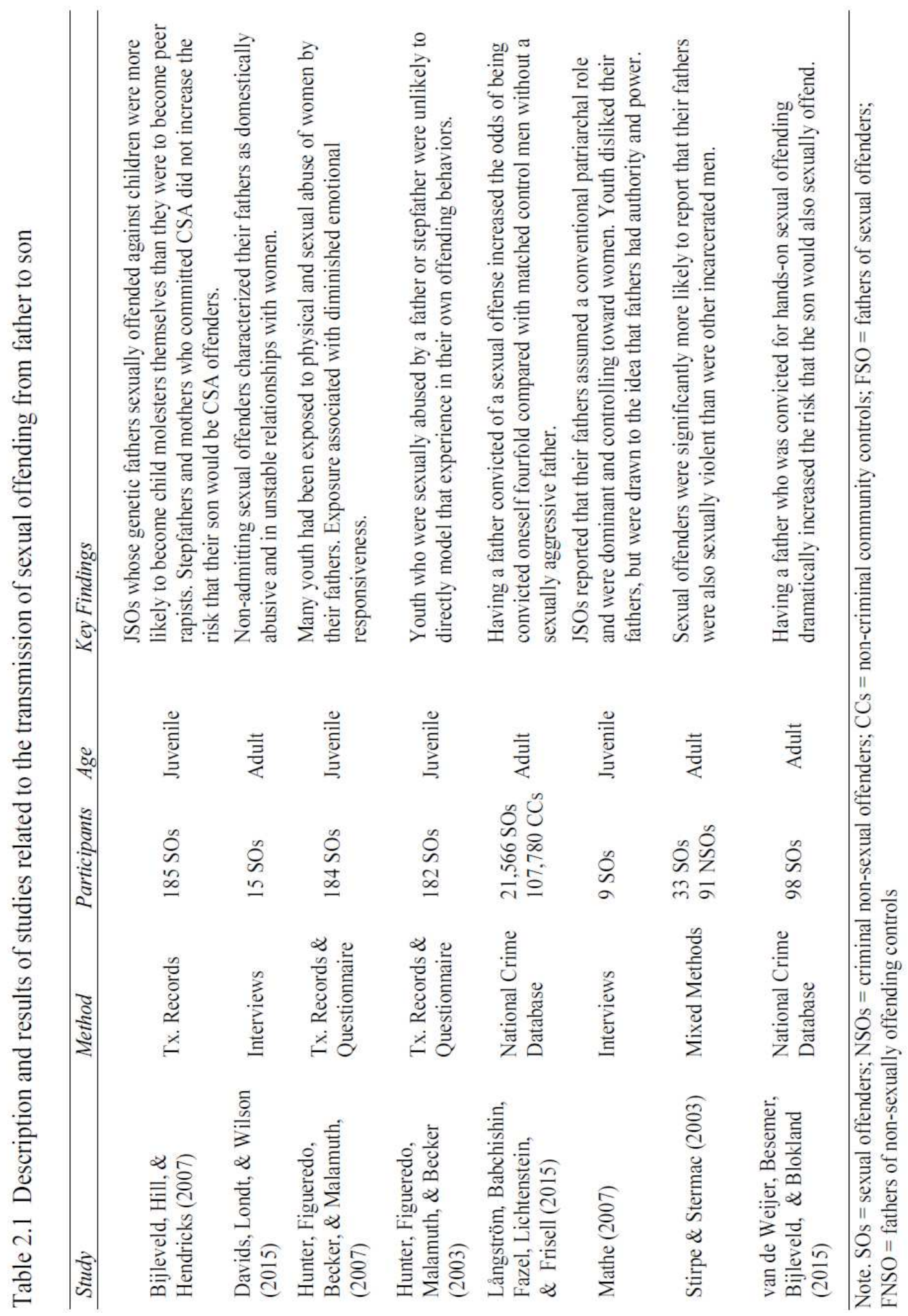




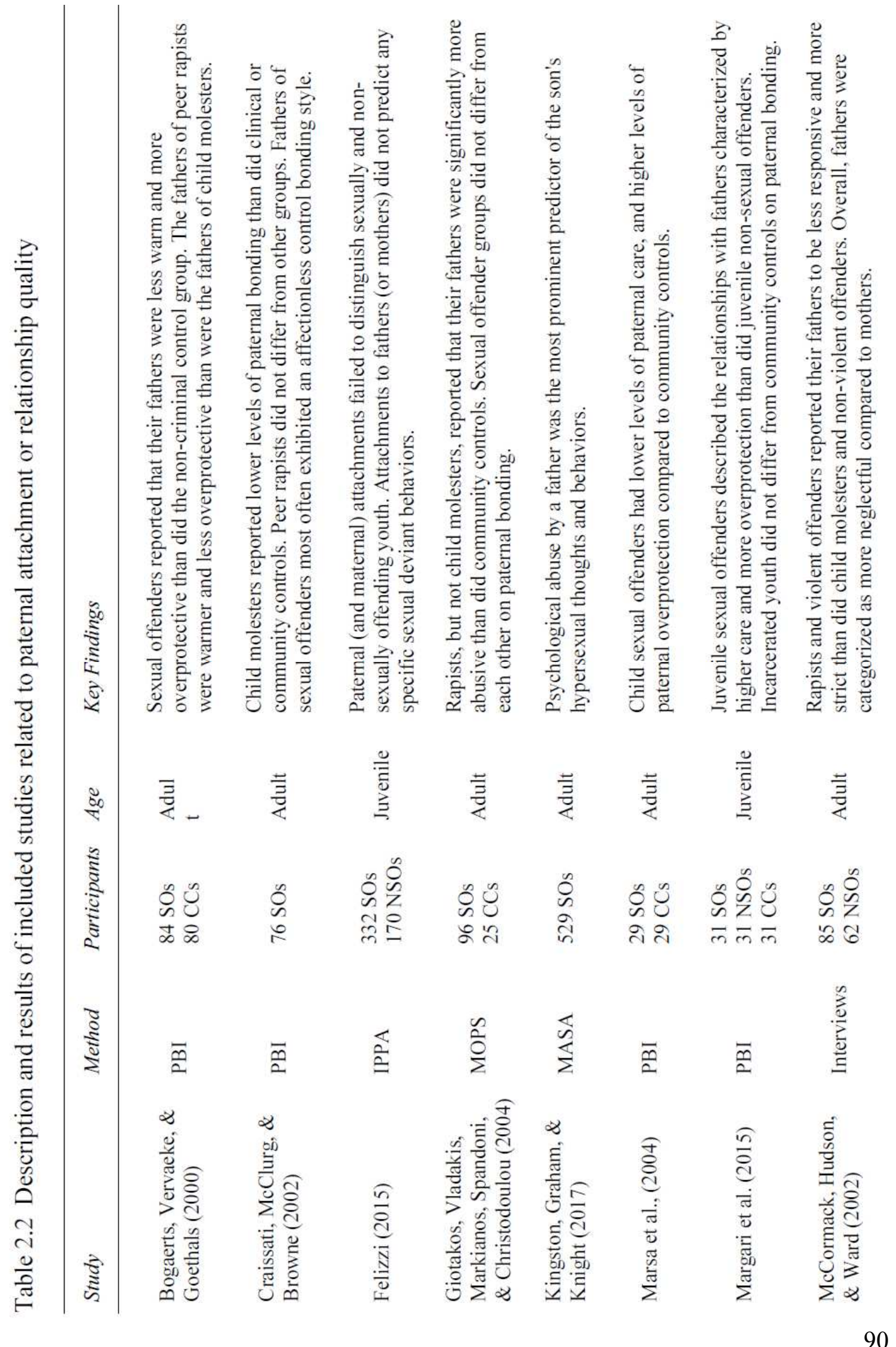




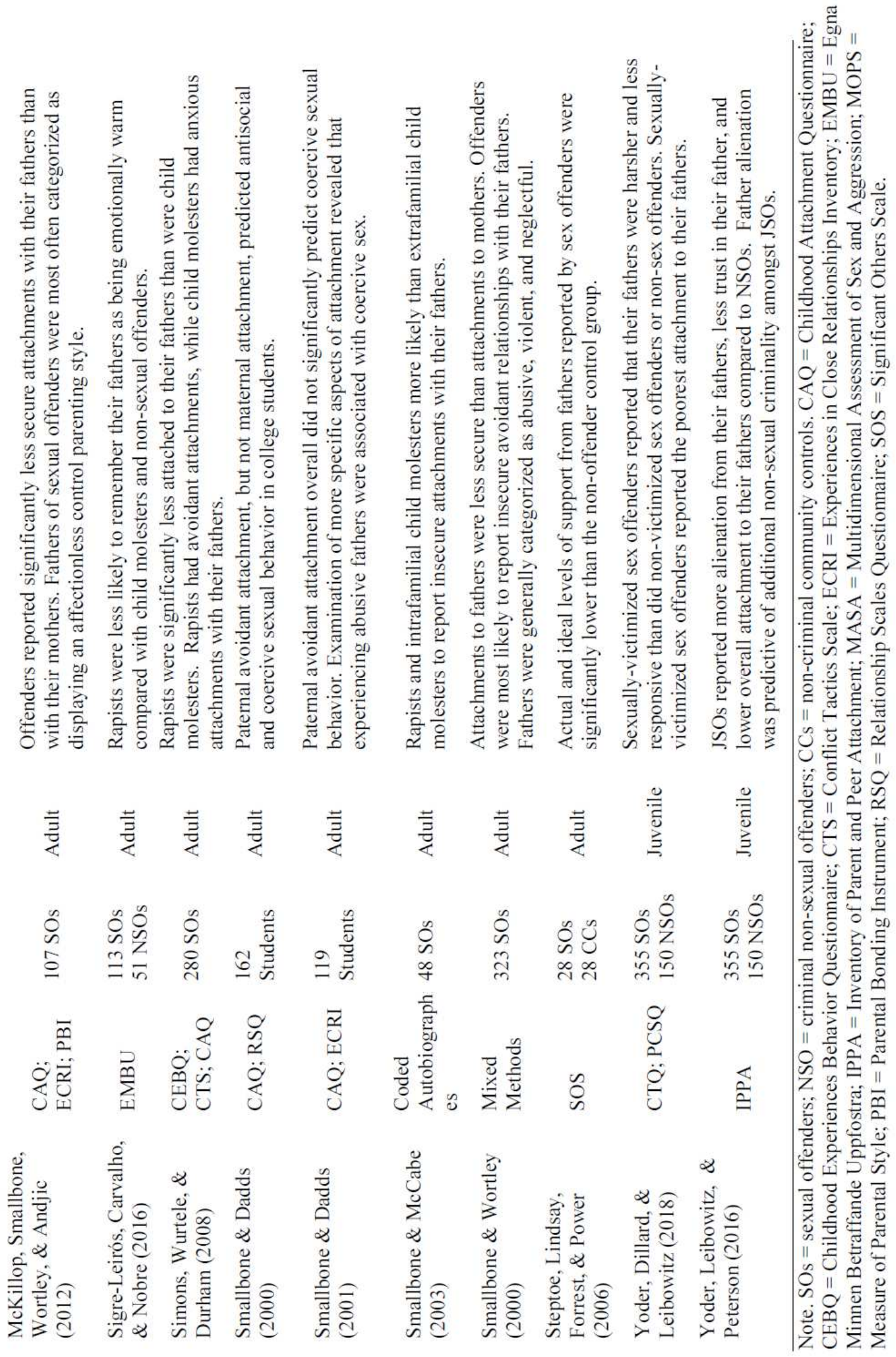




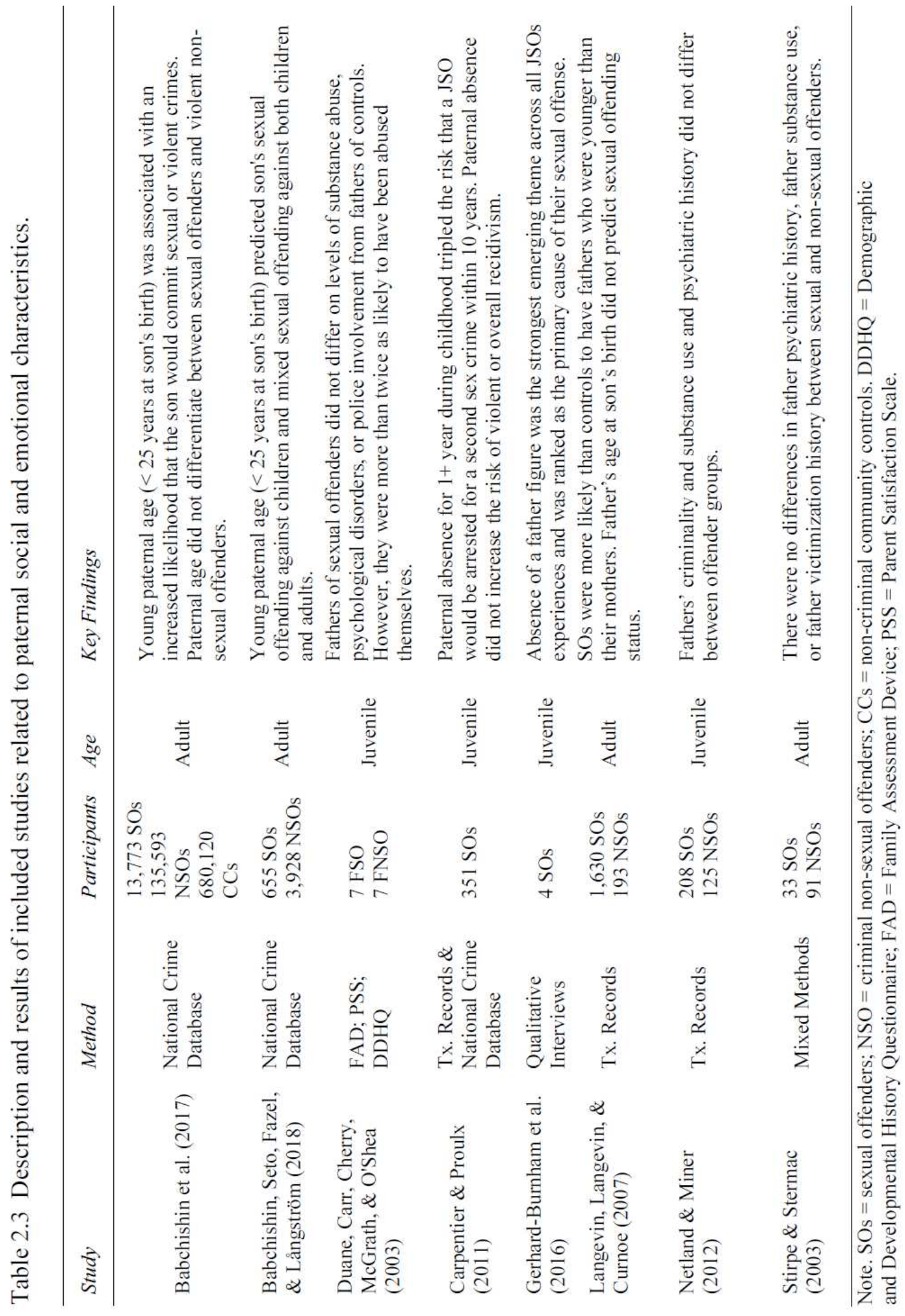




\section{Figures}

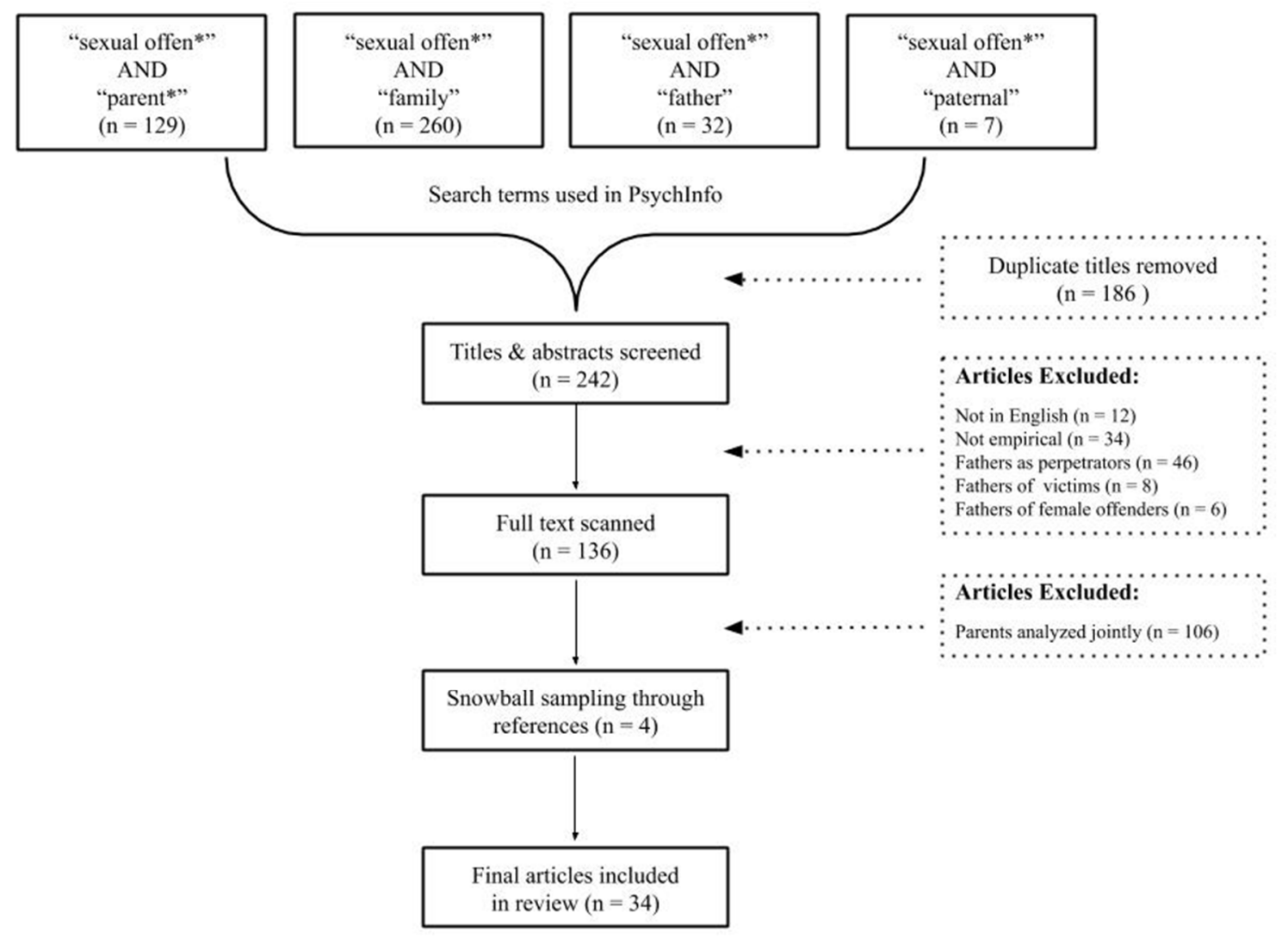

Figure 2.1 Model of electronic search strategy. 


\section{References}

Babchishin, K. M., Seto, M. C., Sariaslan, A., Lichtenstein, P., Fazel, S., \& Långström, N. (2017). Parental and perinatal risk factors for sexual offending in men: a nationwide case-control study. Psychological Medicine, 47(2), 305-315. doi: $10.1017 / \mathrm{S} 003329171600249 \mathrm{X}$

Babchishin, K. M., Seto, M. C., Fazel, S., \& Långström, N. (2018). Are there early risk markers for pedophilia? A nationwide case-control study of child sexual exploitation material offenders. The Journal of Sex Research, 56, 203-212. doi: 10.1080/00224499.2018.1492694

Bandura, A. (1978). Social learning theory of aggression. Journal of Communication, 28, 12-29.

Bandura, A., Ross, D. \& Ross, S.A. (1961). Transmission of aggression through imitation of aggressive models. Journal of Abnormal and Social Psychology, 63, 575-82.

Basile, K. C., Rostad, W. L., Leemis, R. W., Espelage, D. L., \& Davis, J. P. (2018). Protective factors for sexual violence: Understanding how trajectories relate to perpetration in high school. Prevention Science, 19(8), 1123-1132. doi: $10.1007 /$ s11121-018-0940-3

Besemer, S., \& Farrington, D. P. (2012). Intergenerational transmission of criminal behaviour: Conviction trajectories of fathers and their children. European Journal of Criminology, 9(2), 120-141. doi: 10.1177/1477370811422801

Bijleveld, C., Hill, J., \& Hendriks, J. (2016). Sexual abuse within the family: The intergenerational transmission of victimhood and offending. In H. Kury, S. Redo, \& E. Shea (Eds.), Women and children as victims and offenders: Background, 
prevention, reintegration (pp. 905-921), Switzerland: Springer International.

Boller, K., Bradley, R., Cabrera, N., Raikes, H., Pan, B., Shears, J., \& Roggman, L. (2006). The Early Head Start father studies: Design, data collection, and summary of father presence in the lives of infants and toddlers. Parenting, 6, 117-143. doi: $10.1080 / 15295192.2006 .9681302$

Bogaerts, S., Vervaeke, G., \& Goethals, J. (2000). Research on parental sensitivity, trust, intimacy and adult romantic attachment as predictors for sexual delinquency. European Journal on Criminal Policy and Research, 8(4), 503-515. doi: 10.1023/A:1008756518205

Bowlby, J. (1944). Forty-four juvenile thieves: Their characters and home lives. International Journal of Psycho-Analysis, 25, 19-52.

Bowlby, J. (1969). Attachment and loss, Vol. I: Attachment. New York: Basic Books. Braverman, M. T. (2013). Negotiating measurement: Methodological and interpersonal considerations in the choice and interpretation of instruments. American Journal of Evaluation, 34(1), 99-114. doi: 10.1177/1098214012460565

Burton, D. L., Miller, D. L., \& Shill, C. T. (2002). A social learning theory comparison of the sexual victimization of adolescent sexual offenders and nonsexual offending male delinquents. Child Abuse \& Neglect, 26, 893-907. doi: 10.1016/S01452134(02)00360-5

Carpentier, J., \& Proulx, J. (2011). Correlates of recidivism among adolescents who have sexually offended. Sexual Abuse, 23, 434-455. doi: 10.1177/1079063211409950

Craissati, J., McClurg, G., \& Browne, K. (2002). The parental bonding experiences of sex offenders: A comparison between child molesters and rapists. Child Abuse \& 
Neglect, 26(9), 909-921. doi: 10.1016/S0145-2134(02)00361-7

Center for Sex Offender Management (CSOM). (2008). Fact sheet: What you need to know about sex offenders. Retrieved from https://www.csom.org/pubs/needtoknow_fs.pdf

Davids, O., Londt, M., \& Wilson, L. (2015). Imprisoned sex offenders' chronic denial and their childhood family environment. The Open Family Studies Journal, 7(1), 42-47. doi: $10.2174 / 1874922401507010042$

Demuth, S., \& Brown, S. L. (2004). Family structure, family processes, and adolescent delinquency: The significance of parental absence versus parental gender. Journal of Research in Crime and Delinquency, 41(1), 58-81. doi:

$10.1177 / 0022427803256236$

Department of Justice (DOJ), United States. (2014). Sex offender management and planning initiative. Retrieved from https://www.smart.gov/SOMAPI

Dishion, T. J., Owen, L. D., \& Bullock, B. M. (2004). Like father, like son: Toward a developmental model for the transmission of male deviance across generations. European Journal of Developmental Psychology, 1(2), 105-126. doi: $10.1080 / 17405620444000094$

Duane, Y., Carr, A., Cherry, J., McGrath, K., \& O'Shea, D. (2003). Profiles of the parents of adolescent CSA perpetrators attending a voluntary outpatient treatment programme in Ireland. Child Abuse Review: Journal of the British Association for the Study and Prevention of Child Abuse and Neglect, 12(1), 5-24. doi: 10.1002/car.776

Felizzi, M. V. (2015). Family or caregiver instability, parental attachment, and the 
relationship to juvenile sex offending. Journal of Child Sexual Abuse, 24, 641658. doi: $10.1080 / 10538712.2015 .1057668$

Furstenberg, F. F., \& Harris, K. M. (1993). When and why fathers matter: Impacts of father involvement on the children of adolescent mothers. In R. Lerman \& T. Ooms (Eds.), Young unwed fathers: Changing roles and emerging policies (pp. 117-138). Philadelphia: Temple University Press.

Gerhard-Burnham, B., Underwood, L. A., Speck, K., Williams, C., Merino, C., \& Crump, Y. (2016). The lived experience of the adolescent sex offender: a phenomenological case study. Journal of Child Sexual Abuse, 25, 93-109. doi: $10.1080 / 10538712.2016 .1111965$

Giotakos, O., Vaidakis, N., Markianos, M., Spandoni, P., \& Christodoulou, G. N. (2004). Temperament and character dimensions of sex offenders in relation to their parental rearing. Sexual and Relationship Therapy, 19(2), 141-150. doi:

$10.1080 / 14681990410001691352$

Grady, M. D., Yoder, J., \& Brown, A. (2018). Childhood maltreatment experiences, attachment, sexual offending: testing a theory. Journal of Interpersonal Violence. Advance online publication. doi: 10.1177/0886260518814262

Guilamo-Ramos, V., Bouris, A., Lee, J., McCarthy, K., Michael, S. L., Pitt-Barnes, S., \& Dittus, P. (2012). Paternal influences on adolescent sexual risk behaviors: A structured literature review. Pediatrics, 130(5), e1313-e1325. doi:

10.1542/peds.2011-2066

Hayslett-McCall, K. L., \& Bernard, T. J. (2002). Attachment, masculinity, and selfcontrol: A theory of male crime rates. Theoretical Criminology, 6(1), 5-33. doi: 
$10.1177 / 136248060200600101$

Hoeve, M., Dubas, J. S., Eichelsheim, V. I., Van Der Laan, P. H., Smeenk, W., \& Gerris, J. R. (2009). The relationship between parenting and delinquency: A metaanalysis. Journal of Abnormal Child Psychology, 37(6), 749-775. doi:

$10.1007 / \mathrm{s} 10802-009-9310-8$

Hoeve, M., Stams, G. J. J., van der Put, C. E., Dubas, J. S., van der Laan, P. H., \& Gerris, J. R. (2012). A meta-analysis of attachment to parents and delinquency. Journal of Abnormal Child Psychology, 40(5), 771-785. doi: 10.1007/s10802-011-9608-1

Hunter, J. A., Figueredo, A. J., Becker, J. V., \& Malamuth, N. (2007). Non-sexual delinquency in juvenile sexual offenders: The mediating and moderating influences of emotional empathy. Journal of Family Violence, 22(1), 43-54. doi: $10.1007 /$ s10896-006-9056-9

Hunter, J. A., Figueredo, A. J., Malamuth, N. M., \& Becker, J. V. (2003). Juvenile sex offenders: Toward the development of a typology. Sexual Abuse: A Journal of Research and Treatment, 15(1), 27-48. doi: 10.1023/A:1020663723593

Jespersen, A. F., Lalumière, M. L., \& Seto, M. C. (2009). Sexual abuse history among adult sex offenders and non-sex offenders: A meta-analysis. Child Abuse \& Neglect, 33, 179-192. doi: 10.1016/j.chiabu.2008.07.004

Kingston, D. A., Graham, F. J., \& Knight, R. A. (2017). Relations between self-reported adverse events in childhood and hypersexuality in adult male sexual offenders. Archives of Sexual Behavior, 46(3), 707-720. doi: 10.1007/s10508-016-0873-5

Klann, E. M., Wong, Y. J., \& Rydell, R. J. (2018). Firm father figures: A moderated mediation model of perceived authoritarianism and the intergenerational 
transmission of gender messages from fathers to sons. Journal of Counseling Psychology, 65, 500-511. doi: 10.1037/cou0000296

Langevin, R., Langevin, M., \& Curnoe, S. (2007). Family size, birth order, and parental age among male paraphilics and sex offenders. Archives of Sexual Behavior, 36(4), 599-609. doi: 10.1007/s10508-006-9110-y

Långström, N., Babchishin, K. M., Fazel, S., Lichtenstein, P., \& Frisell, T. (2015). Sexual offending runs in families: A 37-year nationwide study. International Journal of Epidemiology, 44(2), 713-720. doi: 10.1093/ije/dyv029

Livingston, G. (2014). Growing number of dads home with the kids: Biggest increase among those caring for family." Washington, D.C.: Pew Research Center's Social and Demographic Trends Project.

Loeber, R., \& Stouthamer-Loeber, M. (1986). Family factors as correlates and predictors of juvenile conduct problems and delinquency. Crime and Justice, 7, 29-149. doi: $10.1086 / 449112$

Lundahl, B. W., Tollefson, D., Risser, H., \& Lovejoy, M. C. (2008). A meta-analysis of father involvement in parent training. Research on Social Work Practice, 18, 97106. doi: $10.1177 / 1049731507309828$

Lussier, P., Blokland, A., Mathesius, J., Pardini, D., \& Loeber, R. (2015). The childhood risk factors of adolescent $\square$ onset and adult $\square$ onset of sex offending: Evidence from a prospective longitudinal study. In A. Blokland \& P. Lussier (Eds.), Sex offenders: A criminal career approach (1st ed., pp. 93-128). Oxford: Wiley Blackwell.

Margari, F., Lecce, P. A., Craig, F., Lafortezza, E., Lisi, A., Pinto, F... \& Margari, L. 
(2015). Juvenile sex offenders: Personality profile, coping styles and parental care. Psychiatry Research, 229(1-2), 82-88. doi: 10.1016/j.psychres.2015.07.066

Marsa, F., O’Reilly, G., Carr, A., Murphy, P., O’sullivan, M., Cotter, A., \& Hevey, D. (2004). Attachment styles and psychological profiles of child sex offenders in Ireland. Journal of Interpersonal Violence, 19, 228-251. doi:

$10.1177 / 0886260503260328$

Marshall, W. L. (1989). Intimacy, loneliness and sexual offenders. Behaviour Research and Therapy, 27, 491-503. doi: 10.1016/0005-7967(89)90083-1

Marshall, W. L. (1993). The role of attachments, intimacy and loneliness in the etiology and maintenance of sexual offending. Sexual and Marital Therapy, 8, 109-121. doi: $10.1080 / 14681990903550191$

Marshall, W. L., \& Marshall, L. E. (2010). Attachment and intimacy in sexual offenders: An update. Sexual and Relationship Therapy, 25, 86-90. doi: $10.1080 / 14681991003589568$

Marsiglio, W., \& Cohan, M. (2000). Contextualizing father involvement and paternal influence: Sociological and qualitative themes. In E. Peters, G. Peterson, S. Steinmetz, \& R. Day (Eds.), Fatherhood: Research, interventions, and policies (pp. 75-96). New York: The Haworth Press.

Mathe, S. (2007). Juvenile sexual offenders: We are the sons of our fathers. Agenda, 21(74), 133-140.

McCormack, J., M $\square$ Hudson, S., \& Ward, T. (2002). Sexual offenders' perceptions of their early interpersonal relationships: An attachment perspective. Journal of Sex Research, 39, 85-93. doi: 10.1080/00224490209552127 
McKillop, N., Smallbone, S., Wortley, R., \& Andjic, I. (2012). Offenders' attachment and sexual abuse onset: A test of theoretical propositions. Sexual Abuse, 24(6), 591-610. doi: 10.1177/1079063212445571

Milkie, M. A., \& Denny, K. E. (2014). Changes in the cultural model of father involvement: Descriptions of benefits to fathers, children, and mothers in Parents' Magazine, 1926-2006. Journal of Family Issues, 35(2), 223-253. doi: $10.1177 / 0192513 X 12462566$

Netland, J. D., \& Miner, M. H. (2012). Psychopathy traits and parental dysfunction in sexual offending and general delinquent adolescent males. Journal of Sexual Aggression, 18(1), 4-22. doi: 10.1080/13552600.2011.632696

O’Neil, J. M. (1982). Gender-role conflict and strain in men's lives. In K. Solomon \& N Levy (Eds.), Men in transition (pp. 5-44). Boston, MA: Springer.

O’Neil, J. M. (2015). Men's gender-role conflict. Washington, DC: American Psychological Association.

Pallini, S., Baiocco, R., Schneider, B. H., Madigan, S., \& Atkinson, L. (2014). Early child-parent attachment and peer relations: A meta-analysis of recent research. Journal of Family Psychology, 28, 118-123. doi: 10.1037/a0035736

Pleck, J. H. (1981). The myth of masculinity. Cambridge, MA: MIT Press.

Pleck, J. H. (1995). The gender role strain paradigm: An update. In R. F. Levant \& W. S. Pollack (Eds.), The new psychology of men (pp. 11-32). New York: Basic Books.

Prentky, R. A., \& Knight, R. A. (1993). Age of onset of sexual assault: Criminal and life history correlates. In G. C. N. Hall, R. Hirschman, J. R. Graham, \& M. S. Zaragoza (Eds.), Sexual aggression: Issues in etiology assessment, and treatment 
(pp. 43-62). Washington, DC: Taylor \& Francis.

Reidy, D. E., Shirk, S. D., Sloan, C. A., \& Zeichner, A. (2009). Men who aggress against women: Effects of feminine gender role violation on physical aggression in hypermasculine men. Psychology of Men \& Masculinity, 10, 1-12. doi: $10.1037 / \mathrm{a} 0014794$

Seidman, B., Marshall, W. L., Hudson, S. M., \& Robertson, P. J. (1994). An examination of intimacy and loneliness in sex offenders. Journal of Interpersonal Violence, 9, 518-534. doi: 10.1177/088626094009004006

Seto, M. C., \& Lalumière, M. L. (2010). What is so special about male adolescent sexual offending? A review and test of explanations through meta-analysis.

Psychological Bulletin, 136, 526-575. doi: 10.1037/a0019700

Sigre-Leirós, V., Carvalho, J., \& Nobre, P. (2016). Preliminary findings on men's sexual self-schema and sexual offending: differences between subtypes of offenders. The Journal of Sex Research, 53(2), 204-213. doi: 10.1080/00224499.2015.1012289

Simons, D. (2015). Sex offender typologies. In C. Lobanov-Rotovsky \& R. Przybylski (Eds.), Sex offender management and planning initiative (pp. 55-75). Washington DC: Department of Justice.

Sitney, M. H., \& Kaufman, K. L. (2020). The impact of disrupted caregiving for juvenile sexual offenders. Journal of Sexual Aggression, 26, 274-287. doi: $10.1080 / 13552600.2019 .1618933$

Smallbone, S. W., \& Dadds, M. R. (1998). Childhood attachment and adult attachment in incarcerated adult male sex offenders. Journal of Interpersonal Violence, 13(5), 555-573. doi: 10.1177/088626098013005001 
Smallbone, S. W., \& Dadds, M. R. (2000). Attachment and coercive sexual behavior. Sexual Abuse: A Journal of Research and Treatment, 12(1), 3-15. doi: 10.1023/A:1009555619323

Smallbone, S. W., \& Dadds, M. R. (2001). Further evidence for a relationship between attachment insecurity and coercive sexual behavior in nonoffenders. Journal of Interpersonal Violence, 16(1), 22-35. doi: 10.1177/088626001016001002

Smallbone, S. W., \& McCabe, B. A. (2003). Childhood attachment, childhood sexual abuse, and onset of masturbation among adult sexual offenders. Sexual Abuse: $A$ Journal of Research and Treatment, 15(1), 1-9. doi: 10.1023/A:1020616722684

Smallbone, S., \& Wortley, R. (2000). Child sexual abuse in Queensland: Offender characteristics and modus operandi. Brisbane: Queensland Crime Commission and Queensland Police Service.

Steptoe, L., Lindsay, W. R., Forrest, D., \& Power, M. (2006). Quality of life and relationships in sex offenders with intellectual disability. Journal of Intellectual and Developmental Disability, 31(1), 13-19. doi: 10.1080/13668250500488652

Stewart, K. E., Sitney, M. H., Kaufman, K. L., DeStefano, J., \& Bui, T. (2019). Preventing juvenile sexual offending through parental monitoring: a comparison study of youth's experiences of supervision. Journal of Sexual Aggression, 25(1), 16-30. doi: 10.1080/13552600.2018.1528796

Stirpe, T. S., \& Stermac, L. E. (2003). An exploration of childhood victimization and family-of-origin characteristics of sexual offenders against children. International Journal of Offender Therapy and Comparative Criminology, 47(5), 542-555. doi: $10.1177 / 0306624 X 03253316$ 
U.S. Census Bureau. (2018). Household relationship and living arrangements of children under 18 years, by age and sex: 2018. Retrieved from: https://www.census.gov/data/tables/2018/demo/families/cps-2018.html

Van de Weijer, S. G. A., Besemer, S., Blokland, A. A., \& Bijleveld, C. C. J. H. (2015). The concentration of sex offenses within British and Dutch families. In A. A. Blokland \& P. Lussier (Eds.), Sex offenders: A criminal career approach (pp. 321-348). Oxford: Wiley.

Van Wijk, A., Vermeiren, R., Loeber, R., Hart-Kerkhoffs, L. T., Doreleijers, T., \& Bullens, R. (2006). Juvenile sex offenders compared to non-sex offenders: A review of the literature 1995-2005. Trauma, Violence, \& Abuse, 7, 227-243. doi: $10.1177 / 1524838006292519$

Worley, K. B., Church, J. K., \& Clemmons, J. C. (2012). Parents of adolescents who have committed sexual offenses: Characteristics, challenges, and interventions. Clinical Child Psychology and Psychiatry, 17, 433-448. doi: $10.1177 / 1359104511417787$

Yeung, W. J., Duncan, G. J., \& Hill, M. S. (2000). Putting fathers back in the picture: Parental activities and children's adult outcomes. Marriage \& Family Review, 29, 97-113. doi: 10.1300/J002v29n02_07

Yoder, J., Dillard, R., \& Leibowitz, G. S. (2018). Family experiences and sexual victimization histories: a comparative analysis between youth sexual and nonsexual offenders. International Journal of Offender Therapy and Comparative Criminology, 62, 2917-2936. doi: 10.1177/0306624X17738063

Yoder, J. R., Grady, M., \& Dillard, R. (2018). Maternal caregiving practices and child 
abuse experiences as developmental antecedents to insecure attachments:

Differential pathways between adolescents who commit sexual and non-sexual crimes. Sexual Abuse. Advance online publication. doi:

$10.1177 / 1079063218784557$

Yoder, J. R., Leibowitz, G. S., \& Peterson, L. (2016). Parental and peer attachment characteristics: differentiating between youth sexual and non-sexual offenders and associations with sexual offense profiles. Journal of Interpersonal Violence, 33(17), 2643-2663. doi: 10.1177/0886260516628805

Zanoini, L., Warburton, W., Bussey, K., \& McMaugh, A. (2013). Fathers as "core business" in child welfare practice and research: An interdiciplinary review. Child and Youth Services Review, 35, 1055-1070. doi:

10.1016/j.childyouth.2013.04.018 


\title{
Chapter 4: Manuscript Three -
}

\section{Paternal impacts specific to sexual offending: A confluence model}

Note: This manuscript has been submitted to the Journal of Child Sexual Abuse and is under review.

\begin{abstract}
Current research suggests that paternal caregivers influence their sons' sexually aggressive behavior through modeling abusive actions themselves and through harsh and emotionally-distant parenting styles. Furthermore, some evidence suggests that youth who commit sexual offenses are disproportionately likely to have experienced caregiving from a substitute, rather than biological, father. However, to date, these multiple pathways for juvenile sexual offending have been examined separately from one another. This study tested an integrated model to provide a clearer explanation of how juveniles' experiences with their paternal caregivers inform their decisions to begin engaging in sexually abusive acts. Specifically, this study aimed to understand the unique and combined impacts of (a) intergenerational transmission of violence by a father, (b) weak attachment to paternal caregivers, and (c) being cared for by a nonbiological father on sexual offending behavior in youth. Results indicated that an abusive paternal parenting style may be more predictive of the son's sexual offending behaviors than is witnessing a father act violently or nonbiological paternal caregiving. Furthermore, overcontrolling fathers were found to be more likely to parent sons who offended inside their families than less controlling fathers. Recommendations for research, practice and policy are presented to contribute to the knowledge of male caregivers' roles in the risk and resilience of juvenile sexual offending.




\section{Introduction}

Family factors have emerged as central correlates to the engagement in and desistance from sexually aggressive behavior in young people. Research has shown that youth who are convicted of sex crimes are likely to have experienced multiple instances of abusive or neglectful parenting (Felizzi, 2015; Seto \& Lalumière, 2010). At the same time, prevention programming that has focused on improving family relationships, increasing parental monitoring, and decreasing abusive or neglectful parenting has been associated with reductions in both sexual and general recidivism among young people (Worley, Church, \& Clemmons, 2012; Yoder, 2014).

One explanation for the relationship between caregiving dynamics and juvenile offending is the importance of male caregivers for these youth. Drawing from the broader juvenile delinquency literature, youths' relationships with their father figures are more predictive of engagement in early criminal behavior than are maternal caregiving variables (Apel \& Kaukinen, 2008; Demuth \& Brown, 2004). Some scholars have suggested that fathers are less likely to monitor their children's behavior and are less emotionally close to their children, the combination of which increases the likelihood of adolescent delinquency (Coles, 2015). Recent research with boys who commit sexual offenses suggests that male caregivers may have special importance for this population in particular (Sitney \& Kaufman, 2020a). To date, three separate theoretical mechanisms have been used to explain the impact of male caregivers for young people who engage in coercive sex: the intergenerational transmission of violence hypothesis, attachment theory, and the broken homes theory of juvenile delinquency.

\section{Intergenerational Transmission of Violence}


Examinations of coercive sexual behavior in youth have commonly utilized the intergenerational transmission of violence hypothesis, which states that children learn to model abusive actions that they see demonstrated by their caregivers (Bandura, 1971, 1973, 1986). Within this body of work, multiple studies have found that having a violent father increases a boy's risk for perpetrating sexual abuse (Bijleveld, Hill, \& Hendricks, 2016; Hunter, Figueredo, Becker, \& Malamuth, 2007; Långström, Babchishin, Fazel, Lichtenstein, \& Frisell, 2015; Stirpe \& Stermac, 2003; Van de Weijer, Besemer, Bijleveld, \& Blokland, 2015). This transmission appears to be especially true when fathers commit acts of child molestation, rather than peer rape. Fathers who have been convicted of child molestation are significantly more likely to have a son who is also charged with a sex crime than are fathers who have been arrested for a sexual offense involving an adult victim (Långström et al., 2015).

According to qualitative research with youth who were convicted of sexual offenses, this intergenerational transmission of violence occurs through learned norms (Mathe, 2007). Sexually offending sons report that they used sexual violence to obtain authority in a manner similar to that demonstrated by their fathers. Witnessing such violence by their fathers shaped their masculine identities and directly impacted their own decisions to engage in coercive sexual behaviors (Davids, Londt, \& Wilson, 2015).

\section{Attachment}

Researchers using an attachment theory perspective have found that the father-son relationship is aslo associated with the commission of a sexual offense. At its core, attachment theory argues that the relationship between infant and caregiver becomes the child's model for all future interpersonal relationships (Bowlby, 1969, 1973, 1980). 
Within the literature on sexual offending, studies have demonstrated that men who engage in coercive sex often also report poor attachments to their fathers (Marsa et al., 2004; McKillop, Smallbone, Wortley, \& Andjic, 2012; Sitney \& Kaufman, 2020; Yoder, Dillard, \& Leibowitz, 2018; Yoder, Leibowitz, \& Peterson, 2016). Additionally, paternal attachment has been shown to explain more variance in the development of sexual aggression than maternal attachment variables (Kingston et al., 2017; Smallbone \& Dadds, 2000). Attachment to fathers even appears to impact sexual offenders' choice of victims, as studies have repeatedly found that men who offend against same aged peers report poorer relationships with their fathers than do men who offend against children (Giotakos et al., 2004; McCormack et al., 2002; Sigre-Leirós et al., 2016; Simons, Wurtele, \& Durham, 2008; Smallbone \& McCabe, 2003). These findings support a commonly asserted pathway to sexual violence whereby insecurely-attached boys learn to distance themselves from peers and other close relationships. As these young men grow, their loneliness begins to manifest itself in sexual aggression as a way to achieve interpersonal intimacy (Marshall, 1989; 1993; Marshall \& Marshall, 2010).

\section{Broken Homes}

Finally, research that stems from the broken homes theory of juvenile delinquency finds that youth who commit sexual offenses are unlikely to have lived in nuclear, heterosexual households (Duane, Carr, Cherry, McGrath, \& O’Shea, 2003; Felizzi, 2015; Wells \& Rankin, 1991). Instead, they are often raised by single parents, stepparents, custodial grandparents, or foster parents. This pathway suggests that the lack of a consistent male caregiver means that youth receive both less monitoring and less affectionate care. The combination of physical and emotional neglect leads young men to 
both seek out intimacy and allows them the freedom to groom and perpetrate against their victims (O'Toole \& Jeglec, 2014).

However, the evidence is mixed regarding the types of substitute caregivers which may increase a youth's risk of delinquency and sexual offending. Apel and Kaukinen (2008), found that the presence of a stepfather, adoptive father, or foster father significantly increased the risk of antisocial behavior in youth. On the other hand, contrasting evidence from Demuth and Brown (2004) indicated that boys raised in mother-stepfather families were less likely to become delinquent than were youth raised by single biological fathers. Additionally, studies that have included custodial grandfathers suggest that youth parented primarily by older relatives do not show the same levels of delinquent behavior that are exhibited by their peers with other types of substitute fathers (Apel \& Kaukinen, 2008; Harper \& McLanahan, 2004). The mechanisms by which kinship care may be either a protective factor or risk factor for juvenile delinquency remains relatively unexplored. Furthermore, no work has yet specifically examined the impact of kinship care on juvenile sexual offending behavior.

\section{The Current Study}

To date, the three theoretical mechanisms for explaining paternal impacts on youth sexual offending behaviors, intergenerational transmission of violence theory, attachment theory and broken homes theory, have only been examined separately. Given the increased attention being devoted to this area, there is a need to integrate these theories in a single model in order to determine their unique and shared impacts (Sitney \& Kaufman, 2020b). Thus, the first goal of the current study is to test an integrated model 
of paternal caregiving risk factors that may predict juvenile engagement in sexually aggressive behaviors. Specifically, this study examines the following question:

(Research Question 1) What unique or shared ability does the intergenerational transmission of violence hypothesis, the attachment hypothesis, and the broken homes hypothesis have to explain paternal impacts on youth sexual offending behavior opposed to other forms of juvenile delinquency?

Second, as evidence accumulates indicting that paternal caregivers may be especially impactful for youth who engage in coercive sex, a second research question seeks to clarify the role of paternal caregivers in various forms of sexual offending.

(Research Question 2) In what ways do paternal caregivers impact their sexually aggressive sons' choice of victims?

\section{Method}

\section{Institutional Review Board}

The data collected for this study were part of a larger data set examining etiological factors primarily concerned with the sexual histories and sexual fantasies of youth who commit sex crimes. The overall study was subject to a full review and was approved by the Institutional Review Board (IRB) at a state university in the Pacific Northwest. As the analyses specific to the current project strictly involved secondary data analysis, this work was determined to be exempt from review by the IRB.

\section{Sample}


In total, 268 incarcerated youth were sampled. However, 38 participants were ultimately excluded from analyses due to missing data on one of the central variables (19 missing crime type, 16 missing MOPS, 3 missing parent identifiers). As a result, 230 youth remained in the final sample. Participants who were excluded due to missing data did not differ from included participants in terms of age $[t(263)=-1.09, n s]$, education level $\left[\chi^{2}(5, \mathrm{~N}=269)=.499, n s\right]$, or length of stay in the facility $[\mathrm{t}(224)=.05, n s]$.

All youth identified as male and ranged in age from 14 to 24 years old $(M=18.4$ years). Though some youth were over the age of 18 at the time of data collection, all youth committed their index offense before their $18^{\text {th }}$ birthday and were charged as juveniles. On average, youth in this sample had completed 10th grade and had been incarcerated in a juvenile detention facility for 1.5 years at the time of data collection. Racial information was not gathered from the youth due to concerns regarding identifiability amongst the small proportion of youth of color. However, because over $95 \%$ of the youth in the detention facility agreed to participate in this study, the official race/ethnicity information collected by the institution is an applicable proxy. The majority of youth in detention identified as White (61\%). An additional $16 \%$ of youth identified as Hispanic, $14 \%$ identified as Black, $7 \%$ as Native, $1 \%$ as Asian, and $1 \%$ as Other.

\section{Procedure}

Consent. Initial consent was granted by the head administrator at the correctional facility. As incarcerated youth are considered wards of the state, the facility acts as their legal guardian. Youth were recruited to participate during their free time inside their living quarters and provided written assent. The voluntary and anonymous nature of 
participation in this study was emphasized and the youth were informed that they could stop participating for any reason without consequence.

Data Collection. Once consent and assent forms had been signed, participants received a packet of paper-and-pencil questionnaires. Corrections staff were present during data collection, per institutional policy, but were asked to refrain from interacting with the youth during their participation. Instead, all questions and materials were handled by research staff.

\section{Measures}

Demographics. The demographics form asked questions about the participants' age, educational history, and criminal offense history. Youth who had been convicted of sexual offenses were asked to report details about their relationship to their victims and the extent of their sexually aggressive behaviors. Finally, youth were also asked to identify their primary male and female caregivers and to indicate the amount of time they lived in the same house as each caregiver.

Offense type. Youth's index offense was used as the dependent variable for these analyses. Three offense types were generated: Youth who were convicted of sexual offenses $(n=87)$, youth who were convicted of violent, but non sexual offenses $(n=$ $87)$, and youth who were convicted of nonsexual - nonviolent offenses $(n=56)$. Youth who had been convicted of a sexual offense, even if they were additionally charged with non-sexual offenses, were still included in the sexual offense group. Similarly, any violent charge took precedence over nonviolent charges.

Additional coding was performed to categorize the choice of victims in the index offenses which were sexual in nature. First, youth who committed sexual offenses were 
dichotomized as offending against either same-aged peers or children much younger than themselves. Youth whose victim was within three years of them were considered to have peer victims $(n=21)$. Youth whose victim was more than three years younger than them, or was under the age of twelve, were considered child victims $(n=53)$. These cutoffs are consistent with the legal definitions of juvenile sexual offenses for the area (ORS 163.411, ORS 163.408, RCW 9A.44.073). Furthermore, youth who committed sexual offenses were classified as having intra- or extra-familial victims. Youth whose victim lived in the same household or was biologically related to them were considered intrafamilial offenders $(n=28)$. Youth whose victim was not biologically related to them and lived outside of their house were considered extra-familial offenders $(n=47)$.

Child Maltreatment Experiences. The Adverse Childhood Experiences Scale (ACEs; Finkelhor, Shattuck, Turner, \& Hamby, 2015) was used to determine the extent to which the youth had witnessed paternal models of violent behavior. This scale is comprised of 14 yes-no items that assess experiences of abuse and neglect. This measure has been shown to be a valid risk assessment tool $\left(\mathrm{R}^{2}=0.46\right.$; Finkelhor et al., 2015) and has been successfully used to predict a number of sexually violent experiences (Levenson \& Grady, 2016; Ports, Ford, \& Merrick, 2016). However, for the purposes of this study, only the three variables that specifically related to witnessing abusive behavior by fathers were included (e.g. "was your mother or stepmother often or very often pushed, grabbed, slapped, or had something thrown at her? [by your father or stepfather].”) Youth could, therefore, receive a score of 0-3 based on their endorsement of the paternal violence items. This subscale was determined to be sufficiently reliable $(\alpha=.93)$ and unidimensional through the use of a scree plot which returned a 1-factor solution. 
Parenting Styles. Youths' perceptions of their caregivers' parenting styles were assessed using the Measure of Parental Style (MOPS; Parker et al., 1997). The MOPS is a 30-item self-report measure composed of two, identical, 15 -item scales that ask the participant to rate their relationships with their maternal caregiver and their paternal caregiver separately using a 4 -point Likert-type scale $(0=$ not true at all, $3=$ extremely true). This measure has previously been validated to assess the parental styles in adult sexual offender populations (Giotakos, Vaidakis, Markianos, Spandoni, \& Christodoulou, 2004).

Upon completion of the measure, the total MOPS score for each parent can be used as a metric for rating the relationship quality between parent and child. Higher scores indicate more dysfunctional relationships. These items can be further divided into three subscales of parenting styles: Indifference (e.g., "my [mother/father] ignored me"), Abuse (e.g., "my [mother/father] made me feel in danger"), and Overcontrol (e.g., "my [mother/father] was overprotective of me").

Paternal Caregiver Type. Finally, biological relationship to one's male caregiver is used as a predictor variable in the full model. This variable has four discrete levels based on the youth's self-report of their male caregivers: (1) biological father, (2) nonbiological father, (3) male family member caregiver, and (4) no father. Nonbiological fathers included stepfathers, adoptive fathers, and foster-fathers. Male family member caregivers included custodial grandfathers, custodial uncles, and custodial older brothers.

\section{Results}

\section{Group Differences}


Descriptive statistics of demographic variables were compared across groups.

First, a univariate ANOVA revealed that youth who committed nonviolent crimes $(M=$ $17.52, S D=1.41)$ were significantly younger than youth who committed violent crimes $(M=18.43, S D=2.01)$ or sexual crimes $(M=19.10, S D=2.34), F(2,224)=1.58, p<$ .05. Second, a univariate ANOVA revealed a significant group difference in educational attainment, $F(2,176)=4.99, p<.01$. Specifically, this test revealed that youth who committed sexual crimes $(M=12.11, S D=1.12)$ had significantly more education than did nonviolent youth $(M=11.50, S D=0.81)$. Youth who committed violent crimes $(M=$ $11.93, S D=1.02)$ did not differ from the other groups on education attainment. Third, a univariate ANOVA measuring length of stay indicated that youth who committed sexual offenses $(M=24.80$ months, $S D=24.00)$ or violent offenses (17.51 months, $S D=20.02)$ had been incarcerated for significantly longer than had nonviolent youth $(M=10.32$ months, $S D=13.80), F(2,206)=7.94, p<.01$. The length of incarceration for youth who committed violent or sexual offenses did not significantly differ.

\section{Exploration of Predictor Variables}

In order to more thoroughly understand the variables of interest in this study, several exploratory analyses were performed. First, correlation analyses were run to identify any issues of multicollinearity. A small positive effect size was found $(\mathrm{r}=.18)$ between the maternal and paternal MOPS scales. This suggests that the two scales have a reasonable degree of local independence (Crocker \& Algina, 2006). Thus, the maternal and paternal MOPS scores were included separately in the final model.

Second, the distribution of caregiver types was explored, revealing a wide diversity of caregiver arrangements (See Table 3.1). Among the full sample of 
participants, only $27 \%$ identified both their biological mother and their biological father as their primary caregivers. A large proportion of youth were raised by a grandparent $(32 \%)$, a stepparent $(21 \%)$, or a single parent $(17 \%)$. This variety in caregiving relationships found in the full sample was also seen in all three offense groups when analyzed separately.

More salient to the current analyses were the differences in caregiver type distribution by gender of caregiver. Paternal caregivers were especially diverse. Only $37 \%$ of the total sample reported that their biological father was their primary male caregiver. In the place of biological fathers, $27 \%$ of the youth reported that they were raised by a stepfather, an adoptive father or a foster father. An additional $14 \%$ of youth reported that their grandfather or other male relative was their male caregiver. Finally, a full $22 \%$ of youth reported that they had no male caregivers in their lives. Much less variety was seen amongst mothers. The majority of youth were raised by their biological mothers (73\%). Kinship mothers (e.g., custodial grandmothers) made up an additional $18 \%$ of primary female guardians.

Finally, MOPS scores were examined for each type of paternal caregiver (biofathers, substitute fathers, or kinship fathers). Youth did not report differences in paternal abuse or paternal overcontrol based on caregiver type. However, youth raised by kinship fathers (e.g., custodial grandfathers) perceived them to be more neglectful and indifferent to their needs than did youth raised by biological or substitute fathers $F(3,207)=19.34$, $p<.01$. This result remained significant when youth who committed sexual offenses were examined independently $F(3,83)=5.53, p<.01$.

\section{Offense Outcomes}


To address Research Question One, a multinomial logistic regression analysis was performed with the three offense types (nonviolent, violent, and sexual) as outcomes, five central predictors (three MOPS subscales, ACES, and paternal caregiver type), and three control variables (length of stay in detention, educational attainment, and participant's age). A test of the full model with all predictors against a constant only model was statistically significant $\chi^{2}(16, N=230)=285.05, p<.001$, Nagelkerke's pseudo $R^{2}=.70$ (See Table 3.2).

Closer examination of the variables included in this model revealed that differences in MOPS abuse and indifference scores accounted for a large portion of the variance, while the MOPS overcontrol subscale, paternal caregiver type, and witnessing paternal violence did not distinguish between groups. Within the MOPS variables, high levels of paternal abuse was associated with committing a sexual offense. Controlling for the other variables, paternal abuse was positively related to the probability of committing a sexual offense (vs. nonviolent offenses: $b=-3.77$, Wald $\chi^{2}=2.27, p<.05$; vs. violent offenses: $b=-4.39$, Wald $\chi^{2}=2.83, p<.05$ ). For every additional one-unit increase in paternal abuse, the probability of committing a sexual offense increased by $97 \%$ compared membership in the nonviolent offense group and $98 \%$ compared to membership in the violent offenses group.

Separately, high levels of paternal indifference was associated with greater likelihood of committing a violent offense, rather than a committing a sexual offense ( $b$ $=2.82$, Wald $\left.\chi^{2}=2.21, p<.01\right)$. For every additional one-unit increase in paternal indifference, the probability of being in the violent offenses group, instead of the sexual 
offenses group, increased by $84 \%$. Paternal indifference did not significantly distinguish youth in the nonviolent group from either the sexual or violent offending youth.

A second variation of this model was run with the inclusion of maternal variables (i.e., mother MOPS subscale scores and maternal caregiver type). The pattern of results remained unchanged $\chi^{2}(18, N=230)=409.89, p<.001$, Nagelkerke's pseudo $R^{2}=.37$. Neither the maternal MOPS subscales nor maternal caregiver type independently predicted offense type when controlling for the other variables. However, in this full model, paternal abuse continued to significantly predict committing a sexual offense compared to committing a violent offense $\left(b=4.03\right.$, Wald $\left.\chi^{2}=2.51, p<.05\right)$ or a nonviolent offense $\left(b=3.56\right.$, Wald $\left.\chi^{2}=2.06, p<.05\right)$. Furthermore, paternal indifference continued to statistically differentiate youth who committed violent offenses from youth who committed sexual offenses $\left(b=2.86\right.$, Wald $\left.\chi^{2}=2.10, p<.05\right)$.

\section{Choice of Victims}

To determine if the paternal predictor variables impact youth who commit sexual offenses' choice of victim (Research Question Two), two additional binomial logistic regressions were conducted using only youth who committed sexual offenses. First, paternal MOPS subscale scores, ACES, and paternal caregiver type were entered into a model to predict the youth's choice to offend against peer or child victims. Variables in this model did not significantly explain variance in choice of victim, $\chi^{2}(5, N=70)=$ $74.17 p=n s$. Victim age could not be adequately distinguished on the basis of the paternal caregiving variables.

Second, the same predictor variables were included in a new model to predict having intra- or extra-familial victims, with extra-familial victims. Again, the overall 
model was not significant, $\chi^{2}(5, N=70)=78.43, p=n s$. However, the higher scores on the paternal overcontrol subscale of the MOPS appeared to independently predict having intra-familial victims $\left(b=6.66\right.$, Wald $\left.\chi^{2}=3.90, p<.05\right)$. To assess the robustness of this result, an additional binomial logistic regression was run which included only two predictors: paternal and maternal overcontrol subscale scores. Intra- and extra-familial offending was again included as the dependent variable. This simplified model was significant $\chi^{2}(2, N=69)=86.02 p<.05$. Controlling for maternal overcontrol, paternal overcontrol significantly increased the probability of having an intra-familial victim $(b=$ 4.71, Wald $\left.\chi^{2}=4.60, p<.05\right)$. Maternal overcontrol did not account for significant variance in this analysis.

\section{Discussion}

This investigation attempts to combine the previously siloed literatures that suggest fathers may influence their sons' sexually aggressive behavior. One faction of the literature finds that sexual violence may be passed down from generation to generation through witnessing fathers commit gender-based violence. Separate research, using an attachment perspective, has suggested that father-son relationship quality may be a source of risk or protective factors for youth sexual offending. Therefore, Research Question One sought to understand if the combination of witnessing paternal violence and fatherson relationship quality can uniquely predict youth sexual offending behaviors in a unified model.

The results of this study suggest that father-son relationship quality may distinguish youth who commit sex crimes from other incarcerated youth over and above witnessing fathers engage in violence. Specifically, having a father with an abusive 
parenting style predicted sexual offending to a greater extent than non-sexual violent offending or non-sexual nonviolent offending. This result remained stable even after controlling for maternal parenting style. The contribution of abusive fathers to sexual offending is well established in the literature (Kingston et al., 2017; Yoder, Dillard, \& Liebowitz, 2018). The present findings, however, add that abusive paternal parenting practices may outweigh other potential risk factors for sexual offending, such as witnessing fathers commit violence or experiencing caregiver disruption.

By contrast, youth who reported that their fathers were highly indifferent or neglectful of them were significantly more likely to have committed a violent, but nonsexual, crime. This pattern of findings is consistent with previous literature which suggests that youth who commit non-sexual crimes are monitored less closely than are youth who commit sexual crimes or non-criminal youth (Stewart, Sitney, Kaufman, DeStefano, \& Bui, 2019). Neglectful or indifferent fathers, however, did not often produce youth who committed sex crimes in the present study. The conclusions that may be extrapolated from this series of findings, therefore, are that having an absent or highly neglectful father puts youth at risk for acts of delinquency, while having a present but abusive father is a risk factor for sexual offending specifically.

Furthermore, the results of the present analyses suggest that, by and large, paternal caregiver type does not significantly impact a youth's choice of criminal offense. Parental caregiver type did not distinguish youth who committed sex crimes from violent or nonviolent juvenile delinquents in any of the reported models. Yet, two insights emerged from this examination of paternal caregivers. First, all three groups of incarcerated youth in this sample reported a diverse array of male primary caregivers. As 
a whole, merely $37 \%$ of youth reported that they consider their biological father to be their primary male caregiver. Instead, substitute fathers and kinship fathers were prevalent amongst youth of all three offense types. In fact, more youth incarcerated for sexual offenses were raised by men other than their biological fathers (46\%) than were raised by their biological fathers (41\%). Additionally, a significant number of youths in this study were raised without any father whatsoever $(22 \%)$. However, it is notable that this percentage is largely driven by the high amounts of youth who committed violent offenses (31\%) and nonviolent offenses (23\%) who were raised fatherless. A much smaller percentage of youth who committed sexual offenses (13\%) reported having no father in their lives. Second, youth raised primarily by custodial male family members (e.g. grandparents) rated these men as more neglectful and indifferent to their needs than did youth raised by biological fathers or substitute fathers. This finding remained significant when youth who committed sexual offenses were analyzed alone. This finding adds to the mixed literature which finds that custodial grandparents can be considered either a risk or a protective factor for criminal behavior in juveniles.

The results for Research Questions One paint a picture of the prototypical father of incarcerated youth. Indifferent, neglectful, or absent fathers put their sons at risk for committing violent, but not sexual, crimes. On the other hand, when fathers are present but abusive, their sons are at risk for committing sexual offenses. The biological relationship between father and son does not appear to influence these results, though neither group is likely to live in a nuclear, biological family unit. Thus, any form of present, warm, and supportive male figure may reduce a youth's risk of offending both violently or sexually. 
Finally, Research Question Two sought to highlight any particular impacts that fathers may influence in their son's choice of sexual offense victims. No significant results were found between youth who offended against same-age peers and youth whose victims were significantly younger than they were. However, this model revealed that highly overcontrolling fathers are more likely to produce sons who offend within their own families than are fathers with a less controlling parental style. This is perhaps unsurprising. For, if these fathers focus on controlling their sons' movements, those sons likely have limited access to potential victims. Therefore, they take advantage of the sole location where the intense monitoring is suspended -- inside the home.

\section{Implications}

Research. This study had the potential to integrate theories from multiple evidence-based trajectories of sexual offending. To date, the conceptualization of male sexual offending as occurring through intergenerational transmission and attachment theories have been siloed from one another. This investigation attempts to incorporate insights from both areas of inquiry. The results of this study indicate that fathers with an abusive parenting style significantly increase the risk of their sons committing a sexual offense, over and above maternal caregiving variables. As a whole, research on attachment and caregiving styles has so far focused on mothers. The results from this research suggest that paternal caregiving variables are equally, or perhaps even more so, deserving of attention in the prevention literature.

Additionally, this study adds to a very limited literature which has specifically examined the differential impacts of biological and substitute fathers on sexual offending behavior. Given that this population of boys are disproportionately likely to be raised by 
men other than their biological fathers, more nuanced understandings of the paternal caregiving relationships of youth who commit sex crimes are crucially needed. The findings from this work specifically indicate a need for increased investigations of the relationship between custodial grandfathers and juveniles who engage in coercive sex, as the youth in this study perceived these caregivers to be the most neglectful.

Practice. The present findings suggest that an emphasis on father-son relationship building may be especially effective for the prevention and desistance of juvenile sexual offending. It appears from this research that youth who perceive their male caregivers to be abusive are at greater risk for sexual offending over other types of criminal offenses. This finding provides interesting insights for treatment protocols as it necessitates that interventions must go beyond encouraging fathers to simply be present in the lives of their sons. In order to truly combat juvenile sexual offending, interventions with father figures must focus on developing a parenting style that is free from abuse. Present, but abusive fathers, increase a youth's risk of sexual offending rather than decreasing such risk.

Involving caregivers in therapy is common practice for youth receiving either outpatient or inpatient services for deviant sexual behavior. However, this work also suggests that practitioners should not limit family therapy to the youth and their biological parents. When asked to self-report a primary male caregiver in this study, youth incarcerated for sexual offenses were equally likely to endorse a substitute father as they were to select their biological father. For this population, stepfathers, foster fathers, and male family members are likely influencers of the youth's construction of social norms regarding masculinity. This work, therefore, encourages practitioners to support 
the development of paternal relationships between youth and multiple, diverse, male caregiving figures.

Policy. Ultimately, the study findings lead to a number of policy implications. In order to reduce child sexual abuse, programs should expand their focus beyond exclusively treating juvenile offending. First, programs that seek to end child sexual abuse ought to expand their mandate to actively address the role that male caregivers play in their son's aggressive sexual behavior. This recommendation extends to all levels of prevention efforts. Increasingly, work is being done to teach boys healthy masculinity norms, yet fathers are often absent from these interventions (Boller et al., 2006; Yeung, Duncan, \& Hill, 2000). Primary prevention approaches (e.g. parent training classes) should be encouraged to focus recruitment on male caregivers. Meanwhile, secondary prevention efforts (e.g., court diversion programs for youth) may incentivize fathers to engage in family therapy by providing incentives (e.g., reduced court fees). Finally, tertiary interventions should be designed to teach incarcerated youth effective ways to break the intergenerational cycle of offending by becoming supportive and caring fathers themselves. Parent-training programs for incarcerated juvenile offenders have been shown to be popular with the youth and have led to a number of positive outcomes including increased knowledge regarding healthy childcare practices (Buston, Parkes, Thomson, Wight, \& Fenton, 2012).

Limitations. This investigation also has a number of limitations. First, as the data collected for this project was a subset of a larger data collection effort, some variables of interest were captured through the use of brief measures in order to respect the youth's time. For instance, youth's experiences of witnessing fathers commit acts of violence 
were derived from a three-item subscale of the ACES. These items combined experiences of witnessing male caregivers being physically, sexually, and emotionally violent toward female caregivers. As such, this work is unable to differentially examine the role of witnessing sexual violence, in particular, on the development of youth sexual offending. More research is warranted to examine the specific events witnessed by sexually violent and delinquent youth in their homes.

Second, the Measure of Parental Style (MOPS) scale, which is the primary tool used to assess attachment relationships between youth and their caregivers in this study, provides an incomplete picture of parent-child relationships. It is designed to only assess a single male and female set of primary caregivers. This prevents youth with two caregivers of the same gender from accurately conveying their experience. For instance, if a youth is primarily cared for by his biological mother and stepfather, but also sees their biological father on the weekends, that youth would have to choose to rate either their biological or stepfather on the MOPS. They would be unable to rate both caregivers. Given the vast heterogeneity in caregiver arrangements found in this study, it is clear that this area of research is in need of a more flexible tool capable of capturing the wide range of parental caregiving arrangements.

The MOPS scale is also a deficit-based measure. This means that youth were prevented from describing the positive traits held by their caregivers. Therefore, this work was unable to explore potential caregiver-specific protective factors which may help the youth resist committing serious offenses or may aid in supporting treatment and protecting against recidivism. Additional studies ought to include a strengths-based 
measure of caregiving alongside the MOPS to gather a more full picture of these youths' relationships with their caregivers.

Third, this study excluded several important groups of youth, which limit the generalizability of its findings. Notably, it is lacking a non-incarcerated control group. Incarcerated youth are, by definition, separated from their caregivers for long periods of time. In fact, this sample of youth had been incarcerated for an average of one and a half years prior to data collection. The impact of that separation cannot be accounted for in this study. Replicating this study with youth under community supervision is much needed in order to clarify the role of incarceration in the youth's perceived relationship quality with their caregivers.

\section{Conclusion}

While, perhaps justifiably, the focus of juvenile sexual offending research, treatment, and policy has targeted the youth themselves, their behaviors are also informed by distal factors. Paternal caregivers represent merely one of the many important ecological components of sexual offending. Nevertheless, their influence over their sons' development is transmitted through multiple pathways and permeates both broad and specific decisions regarding sexual behavior. Ultimately, the value of this work resides in

the conclusions that sexual offenses cannot be wholly located within the offender and that the male caregiver of that offender is much more crucial than has been previously acknowledged. 
Tables

Table 3.1 Primary caregivers by offense types

\begin{tabular}{|c|c|c|c|c|}
\hline & Full Sample & SO & $V O$ & $N V O$ \\
\hline Bio Mother \& Bio Father & $\begin{array}{c}27 \% \\
{[n=63]}\end{array}$ & $\begin{array}{c}29 \% \\
{[n=25]}\end{array}$ & $\begin{array}{c}26 \% \\
{[n=23]}\end{array}$ & $\begin{array}{c}27 \% \\
{[n=15]}\end{array}$ \\
\hline Bio Mother & $\begin{array}{c}73 \% \\
{[n=166]}\end{array}$ & $\begin{array}{c}68 \% \\
{[n=59]}\end{array}$ & $\begin{array}{c}79 \% \\
{[n=68]}\end{array}$ & $\begin{array}{c}70 \% \\
{[n=39]}\end{array}$ \\
\hline $\begin{array}{l}\text { Step/Adoptive/Foster } \\
\text { Mother }\end{array}$ & $\begin{array}{c}5 \% \\
{[n=12]}\end{array}$ & $\begin{array}{c}8 \% \\
{[n=8]}\end{array}$ & $\begin{array}{c}4 \% \\
{[n=3]}\end{array}$ & $\begin{array}{c}3 \% \\
{[n=2]}\end{array}$ \\
\hline Kinship Mother & $\begin{array}{c}18 \% \\
{[n=41]}\end{array}$ & $\begin{array}{c}19 \% \\
{[n=17]}\end{array}$ & $\begin{array}{c}16 \% \\
{[n=14]}\end{array}$ & $\begin{array}{c}18 \% \\
{[n=10]}\end{array}$ \\
\hline No Mother & $\begin{array}{c}4 \% \\
{[n=10]}\end{array}$ & $\begin{array}{c}5 \% \\
{[n=4]}\end{array}$ & $\begin{array}{c}1 \% \\
{[n=1]}\end{array}$ & $\begin{array}{c}9 \% \\
{[n=5]}\end{array}$ \\
\hline Bio Father & $\begin{array}{c}37 \% \\
{[n=85]}\end{array}$ & $\begin{array}{c}41 \% \\
{[n=36]}\end{array}$ & $\begin{array}{c}32 \% \\
{[n=28]}\end{array}$ & $\begin{array}{c}38 \% \\
{[n=21]}\end{array}$ \\
\hline $\begin{array}{l}\text { Step/Adoptive/Foster } \\
\text { Father }\end{array}$ & $\begin{array}{c}27 \% \\
{[n=62]}\end{array}$ & $\begin{array}{c}31 \% \\
{[n=27]}\end{array}$ & $\begin{array}{c}25 \% \\
{[n=22]}\end{array}$ & $\begin{array}{c}23 \% \\
{[n=13]}\end{array}$ \\
\hline Kinship Father & $\begin{array}{c}14 \% \\
{[n=32]}\end{array}$ & $\begin{array}{c}15 \% \\
{[n=13]}\end{array}$ & $\begin{array}{c}13 \% \\
{[n=10]}\end{array}$ & $\begin{array}{c}16 \% \\
{[n=9]}\end{array}$ \\
\hline No Father & $\begin{array}{c}22 \% \\
{[n=51]}\end{array}$ & $\begin{array}{c}13 \% \\
{[n=11]}\end{array}$ & $\begin{array}{c}31 \% \\
{[n=27]}\end{array}$ & $\begin{array}{c}23 \% \\
{[n=13]}\end{array}$ \\
\hline
\end{tabular}

Note. $\mathrm{SO}=$ convicted of a sexual offense; $\mathrm{VO}=$ convicted of a violent (nonsexual) offense; $\mathrm{NVO}=$ convicted of a nonviolent offense 


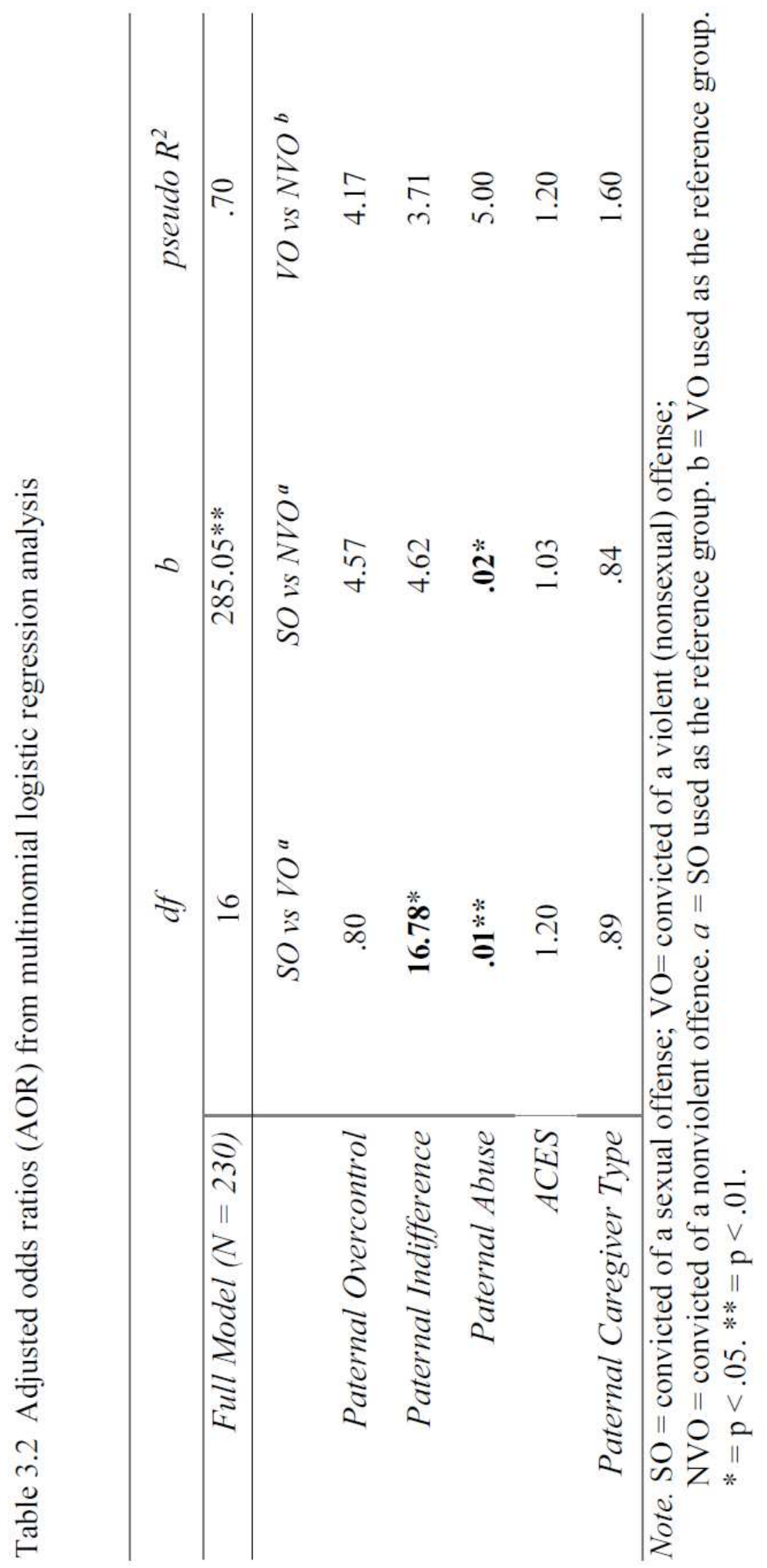




\section{References}

Apel, R., \& Kaukinen, C. (2008). On the relationship between family structure and antisocial behavior: Parental cohabitation and blended households. Criminology, 46(1), 35-70. doi:10.1111/j.1745-9125.2008.00107.x

Bandura, A. (1971). Social learning theory of aggression. In J. F. Knutson (Ed.), Control of aggression: Implications from basic research (pp. 201-250). Chicago: AldineAtherton.

Bandura, A. (1973). Aggression: A social learning analysis. Englewood Cliffs, NJ: Prentice-Hall.

Bandura, A. (1986). The social learning perspective: Mechanisms of aggression. In $\mathrm{H}$. Toch (Ed.), Psychology of crime and criminal justice (pp. 198-236). Prospect Heights, IL: Waveland Press.

Bijleveld, C., Hill, J., \& Hendriks, J. (2016). Sexual abuse within the family: The intergenerational transmission of victimhood and offending. In H. Kury, S. Redo, \& E. Shea (Eds.), Women and children as victims and offenders: Background, prevention, reintegration (pp. 905-921), Switzerland: Springer International.

Boller, K., Bradley, R., Cabrera, N., Raikes, H., Pan, B., Shears, J., \& Roggman, L. (2006). The early head start father studies: Design, data collection, and summary of father presence in the lives of infants and toddlers. Parenting, 6(2-3), 117-143. doi: $10.1080 / 15295192.2006 .9681302$

Bowlby, J. (1969). Attachment and loss: Vol. 1. Attachment. New York: Basic Books. 
Bowlby, J. (1973). Attachment and loss: Vol. 2. Separation: Anxiety and anger. New York: Basic Books.

Bowlby, J. (1980). Attachment and loss: Vol. 3. Sadness and depression. New York: Basic Books.

Buston, K., Parkes, A., Thomson, H., Wight, D., \& Fenton, C. (2012). Parenting interventions for male young offenders: A review of the evidence on what works. Journal of Adolescence, 35(3), 731-742. doi:

10.1016/j.adolescence.2011.10.007

Coles, R. L. (2015). Single-father families: A review of the literature. Journal of Family Theory \& Review, 7, 144-166. doi: 10.1111/jftr.12069

Davids, O., Londt, M., \& Wilson, L. (2015). Imprisoned sex offenders' chronic denial and their childhood family environment. The Open Family Studies Journal, 7(1), 42-47. doi: $10.2174 / 1874922401507010042$

Demuth, S., \& Brown, S. L. (2004). Family structure, family processes, and adolescent delinquency: The significance of parental absence versus parental gender. Journal of Research in Crime and Delinquency, 41(1), 58-81. doi:

$10.1177 / 0022427803256236$

Dolan, M. M., Casanueva, C., Smith, K. R., \& Bradley, R. H. (2009). Parenting and the home environment provided by grandmothers of children in the child welfare system. Children and Youth Services Review, 31(7), 784-796. doi:

10.1016/j.childyouth.2009.02.005

Duane, Y., Carr, A., Cherry, J., McGrath, K., \& O'Shea, D. (2003). Profiles of the parents of adolescent CSA perpetrators attending a voluntary outpatient treatment 
programme in Ireland. Child Abuse Review: Journal of the British Association for the Study and Prevention of Child Abuse and Neglect, 12(1), 5-24.

doi:10.1002/car.776

Felizzi, M. V. (2015). Family or caregiver instability, parental attachment, and the relationship to juvenile sex offending. Journal of Child Sexual Abuse, 24, 641658. doi: $10.1080 / 10538712.2015 .1057668$

Finkelhor, D., Turner, H. A., Shattuck, A., \& Hamby, S. L. (2015). Prevalence of childhood exposure to violence, crime, and abuse: Results from the national survey of children's exposure to violence. JAMA Pediatrics, 169(8), 746-754. doi: 10.1001/jamapediatrics.2015.0676

Giotakos, O., Vaidakis, N., Markianos, M., Spandoni, P., \& Christodoulou, G. N. (2004). Temperament and character dimensions of sex offenders in relation to their parental rearing. Sexual and Relationship Therapy, 19(2), 141-150. doi:

$10.1080 / 14681990410001691352$

Harper, C. C., \& McLanahan, S. S. (2004). Father absence and youth incarceration. Journal of Research on Adolescence, 14(3), 369-397. doi: 10.1111/j.15327795.2004.00079.x

Hunter, J. A., Figueredo, A. J., Becker, J. V., \& Malamuth, N. (2007). Non-sexual delinquency in juvenile sexual offenders: The mediating and moderating influences of emotional empathy. Journal of Family Violence, 22(1), 43-54. doi: $10.1007 / \mathrm{s} 10896-006-9056-9$ 
Hunter, J. A., Figueredo, A. J., Malamuth, N. M., \& Becker, J. V. (2003). Juvenile sex offenders: Toward the development of a typology. Sexual Abuse: A Journal of Research and Treatment, 15(1), 27-48. doi: 10.1023/A:1020663723593

Kingston, D. A., Graham, F. J., \& Knight, R. A. (2017). Relations between self-reported adverse events in childhood and hypersexuality in adult male sexual offenders. Archives of Sexual Behavior, 46(3), 707-720. doi: 10.1007/s10508-016-0873-5

Långström, N., Babchishin, K. M., Fazel, S., Lichtenstein, P., \& Frisell, T. (2015). Sexual offending runs in families: A 37-year nationwide study. International Journal of Epidemiology, 44(2), 713-720. doi: 10.1093/ije/dyv029

Levenson, J. S., \& Grady, M. D. (2016). The influence of childhood trauma on sexual violence and sexual deviance in adulthood. Traumatology, 22(2), 94-103. doi: $10.1037 / \operatorname{trm} 0000067$

Marsa, F., O’Reilly, G., Carr, A., Murphy, P., O’sullivan, M., Cotter, A., \& Hevey, D. (2004). Attachment styles and psychological profiles of child sex offenders in Ireland. Journal of Interpersonal Violence, 19, 228-251. doi:10.1177/ 0886260503260328

Marshall, W. L. (1989). Intimacy, loneliness and sexual offenders. Behaviour Research and Therapy, 27, 491-503. doi: 10. 1177/088626097012003001

Marshall, W. L. (1993). The role of attachments, intimacy and loneliness in the etiology and maintenance of sexual offending. Sexual and Marital Therapy, 8, 109-121. doi: $10.1080 / 14681990903550191$ 
Marshall, W. L., \& Marshall, L. E. (2010). Attachment and intimacy in sexual offenders: An update. Sexual and Relationship Therapy, 25, 86-90. doi: $10.1080 / 14681991003589568$

Mathe, S. (2007). Juvenile sexual offenders: We are the sons of our fathers. Agenda, 21(74), 133-140. doi:10.1080/10130950.2007.9674887

McCormack, J., M $\square$ Hudson, S., \& Ward, T. (2002). Sexual offenders' perceptions of their early interpersonal relationships: An attachment perspective. Journal of Sex Research, 39(2), 85-93. doi: 10.1080/00224490209552127

McKillop, N., Smallbone, S., Wortley, R., \& Andjic, I. (2012). Offenders' attachment and sexual abuse onset: A test of theoretical propositions. Sexual Abuse, 24(6), 591-610. doi: 10.1177/1079063212445571

O’Toole, M. J., \& Jeglic, E. L. (2014). The relationship between childhood family environment and adult sexual offending in a sample of sexual offenders. Psi Chi Journal of Psychological Research, 19(4), 173-182. doi: 10.24839/21648204.JN19.4.173

Parker, G., Roussos, J., Hadzi-Pavlovic, D., Mitchell, P., Wilhelm, K., \& Austin, M. P. (1997). The development of a refined measure of dysfunctional parenting and assessment of its relevance in patients with affective disorders. Psychological Medicine, 27(5), 1193-1203. doi: 10.1017/s003329179700545x

Ports, K. A., Ford, D. C., \& Merrick, M. T. (2016). Adverse childhood experiences and sexual victimization in adulthood. Child Abuse \& Neglect, 51, 313-322. doi: 10.1016/j.chiabu.2015.08.017 
Seto, M. C., \& Lalumière, M. L. (2010). What is so special about male adolescent sexual offending? A review and test of explanations through meta-analysis. Psychological Bulletin, 136, 526-575. doi: 10.1037/a0019700

Sigre-Leirós, V., Carvalho, J., \& Nobre, P. (2016). Preliminary findings on men's sexual self-schema and sexual offending: differences between subtypes of offenders. The Journal of Sex Research, 53(2), 204-213. doi: 10.1080/00224499.2015.1012289

Simons, D. (2015). Sex offender typologies. In C. Lobanov-Rotovsky \& R. Przybylski (Eds.), Sex offender management and planning initiative (pp. 55-75). Washington DC: Department of Justice.

Simons, D. A., Wurtele, S. K., \& Durham, R. L. (2008). Developmental experiences of child sexual abusers and rapists. Child Abuse \& Neglect, 32(5), 549-560. doi: 10.1016/j.chiabu.2007.03.027

Sitney, M. H., \& Kaufman, K. L. (2019). The impact of disrupted caregiving for juvenile sexual offenders. Journal of Sexual Aggression, 26, 274-287. doi: $10.1080 / 13552600.2019 .1618933$

Sitney, M. H., \& Kaufman, K. L. (2020). A chip off the old block: The impact of fathers on juvenile sexual offenders. Trauma, Violence, and Abuse, advance online publication. doi: 10.1177/1524838019898463

Smallbone, S. W., \& Dadds, M. R. (2000). Attachment and coercive sexual behavior. Sexual Abuse: A Journal of Research and Treatment, 12(1), 3-15. doi: 10.1023/A:1009555619323 
Smallbone, S. W., \& McCabe, B. A. (2003). Childhood attachment, childhood sexual abuse, and onset of masturbation among adult sexual offenders. Sexual Abuse: A Journal of Research and Treatment, 15(1), 1-9. doi: 10.1023/A:1020616722684

Stirpe, T. S., \& Stermac, L. E. (2003). An exploration of childhood victimization and family-of-origin characteristics of sexual offenders against children. International Journal of Offender Therapy and Comparative Criminology, 47(5), 542-555. doi: $10.1177 / 0306624 X 03253316$

Stewart, K. E., Sitney, M. H., Kaufman, K. L., DeStefano, J., \& Bui, T. (2019). Preventing juvenile sexual offending through parental monitoring: a comparison study of youth's experiences of supervision. Journal of Sexual Aggression, 25(1), 16-30. doi: 10.1080/13552600.2018.1528796

Van de Weijer, S. G. A., Besemer, S., Blokland, A. A., \& Bijleveld, C. C. J. H. (2015). The concentration of sex offenses within British and Dutch families. In A. A. Blokland \& P. Lussier (Eds.), Sex offenders: A criminal career approach (pp. 321-348). Oxford: Wiley.

Wells, L. E., \& Rankin, J. H. (1991). Families and delinquency: A meta-analysis of the impact of broken homes. Social Problems, 38(1), 71-93. doi: 10.2307/800639

Worley, K. B., Church, J. K., \& Clemmons, J. C. (2012). Parents of adolescents who have committed sexual offenses: Characteristics, challenges, and interventions. Clinical Child Psychology and Psychiatry, 17(3), 433-448. doi:

$10.1177 / 1359104511417787$ 
Yeung, W. J., Duncan, G. J., \& Hill, M. S. (2000). Putting fathers back in the picture: Parental activities and children's adult outcomes. Marriage \& Family Review, 29(2-3), 97-113. doi: 10.1300/J002v29n02_07

Yoder, J. R. (2014). Service approaches for youths who commit sexual crimes: A call for family-oriented models. Journal of evidence-based social work, 11(4), 360-372. doi:10.1080/10911359.2014.897108

Yoder, J. R., Dillard, R., \& Leibowitz, G. S. (2018). Family experiences and sexual victimization histories: A comparative analysis between youth sexual and nonsexual offenders. International Journal of Offender Therapy and Comparative Criminology, 62, 2917-2936. http://doi.org/10.1177/0306624X17738063

Yoder, J. R., Leibowitz, G. S., \& Peterson, L. (2016). Parental and peer attachment characteristics: differentiating between youth sexual and non-sexual offenders and associations with sexual offense profiles. Journal of Interpersonal Violence, 33(17), 2643-2663. doi:10.1177/0886260516628805 


\section{Chapter 5: Conclusion}

\section{The Problem of Sexual Offending}

World-wide, one in every five girls will experience sexual abuse (World Health Organization, 2016). Horrifically, the perpetrators of a great many of these violations are children themselves (World Health Organization, 2015). This dissertation has sought to advance how we understand the mechanisms underlying juvenile sexual offending. Assuredly, the issue is multifaceted. Evidence-based prevention programs for juvenile sexual offending often tackle issues related to fostering self-regulation, changing deviant cognitions, and developing peer social skills (Letourneau \& Borduin, 2008). Still, in 2020, thirty percent of all incarcerated youth in Oregon were adjudicated for a sexual offense (Oregon Youth Authority, 2020). Clearly, there is work yet to be done in order to help youth develop appropriate sexual attitudes and behaviors.

The intention of this series of studies was to thoroughly explore one potential trigger for juvenile sexual offending. That avenue concerns the role that caregivers, particularly male caregivers, play in the development of their sons' deviant sexual behaviors. Even though this specific research area has generally been absent from the literature, supporting work from the areas of developmental psychology and criminology note that caregivers are often important behavioral role models. Core developmental theories, such as attachment theory, suggest that the relationship between parents and children have life-long impacts on the child (Ainsworth, Blehar, Waters, \& Wall, 1978; Bowlby, 1988). Similarly, research using social learning theory frameworks have 
provided longstanding evidence that young people learn to act in ways that they see modeled by their parents (Bandura, 1978). Furthermore, gender-based theories of development highlight the critical importance of male-caregivers in teaching masculinity norms to their sons (Mussen \& Distler, 1959). In an entirely separate discipline, criminologists have long linked disrupted caregiving experiences to delinquent behavior. For over one-hundred years scholars have been considering the potential negative impacts of absent fathers on a youth's long-term success (Healy \& Bronner, 1926; Shaw $\&$ McKay, 1932). Subsequently, the last century has brought with it a plethora of research on the intergenerational transmission of criminal behavior passed on from parents to children.

Findings from these studies rely upon an abundance of prior scholarly work regarding caregivers. By providing love and support, parents and guardians may act as protective agents against juvenile delinquency. Conversely, those same caregivers may act in ways that increase risk factors for delinquency through harsh and abusive parenting. This dissertation adds nuance to the limited body of literature that has attempted to explicitly link parental variables to sexual offending. Central theories regarding the development of sexual offending have suggested that isolation and loneliness may be at the heart of this type of aggressive behavior (Marshall, 1989). While youth who commit sexual offenses often claim peer rejection as their greatest struggle, their underdeveloped social skills can often be traced back to insufficient caregiving practices during a child's formative years (Marshall, 1993; Marshall \& Marshall, 2010). Interventions that target caregivers, therefore, may well prove to be effective at protecting 
children from many adverse experiences as well as the subsequent negative behaviors that can follow from such a developmental history.

To thoroughly examine the role of caregivers in the development of juvenile sexual offending behaviors, this dissertation uses three independent, yet related, manuscripts. Each of them builds upon the previous project to delve ever deeper into the core functions of caregivers as models for youth behavior. In the remainder of this chapter, each study will be summarized in turn. These summaries will be followed by an analysis of the knowledge derived from considering all three manuscripts simultaneously. Finally, a discussion of implications for future research, treatment practices, and policy changes will be presented.

\section{Study One}

As so little is known about the effects of caregivers on juvenile sex crime, Study One sought to answer two broad research questions. First, this article sought to determine whether youth who commit sex crimes perceive their relationships with their primary caregivers differently than do general juvenile delinquents or non-offending youth.

Second, Study One began an investigation of the impact of caregiver gender and nonbiological status on caregiver-child relationship quality. The results indicated that youth who commit sexual offenses indeed reported significantly worse relationships with their primary caregivers than did non-offending youth or youth who committed non-violent crimes. However, juvenile offenders who committed violent, but non-sexual crimes, reported equally poor relationships to their caregivers as did the youth who committed sexual crimes. Poor caregiver-child relationship quality, therefore, can be theorized as having a general impact on "serious" offending rather than any particular type of crime. 
Nevertheless, it is clear from this work that caregiver variables are important when determining the correlates of juvenile engagement in criminal behavior.

Moreover, practically no prior work had investigated the effects of the caregiver gender or biological status specific to sexual offending. The results of this second analysis indeed determined that caregiver-child relationship quality was moderated by both caregiver gender and the biological relationship between caregiver and child. Gender moderated the regression such that male caregivers were associated with lower relationship quality scores for youth who committed sexual or violent crimes. Juvenile sexual offenders reported slightly worse quality relationships with their male caregivers than did violent juvenile delinquents. However, that pattern did not hold for youth who committed non-violent crimes or noncriminal youth. Those "low-delinquency" youth had equally strong relationships with their male and female caregivers. The biological moderator also impacted the relationship quality of sexually-offending youth and their caregivers, though in an unexpected direction. For youth who commit sex crimes, having a non-biological caregiver was actually associated with a significant increase in relationship quality compared to sexually-offending youth with biological caregivers.

These findings suggest that violent juvenile delinquents and youth who commit sexual offenses may be part of the same general population, or at least affected by caregiving variables in similar ways. However, there also may be areas of caregiving that affect sexual offenders differently than youth who commit other types of crimes. Particularly, youth who commit sexual offenses appear to have especially problematic relationships with their biological fathers compared to other groups. Finally, there is an interesting suggestion here that moving from a biological home to a nonbiological home 
for these youth may have a unique protective effect. This may be due to the emotional toll and feelings of responsibility that weigh on parents of youth who commit sexual offenses, and their behavior toward their son in response to those feelings.

\section{Study Two}

The results of the first study indicated that paternal caregiver status may have special importance in predicting juvenile sexual offending. However, the academic literature regarding male caregivers of sexual offenders is often buried inside larger studies. Therefore, the aim of Study Two was to conduct a systematic review of the literature to summarize what is known about the impact of fathers on sexual offending behavior. This review separately analyzed articles that approached paternal impacts through either (a) an intergenerational transmission of violence lens, (b) an attachment theory lens, or (c) a paternal demographic characteristics lens. Additionally, this review compared the impact of paternal caregiving for men who commit sexual offenses as an adult to juvenile sexual offenders.

These analyses discovered persuasive evidence for the intergenerational transmission of violence hypothesis. Specifically, numerous studies found that sexually aggressive fathers are likely to have sexually aggressive sons. Furthermore, juveniles who commit sex crimes report that they modeled their aggressive behaviors on the violence that their fathers perpetrated, largely against their mothers. One may interpret that interaction with their fathers as an indoctrination into what it means to be masculine. Similarly strong evidence of paternal impact was found in the attachment literature. The fathers of youth who commit sexual offenses tended to be emotionally abusive and subsequently, these young men had poor attachment quality with their male caregivers. It 
is hypothesized that the dysfunctional modes of achieving intimacy through sex resulted from the experiences of rejection by their fathers. Interestingly, this was especially true for men who commit peer rape and less true for men who molest children much younger than themselves. In contrast, no evidence was found that the fathers of boys who commit sex crimes are demographically different than the fathers of other incarcerated young men. In general, these studies reported no differences between fathers of youth who commit sexual offenses and fathers of incarcerated non-sexual offenders in terms of age, arrest history, mental health history, substance abuse history, or even of the father's own history of experiencing sexual victimization. Fathers of sexual offenders, therefore, cannot be identified purely through demographic characteristics. Finally, the pattern of findings for all three paternal triggers for sexual offending was consistent for both juvenile and adult sexual offenders, suggesting generalizability of these impacts.

Multiple conclusions can be drawn from an examination of this systematic review. First, it confirms the finding from Study One that fathers have an impact on the sexual offending behavior of their sons. Study Two furthers those conclusions by adding that paternal influence occurs through multiple pathways, including both the intergenerational transmission of violence pathway and through father-son attachment relationships. Second, this review highlighted how siloed, scattered, and disjointed the literature with regards to paternal caregivers for sexual offenders. Clearly, an integrative model is needed to conjoin these separate theoretical frameworks. This would allow a view of the joint effects of paternal aggression and paternal attachment simultaneously. Finally, some interesting avenues for further exploration were uncovered. Specifically, there is burgeoning research that suggests that fathers may impact not just sexual 
offending behavior generally, but may even have an effect on their son's choice of victims. However, that research is very limited and is in need of additional depth.

\section{Study Three}

This dissertation concludes with a third study that addressed the gaps in the literature which were identified in Studies One and Two. It did so by proposing a confluence model of paternal impacts for juvenile sexual offending. The previous studies found three mechanisms of paternal influence: intergenerational transmission, attachment quality, and caregiver disruption. Here, these pathways were included in a joint model to examine their unique and shared effects on juvenile sexual offending. This research was intended to clarify which practices of paternal caregiving were most predictive of youth committing a sexual offense rather than a non-sexual offense.

This investigation once again found that father-son attachment quality may be particularly useful for distinguishing youth who commit sexual offenses from other incarcerated youth. Those who considered their fathers to have an abusive parenting style were significantly more likely to have committed a sexual offense than to have committed violent or non-violent crimes. In contrast, youth who felt that their fathers had a neglectful parenting style were significantly more likely to have committed a violent offense than non-violent offenders or sexual offenders. Even more specifically, sexual offenders whose fathers were highly overcontrolling were more likely to have intrafamilial victims than were sexual offenders with less controlling fathers. These results persisted even when attachment relationships to mothers were included in the model. The parenting style of fathers, therefore, appears not only to predict juvenile sexual offending generally, but can contribute to predicting the youth's choice of victims. 
While attachment to fathers appeared to significantly predict youth's choice of criminal behavior, this model did not produce many notable results related to the intergenerational transmission of violence hypothesis or the caregiver disruption hypothesis. In this study, many youth had witnessed their fathers domestically abusing their mothers. This adverse childhood experience prevailed amongst all three types of offending and did not distinguish one group of youth from the others. A similar situation occurred in the caregiver disruption variable. The majority of youth in this sample lived in non-nuclear households and most youth had experienced some form of substitute paternal caregiver in their lives. Since non-biological male caregivers were the norm among youth of all three crime types, this variable was unable to distinguish between groups.

The conclusions that can be drawn from this study are three-fold. First, there is clear evidence that paternal variables impact juvenile sexual offending. Sometimes the weight of that influence extends over and beyond matched maternal variables. Fathers with abusive parenting styles may constitute particular risks for the development of sexual aggression in young people. Second, more work is necessary to clarify the role of modeling violence as a mechanism for fathers imparting sexual behavior norms to their sons. This study did not find that fathers modeling violence impacted youths' choice of crimes. However, previous research has found support for intergenerational transmission of violence pathway for sexual assaults (Davids, Londt, \& Wilson, 2015; Långström, Babchishin, Fazel, Lichtenstein, \& Frisell, 2015; Mathe, 2007). Third, this study confirmed that youth who commit sexual offenses, like other incarcerated youth, are more likely to live in disrupted caregiving households than in nuclear households. Step- 
fathers, foster-fathers, and custodial grandfathers were all considered to be primary male caregivers for a large proportion of youth in this study. The findings from this work specify a need for additional investigations of the relationship between custodial grandfathers and juvenile sexual offenders as youth perceived this type of caregiver to be the most neglectful monitors of their actions.

\section{Integration of Findings}

These three studies build upon one another to advance our knowledge of paternal catalysts for juvenile sexual offending. This section will integrate those findings to answer the two pressing questions addressed in this dissertation: (1) Do fathers' actions contribute to their sons' sexual offending behavior?; and (2) If fathers do influence their sons, what are the mechanisms by which that impact occurs?

The results of all three studies demonstrate that fathers do indeed contribute to the etiology of juvenile sexual crime. Both of the empirical studies (Study One and Study Three) found that paternal variables were predictive of juvenile sexual offending over and above general criminal offending. Furthermore, the systematic literature review (Study Two) presented evidence from thirty-four articles that validated fathers as primary facilitators of juvenile sexual offenses. To ensure that these results were specifically related to fatherhood, rather than parenting practices generally, all three manuscripts included findings that controlled for maternal caregiving variables. Repeatedly, paternal caregiving practices were determined to impact youth sexual offending behavior significantly, even when maternal variables were present in the same model. Thus, one key conclusion from this body of work is that fathers uniquely influence the sexual offending behaviors of their sons. 
Clearly fathers have special importance for engagement in youth sexual behaviors, but through what mechanisms does that influence occur? In these studies, three potential pathways have been explored. First, fathers may influence their sons through their parenting style. Second, fathers may influence their sons through modeling sexually or violently abusive behavior themselves. Third, fathers may influence their sons through characteristics of caregiver disruption (father absence, non-biological paternal caregiving, etc).

Throughout all three documents in this series, paternal parenting style remained a consistently strong indicator of juvenile sexual offending behavior. Study One found that youth who commit sexual offenses had particularly poor relationships with their fathers compared to youth who committed less violent crimes or non-offending youth. Study Two found that diverse samples of sexual offenders shared insecure parental attachments. Finally, Study Three found that abusive paternal parenting styles predicted juvenile sexual offending, while neglectful or overcontrolling parenting styles did not. Consequently, there is abundant support in these works that poor paternal caregiving is a significant risk factor for youth at a time when their sexuality is rapidly developing and very impressionable.

Paternal influence on sexual behavior through modeling is a less understood pathway. This body of work found mixed evidence for its utility. Specifically, Study Two presented a strong argument for modeling as a primary mechanism for the transmission of violent behavior from father to son. Multiple articles in the systematic literature review found that sexually violent fathers tend to produce sexually violent sons. However, Study Three did not find support for modeling as a predictor of sexual violence over general 
criminal behavior in juveniles. At the same time, it is important to caution that the variables used in Study Three related to modeling domestic violence rather than sexual violence explicitly. Future studies are needed to specifically examine the transmission of violence hypothesis as a significant transmission pathway for sexual violence.

Finally, the potential for paternal caregiver disruption to influence juvenile sexual offending was explored in all three studies. Most centrally, these works investigated the relationship between non-biological paternal caregiving and juvenile sexual offending. They found that juvenile sexual offenders are very often cared for by men other than their biological father (Study Three). However, having a non-biological paternal caregiver did not impact a youth's decision to commit a sexual offense over a violent or non-violent offense (Study Three). The systematic literature review was consistent with this finding. There, no unique demographic variables which would separate fathers of sexual offenders from other men were found (Study Two). In fact, the only potentially significant finding related paternal caregiving disruptions comes from Study One. This article revealed that having a non-biological caregiver may actually be a protective factor for youth who commit sexual offenses, since their relationships with their sons were more positive than

were youth's relationships with their biological fathers. Therefore, the third conclusion of this dissertation is that, while nonbiological fathers are prevalent in the lives of young men who commit sex crimes, the lack of blood relation between father and son does not constitute an additional risk factor for these youth.

\section{Implications}

A variety of implications warrant mention based on the conclusions presented above. These include the need to discriminate among styles of paternal parenting and 
support, the importance of further research into the different models of paternal abusive behavior, and the need for a broader definition of "fathers." This section will outline the major strengths and future directions that researchers, practitioners, and policymakers may take away from this work.

Research. Three implications for future research should be highlighted based on this series of studies. First, fathers need to be included explicitly in models predicting sexual offending. To date, most researchers present joint parental caregiving practices as predictors for offending. However, it would appear from these studies that fathers hold unique predictive power that is obscured when combined with maternal impacts. Stronger models may be produced by separating paternal and maternal predictors. Second, future researchers investigating the effects of fathers on the sexual offending behaviors of their sons may be encouraged to focus on attachment or relationship quality. The father-son relationship seems to be a consistently strong pathway of influence. More research is especially needed to track how this relationship changes over time, since no study has yet been able to compare paternal relationship quality with their sons both pre- and postadjudication for a sexual offense. Third, more work is necessary to draw conclusive links between fathers modeling sexual aggression and their sons committing sexual aggression. It remains unclear if modeling aggression has a specific pathway for sexual offenses in particular, rather than general violent delinquency. Further, researchers have not yet measured the extent to which juvenile sexual offenders were exposed to paternal models of sexual violence over and above models of physical and emotional abuse.

Practice. Treatment providers, as well, may glean some useful information from this work. Just as researchers may continue to investigate attachment perspectives, 
practitioners too should consider emphasizing the reparation of the father-son relationship when treating juvenile sexual offenders. Strong father-son relationships seem not only to be a protective factor against sexual offending but also may serve to protect against other kinds of violent behavior, as well. Therefore, a treatment plan that focuses on building a secure, loving relationship between father and son may yield dividends in helping delinquent youth to live successfully as adults in the community. However, practitioners must also support the potential for primary male caregivers to be men other than the youth's biological father. Across all of these studies, youth who commit sexual offenses repeatedly reported that they often consider non-biological fathers to be their most significant male influence. Practitioners would do well to ask youth to outline the important men in their lives, rather than to assume importance based on biological connection. In fact, this dissertation suggests that having a strong and supportive nonbiological male guardian may be more beneficial to the youth than simply having a present biological father.

Policy. Finally, guidance for policymakers may be derived from the conclusions presented here. Parenting classes aimed at fathers would be a promising avenue for those who work to develop primary prevention programs against sexual violence. Such classes could help new fathers focus on building strong relationships with their sons as well as modeling appropriate relationship and interpersonal behavior. By shifting to focus on primary prevention with male caregivers, policymakers could keep youth from suffering from the risk factors associated with this kind of delinquency. Furthermore, this work has policy implications for those youth who have already committed sexual offenses and have been incarcerated. Its conclusions indicate that the father-son relationship remains 
severely damaged post-adjudication. Long periods of incarceration further serve to alienate youth from their caregivers and may frustrate any attempts to repair these relationships. Policymakers should continue to think carefully about the benefits of community corrections as opposed to prison terms for youth. Keeping youth at home with their caregivers may benefit the healing critical for recovery.

\section{Limitations}

Despite the work already achieved in considering fathers as key influencers on their sons' behavior, the uniqueness of the male paternal role remains under-emphasized. Naturally, more investigation is required to fully understand the scope of paternal impacts. This section will highlight the limitations of these three studies and will suggest avenues to further extend the present findings.

It is crucial to note that family systems are complex, multifaceted, and dynamic. As such, the static measurement of primary caregivers used throughout these studies could not capture the full extent of male caregiving, as experienced by the youth. These young men reported that the father-figures who cared for them were of many types and that biological fathers were no more present in their lives than were substitutes. It is therefore likely that youth who commit sexual offenses considered two or more men to have been in a primary parenting role. This multiplicity could not be captured in this work. The interplay of multiple male caregivers is an unexplored area, in serious need of further investigations that would parse apart their alternating influences. Discriminations of that order would be instrumental in understanding the paternal transmission of sexual violence norms. 
This work also may be limited in its generalizability due to its reliance on samples from incarcerated youth. In all three studies, juveniles were categorized by their adjudication status. Consequently, the effects of incarceration are inherently intertwined with the effects of parenting. No comparison group of youth who had committed a sexual offense, but remained at home with their caregivers was included. Furthermore, it is certainly possible that the fallout resulting from the reveal of the sexual offending behavior and subsequent trauma of navigating the legal system negatively influenced the father-son relationships examined here. Future work that interviews youth who received community corrections sanctions or out-patient therapy rather than incarceration is critical to help further develop our understanding in this area.

Therefore, studies of this nature are forced to compartmentalize criminal behavior artificially. In the above works, youth were considered sexual offenders even if they had also committed other violent, but non-sexual, crimes. Similarly, violent offenders were categorized as such even if they had committed non-violent criminal offenses more frequently and more recently. Therefore, the lines between types of offenders is often blurred and complex; e.g., is arson a violent or non-violent crime? Should public exposure be considered a sexual offense and be put in the same category as forcible rape? Additionally, the systemic inequities in the United States legal system show that youth of privilege are less likely to be arrested, charged, or convicted for criminal activity of any sort. Therefore, our samples inherently exclude the more affluent youth who have successfully alluded criminal repercussions. These dichotomies create uncertainty surrounding the implications of the three studies. Therefore, replication research is desperately needed to confirm the validity of these findings. 


\section{Conclusion}

This dissertation is addressed to future researchers interested in higher-order factors for sexual offending. While, perhaps justifiably, the focus of juvenile sexual offending research, treatment, and policy has targeted the youth themselves, their behaviors are also informed by distal factors. Paternal caregivers represent merely one of the many important ecological components of sexual offending. Nevertheless, their influence over their sons' development is transmitted through multiple pathways and permeates both broad and specific decisions regarding sexual behavior. Ultimately, the value of this work will reside in the discovery that the significance of sexual offense cannot be wholly located within the offender and that the male caregiver of that offender is much more crucial than has been previously acknowledged. 


\section{References}

Ainsworth, M. D. S., Blehar, M. C, Waters, E., \& Wall, S. (1978). Patterns of

attachment: A psychological study of the strange situation. Hillsdale, NJ: Erlbaum

Bandura, A. (1978). Social learning theory of aggression. Journal of Communication, 28(3), 12-29.

Bowlby, J. (1988). A secure base: Parent-child attachment and healthy human development. New York: Basic Books.

Davids, O., Londt, M., \&amp; Wilson, L. (2015). Imprisoned sex offenders’ chronic denial and their childhood family environment. The Open Family Studies Journal, $7(1), 42-47$.

Healy, W., \& Bronner, A. (1926) Delinquents and criminals. Da Capo Press, New York.

Långström, N., Babchishin, K. M., Fazel, S., Lichtenstein, P., \& Frisell, T. (2015). Sexual offending runs in families: A 37-year nationwide study. International Journal of Epidemiology, 44(2), 713-720.

Letourneau, E. J., \& Borduin, C. M. (2008). The effective treatment of juveniles who sexually offend: An ethical imperative. Ethics \& Behavior, 18(2-3), 286-306.

Marshall, W. L. (1989). Intimacy, loneliness and sexual offenders. Behaviour Research and Therapy, 27, 491-503.

Marshall, W. L. (1993). The role of attachments, intimacy and loneliness in the etiology and maintenance of sexual offending. Sexual and Marital Therapy, 8, 109-121.

Marshall, W. L., \& Marshall, L. E. (2010). Attachment and intimacy in sexual offenders: An update. Sexual and Relationship Therapy, 25, 86-90. 
Mathe, S. (2007). Juvenile sexual offenders: We are the sons of our fathers. Agenda, 21(74), 133-140.

Mussen, P., \& Distler, L. (1959). Masculinity, identification, and father-son relationships. The Journal of Abnormal and Social Psychology, 59(3), 350-356.

Oregon Youth Authority. (2020). OYA quick facts. Retrieved from https://www.oregon.gov/oya/docs/QuickFacts/QuickFacts-Jan2020.pdf

Shaw, C. R., \& McKay, H. D. (1932). Are broken homes a causative factor in juvenile delinquency? Social Forces, 10(4), 514-524.

World Health Organization. (2015). Preventing youth violence: an overview of the evidence. World Health Organization.

World Health Organization. (2016). INSPIRE: seven strategies for ending violence against children: executive summary (No. WHO/NMH/NVI/16.7). World Health Organization. 